\title{
HOW TO CONSTRUCT NATIONALLY REPRESENTATIVE FIRM LEVEL DATA FROM THE ORBIS GLOBAL DATABASE: NEW FACTS AND AGGREGATE IMPLICATIONS
}

\author{
Sebnem Kalemli-Ozcan \\ Bent Sorensen \\ Carolina Villegas-Sanchez \\ Vadym Volosovych \\ Sevcan Yesiltas \\ Working Paper 21558 \\ http://www.nber.org/papers/w21558 \\ NATIONAL BUREAU OF ECONOMIC RESEARCH \\ 1050 Massachusetts Avenue \\ Cambridge, MA 02138 \\ September 2015, Revised January 2022
}

The views expressed herein are those of the authors and do not necessarily reflect the views of the National Bureau of Economic Research. Carolina Villegas-Sanchez acknowledges financial support from Banco Sabadell, Universitat Ramon Llull and AGAUR-Generalitat de Catalunya.

NBER working papers are circulated for discussion and comment purposes. They have not been peer-reviewed or been subject to the review by the NBER Board of Directors that accompanies official NBER publications.

(C) 2015 by Sebnem Kalemli-Ozcan, Bent Sorensen, Carolina Villegas-Sanchez, Vadym Volosovych, and Sevcan Yesiltas. All rights reserved. Short sections of text, not to exceed two paragraphs, may be quoted without explicit permission provided that full credit, including ( $)$ notice, is given to the source. 
How to Construct Nationally Representative Firm Level Data from the Orbis Global Database:

New Facts and Aggregate Implications

Sebnem Kalemli-Ozcan, Bent Sorensen, Carolina Villegas-Sanchez, Vadym Volosovych, and Sevcan Yesiltas

NBER Working Paper No. 21558

September 2015, Revised January 2022

JEL No. E0,F0,O1

\section{$\underline{\text { ABSTRACT }}$}

We construct nationally representative firm-level longitudinal data for European countries using financial statements from the Orbis database. We validate our data by comparing its coverage and firm size distribution to official statistics. We showcase two applications to show the importance of firm representativeness in understanding macroeconomic outcomes. First, we show that smalland-medium-sized firms (SMEs) account for a large share of aggregate economic activity. Second, we document that firm representativeness is important for calculating industry concentration trends over time as the share of economic activity accounted by top firms in an industry changes with the firm samples used.

Sebnem Kalemli-Ozcan

Department of Economics

University of Maryland

Tydings Hall 4118D

College Park, MD 20742-7211

and CEPR

and also NBER

kalemli@econ.umd.edu

Bent Sorensen

Department of Economics

University of Houston

3623 Cullen Blvd

Houston, TX 77204-5019

and CEPR

besorensen@uh.edu
Vadym Volosovych

Finance Group, Department of Business Economics

Erasmus University Rotterdam

Room E2-31

P.O. Box 1738

3000 DR Rotterdam, The Netherlands

and Tinbergen Institute and ERIM

volosovych@ese.eur.nl

Sevcan Yesiltas

Koç University

Department of Economics and Finance

Rumelifeneri Yolu 34450

Sariyer, Istanbul

Turkey

syesiltas@ku.edu.tr

Carolina Villegas-Sanchez

Department of Economics, Finance and Accounting

ESADE Business School

Avenida de Torreblanca, 59

08172 Sant Cugat - Barcelona

SPAIN

SPAIN

carolina.villegas@esade.edu

An Online appendix is available at http://www.nber.org/data-appendix/w21558 


\section{Introduction}

Empirical research based on firm-level data is increasingly important in macro-finance. For this research, one needs firm-level data sets that combine firms' real activity, such as employment and production, with their financing, debt, and assets. Most data sets cover only real activity (national censuses), or financial activity (financial reporting by publicly listed companies). The Orbis global database, from Bureau van Dijk (BvD) - a Moody's Analytics company - is the largest cross-country firm-level database that combines both, encompassing firms' financial statements and their real activity in terms of sales, employment, and investment. This database includes public and private firms' balance sheets, income statements, and detailed information on firms' location, industry, and domestic and foreign owners and subsidiaries, which allows researchers to observe global real and financial interconnections between the firms. In spite of the extensive use of the Orbis database for research, firm-level data downloaded from this database are not nationally representative, either due to the way the data is delivered to researchers and/or due to short-cuts the researchers adopt for quick downloads of an immense database that covers millions of firms over time. We provide a guide for researchers on how to download and organize the data such that it ends up being nationally representative or comes close to being so. ${ }^{1}$

To show the importance of such cross-sectional and dynamic inter-temporal representation, we show two applications using a large set of European countries. First, we use our data to investigate the importance of small-and-medium-sized firms (SMEs) in the economy-wide production and employment in each of the countries in our sample. We show that SMEs account for a large part of real economic activity. Notice that the official statistics show this fact but only for a select set of private sectors and not consistently over time, whereas we confirm this fact for all sectors of a given economy. Second, we investigate industry concentration trends in Europe and document a declining trend. We show that for non-representative samples, one may find increasing industry concentration over time. If a non-representative sample is used, the firms identified as 'top firms' in a given industry and the share of economic activity they account for over time is different from the case where a representative

\footnotetext{
${ }^{1}$ See the online appendix that was originally circulated under the title "How to Construct Nationally Representative Firm Level Data from the ORBIS Global Database," NBER Working Paper No: 21558.
} 
sample of firms is used.

Before turning to these applications, we validate our data set. For the validation exercise in terms of firm representation, we need to show that our firms cover a large part of the aggregate economy and are representative in terms of the firm size distribution given by official sources. We focus on the manufacturing sector for our validation exercise because official aggregate data provided by the Structural Business Statistics (SBS) of Eurostat — which we use for comparison and is provided by each country's national statistical office - is only consistently publicly available for the manufacturing sector across European countries over time. The exercise consists on comparing the aggregated total output, firm size distribution, and presence of foreign companies in our database to official aggregate statistics provided in Eurostat SBS. To validate the foreign companies' aggregate output, we use official data collected by the OECD. The coverage varies by country and over time but for the European countries used in the applications, our firms cover close to $60 \%$ of manufacturing output at the beginning of our sample and more than $70 \%$ at the end of our sample. ${ }^{2}$

For our first application, we take the firms in our data and group them into employment size bins. Then we aggregate the output of those firms and divide by the total output of all our firms. We do this for each of our countries. This exercise confirms that SMEs, defined as firms with 20-250 employees (consistent with the Eurostat definition), account for more than half of aggregate employment and gross output in almost all our countries. This finding will be important also for our second application, which is to show the importance of using representative firm-level data for understanding trends in industry concentration in Europe. Recent research has found that industry concentration, defined as the market shares of the top 4 or top 8 firms in a given 2-digit industry, has increased in the United States (see Grullon et al. (2019) and Crouzet and Eberly (2018)), ${ }^{3}$ but declined in Europe

\footnotetext{
${ }^{2}$ In the data section, we provide a fair account of the advantages and disadvantages of using Orbis as well as the differences in coverage across countries over time.

${ }^{3}$ Grullon et al. (2019) show that over the last two decades, over $75 \%$ of US industries experienced an increase in concentration levels with significant heterogeneity across sectors. Crouzet and Eberly (2018) find that the retail sector accounts for a large share of the increase in the observed aggregate business concentration. Increasing industry concentration trends were documented together with increasing profit margins and firm markups (see De Loecker et al. (2020)). Rossi-Hansberg et al. (2021) show that the positive trend observed in U.S. concentration becomes negative when focusing on measures of local concentration. Amiti and Heise (2021) find that higher import competition caused a decline in the market shares of the top twenty U.S. firms.
} 
(Gutiérrez and Philippon (2017)). ${ }^{4}$ Bajgar et al. (2019) challenge the findings of Gutiérrez and Philippon (2017) and argue that industry concentration in Europe has increased once the role of business groups is taken into account by considering consolidated company statements. We find a declining concentration trend in Europe as in Gutiérrez and Philippon (2017) and explain why there are conflicting results in the literature. We show that firm representation over time is important for obtaining the declining trend result because this affects the firms that are classified as top 4 or top 8 firms in each industry.

In a non-representative sample of firms, the degree of industry concentration has increased only for the subset of firms that solely file consolidated firm statements, as also shown by Bajgar et al. (2019). ${ }^{5}$ However, when a representative sample is used, there is a declining industry concentration trend even if one uses firms with consolidated statements, hence the financial account type does not matter for results in a representative sample of firms. Why is this the case? We dig deeper and show that the increase in filing of consolidated statements is due to the increased presence of foreign-owned firms and changing regulation, which is a natural part of the European integration process since the 2000s. Although foreign firms do not account for a large fraction of aggregate output in these countries (at most $30 \%$ overall), ${ }^{6}$ increasing integration with the largest foreign-owned firms can drive trends in industry concentration if only consolidated statements are considered because multinational companies (MNCs) are required to file those types of statements. In fact, we show that the increasing concentration trend among firms reporting consolidated statements is purely driven by foreign-owned firms.

The standard measure of concentration is the share of gross output by the top 8 firms in a country-sector-year over total gross output in the same cell. We find that when selecting the top 8 firms (ranked by firm output) different concentration trends appear if we focus

\footnotetext{
${ }^{4}$ The increase in average firm markups in Europe has also been limited as shown by Díez et al. (2021), which is attributed to better anti-trust regulation by Covarrubias et al. (2017). Besley et al. (2021) find that average firm profit margins are higher and concentration is lower in non-tradable sectors when antitrust measures are stronger. See Van Reenen (2018) for a review.

${ }^{5}$ Consolidated financial statements are financial statements of an entity with multiple divisions or subsidiaries that can be located in the same country or in different countries.

${ }^{6}$ The average $30 \%$ share is obtained when we consider all countries from our sample that are also covered by the official OECD statistics on the multinational activity. But there is extensive variation across countries. For example, in Luxembourg foreign companies account for more than $50 \%$ of aggregate output, while the same ratio in Germany or Italy is around $20 \%$ with UK and Spain taking about the average values.
} 
on firms reporting unconsolidated accounts versus firms reporting consolidated accounts. Industry concentration decreases for firms reporting unconsolidated statements while it is increasing for those reporting consolidated statements. Most importantly, when combining firms reporting either consolidated or unconsolidated financial statements, the overall message is that industry concentration has declined in Europe since 2001. A priori there is no reason for focusing on a certain set of accounting statements as opposed to combining all statements, as long as one is careful about not double counting the same firm reporting both statements. Focusing on a selected set of statements will lead to focusing on a selected set of firms such as listed firms, business groups, foreign firms, and will give misleading trends in concentration. This practice of selecting certain groups will also deliver biased results due to changing regulation. For example, we show a sharp increase in concentration around 2007, which coincides with a change in the European accounting legislation. ${ }^{7}$

When we use representative samples of firms for our European countries, regardless of the use of different types of financial statements, we find a declining industry concentration trend. This is robust to different denominators that measures total output (i.e., total sample of Orbis firms, the sample of top-100 firms in Orbis and official aggregate sector data from STAN-OECD). The key in getting robust concentration trends is the selection of the "top firms" correctly. There is a non-negligible number of large firms that can account for large shares of activity in a given industry and report unconsolidated accounts. These firms would be left out of studies focusing on the evolution of concentration measures by business groups by construction, as they are not part of such groups but they are nevertheless large. For policies such as anti-trust regulation, it is essential to know about these firms. Of the total number of country-sector-year triplets, in $52 \%$ of these triplets the top- 8 firms report a mixture of consolidated and unconsolidated financial statements (i.e., within the top 8 firms some firms report consolidated sales while other firms report unconsolidated sales), enough to change who is in top 8 group. ${ }^{8}$

\footnotetext{
${ }^{7}$ To promote convergence of accounting standards at the global level, the European Commission introduced new accounting rules on the requirements to report consolidated and unconsolidated accounts in line with international standards adopted by International Financial Reporting Standards (IFRS).

${ }^{8}$ To account for the concern that we are mixing consolidated information from the headquarter and unconsolidated information from subsidiaries and therefore double counting output, we use information on global ultimate owner (GUO), domestic ultimate owner (DUO) and immediate shareholder (ISH) and checked whether the top 8 firms within the same country-industry-year triplet shared owner. We find a negligible number of triplets in which the top 8 firms share owner and therefore, we are confident we are not
} 
The remainder of this paper is organized as follows. Section 2 describes the data set and the construction of representative samples, with details reported in an online appendix. Section 3 explains our data validation exercise. Section 4 presents our application to SMEs. Section 5 presents our application to industry concentration. Section 6 concludes.

\section{Data}

The Orbis database provides harmonized financial and ownership information, at the firm level, across countries. The Orbis database covers more than 100 countries and over 400 million firms as of January 2022. BvD collects data from over 160 different government and commercial information providers, and harmonizes the data in a standard "global" format to facilitate worldwide company comparisons. The Orbis data set includes both private and publicly listed firms and it is not a census survey. The financial and balance sheet information comes from national business registers, governed by country-specific legal and administrative filing requirements. Although most countries oblige limited liability companies to register once they are formed, requirements in terms of firm size for reporting balance sheet items varies across countries. ${ }^{9}$

There is a common misconception that firm-level financial data from national statistical offices always have better coverage than Orbis . For countries where the laws require every firm to file to the national business register, this is not the case because $\mathrm{BvD}$ uses the same sources as the statistical offices. For countries where the law requires only large firms to file financial statements, it might be the case that national statistical offices run different administrative surveys with better coverage of small firms.

For most European countries, reporting to the national business registers is mandatory, however, it might still be the case that researchers will not get full coverage from their Orbis download for a given country if they use a single vintage of the database or a direct download from the Orbis web platform. ${ }^{10}$ In order to have consistent coverage of small and

introducing double-counting of sales in the numerator of the concentration measure.

${ }^{9}$ See Table A.6.1 in online appendix A.6 for a list of the BvD information providers as well as for the details on filing requirements by country.

${ }^{10}$ Many researchers have found that the Orbis web browser interface displays a large number of unique firm identifiers, but the actual financial or real variables, when downloaded, turn out to be missing, especially 
large firms over time and by industry, one has to follow the approach we advocate and use the historical vintages, download data vintage-by-vintage, and match the firm data over time using unique firm identifiers. If a single vintage is used, firms will be missing in a longitudinal sense because Orbis drops non-reporting firms from the database after a certain period of time. In addition, some variables such as "value-added" and "intermediate inputs" may be missing from some downloads, such as those from the commonly used Wharton Research Data Services (WDRS), which does not systematically cover all variables. Singlevintage data will often over-represent larger firms and under-represent smaller firms due to survivorship bias.

Some researchers opt for re-weighing the data, using weights based on official aggregate statistics in order to increase the representativeness of small firms. If our guidelines are followed, there is no need to re-weigh the data to obtain nationally representative firmlevel data sets. ${ }^{11}$ In addition, to produce the correct propensity score weights, the nonrepresentative data needs to be matched first to a fully representative data at the firm-level, such as census, otherwise re-weighing with ad-hoc country-sector weights will introduce more errors as argued by Haltiwanger et al. (2017). Based on our guidelines, BvD has recently developed a new product, labeled the "Historical Product," which links several vintages/disks of the Orbis data through firm identifiers to obtain firm-level longitudinal data sets for many countries, as we have done "manually." Although this new product avoids many of the issues involved by combining numerous vintages/disks, it requires a certain methodology to process the historical data. We provide the guide and programs to process this historical data at http:/ /econweb.umd.edu/ kalemli/orbis.html.

going back in time. There are several reasons for this. First, there is a reporting lag in the BvD products of roughly two years, meaning that a firm's filing in 2017 will appear fully on the media issued/accessed in 2019. Second, depending on the BvD product, certain companies are erased from the database if there is no reporting done for some time, even if the firm continues operating (but not reporting). Third, there is a download cap imposed by $\mathrm{BvD}$ on web interfaces and often this cap causes missing data rather than termination of the download job. Fourth, BvD collection efforts have improved over time. In addition to these technical considerations, certain cleaning and checking procedures have to be implemented.

${ }^{11}$ We describe the methodology for preparing micro data based on Orbis in two self-contained appendices. Online appendix A deals with treatment of firm financial information while online appendix B deals the foreign ownership information. In particular, online appendices A.1 to A.4 describe the organization of Orbis and our advice on data download strategies. Online appendix A.5 describes how to put together the financial data in panel form, while online appendix B.1 explains the methodology used to put together foreign ownership data in panel form. 


\section{Validation}

In order to validate the representativeness of our data set, we proceed in two steps. In the first step, we measure output-based coverage ratios for the manufacturing sector. ${ }^{12}$ We proxy output by firm's operating revenue. We compute the ratio of the value of total output produced by firms in our sample relative to the value of total output from the official Eurostat SBS data for the manufacturing sector. We do this exercise for the European countries that we use in our applications.

Table 1 shows how much of gross output, as reported by Eurostat, is covered by the firms operating in the manufacturing industry in each of the selected European countries over this period. Some cells will be missing due to missing Eurostat data. With the exception of Finland, most countries show close to or above 60\% coverage ratios, especially since 2001. Table 2 shows the overall European coverage, for the manufacturing sector.

Table 1: Coverage of the Manufacturing Sector Based on Gross Output

\begin{tabular}{|c|c|c|c|c|c|c|c|c|c|c|}
\hline Year & $\mathrm{AT}$ & $\mathrm{BE}$ & $\mathrm{CZ}$ & $\mathrm{DE}$ & EE & ES & FI & $\mathrm{FR}$ & GB & GR \\
\hline $\begin{array}{l}2001 \\
2002 \\
2003 \\
2004 \\
2005 \\
2006 \\
2007 \\
2008 \\
2009 \\
2010 \\
2011 \\
2012\end{array}$ & $\begin{array}{c}0.47 \\
0.61 \\
0.59 \\
0.47 \\
0.45 \\
0.67 \\
0.72 \\
0.77 \\
0.72 \\
0.78 \\
0.8 \\
0.76\end{array}$ & $\begin{array}{c}0.78 \\
\text { N/A } \\
0.81 \\
0.8 \\
0.8 \\
0.78 \\
0.79 \\
0.78 \\
0.74 \\
0.78 \\
0.77 \\
0.77\end{array}$ & $\begin{array}{c}0.73 \\
0.7 \\
0.77 \\
0.84 \\
0.86 \\
0.81 \\
0.88 \\
0.8 \\
0.85 \\
0.94 \\
0.9 \\
0.87\end{array}$ & $\begin{array}{c}0.5 \\
0.51 \\
0.57 \\
0.64 \\
0.9 \\
0.73 \\
0.77 \\
0.64 \\
0.6 \\
0.6 \\
0.57 \\
0.48\end{array}$ & $\begin{array}{l}0.92 \\
0.93 \\
0.93 \\
0.97 \\
0.95 \\
0.94 \\
0.96 \\
0.95 \\
0.92 \\
0.92 \\
0.95 \\
0.96\end{array}$ & $\begin{array}{c}0.78 \\
0.8 \\
0.79 \\
0.79 \\
0.78 \\
0.83 \\
0.81 \\
0.85 \\
0.87 \\
0.9 \\
0.85 \\
0.83\end{array}$ & $\begin{array}{c}0.36 \\
0.37 \\
0.39 \\
0.41 \\
0.41 \\
0.4 \\
0.45 \\
0.49 \\
0.46 \\
0.47 \\
0.5 \\
0.51\end{array}$ & $\begin{array}{c}0.79 \\
0.82 \\
0.79 \\
0.83 \\
0.82 \\
0.84 \\
0.87 \\
0.9 \\
0.89 \\
0.92 \\
0.96 \\
0.95\end{array}$ & $\begin{array}{c}0.68 \\
0.66 \\
0.66 \\
0.62 \\
0.7 \\
0.72 \\
0.69 \\
0.67 \\
0.81 \\
0.84 \\
0.89 \\
0.83\end{array}$ & $\begin{array}{c}\mathrm{N} / \mathrm{A} \\
\mathrm{N} / \mathrm{A} \\
0.92 \\
0.73 \\
0.69 \\
0.66 \\
0.68 \\
0.64 \\
0.51 \\
0.47 \\
0.45 \\
0.4\end{array}$ \\
\hline Average & 0.59 & 0.78 & 0.79 & 0.58 & 0.93 & 0.81 & 0.42 & 0.84 & 0.71 & 0.67 \\
\hline Year & $\mathrm{HU}$ & IT & LV & $\mathrm{NO}$ & $\mathrm{PL}$ & PT & $\mathrm{RO}$ & $\mathrm{SE}$ & SI & SK \\
\hline $\begin{array}{l}2001 \\
2002 \\
2003 \\
2004 \\
2005 \\
2006 \\
2007 \\
2008 \\
2009 \\
2010 \\
2011 \\
2012\end{array}$ & $\begin{array}{c}0.91 \\
0.97 \\
0.84 \\
0.91 \\
0.88 \\
0.91 \\
0.88 \\
0.81 \\
0.9 \\
0.84 \\
0.77 \\
0.86\end{array}$ & $\begin{array}{c}0.65 \\
0.71 \\
0.7 \\
0.73 \\
0.77 \\
0.79 \\
0.79 \\
0.9 \\
0.86 \\
0.87 \\
0.89 \\
0.86\end{array}$ & $\begin{array}{c}0.63 \\
0.62 \\
0.61 \\
0.73 \\
0.79 \\
0.8 \\
0.81 \\
0.85 \\
0.81 \\
0.83 \\
0.87 \\
0.83\end{array}$ & $\begin{array}{l}0.75 \\
0.68 \\
0.72 \\
0.69 \\
0.75 \\
0.76 \\
0.69 \\
0.88 \\
0.83 \\
0.83 \\
0.88\end{array}$ & $\begin{array}{c}0.62 \\
0.57 \\
0.59 \\
0.71 \\
0.67 \\
0.7 \\
0.74 \\
0.6 \\
0.74 \\
0.69 \\
0.6 \\
0.62\end{array}$ & $\begin{array}{l}0.63 \\
0.71 \\
0.73 \\
0.75 \\
0.91 \\
0.93 \\
0.92 \\
0.94 \\
0.92 \\
0.93 \\
0.93 \\
0.92\end{array}$ & $\begin{array}{c}0.76 \\
0.74 \\
0.83 \\
0.96 \\
0.95 \\
0.84 \\
0.91 \\
0.9 \\
0.97 \\
0.93 \\
0.91 \\
0.93\end{array}$ & $\begin{array}{l}0.73 \\
0.76 \\
0.74 \\
0.77 \\
0.75 \\
0.79 \\
0.78 \\
0.74 \\
0.87 \\
0.88 \\
0.85 \\
0.78\end{array}$ & $\begin{array}{c}0.83 \\
0.9 \\
0.92 \\
0.89 \\
0.91 \\
0.91 \\
0.91 \\
0.92 \\
0.91 \\
0.99 \\
0.83 \\
0.97\end{array}$ & $\begin{array}{l}0.54 \\
0.62 \\
0.83 \\
0.88 \\
0.78 \\
0.78 \\
0.76 \\
0.99 \\
0.95 \\
0.94 \\
0.98 \\
0.91\end{array}$ \\
\hline Average & 0.87 & 0.77 & 0.74 & 0.74 & 0.64 & 0.82 & 0.85 & 0.77 & 0.85 & 0.76 \\
\hline
\end{tabular}

Notes: The country codes are AT (Austria), BE (Belgium), CZ (Czech Republic), DE (Germany), Estonia (EE), ES (Spain), FI (Finland), FR (France), GB (United Kingdom), GR (Greece), HU (Hungary), IT (Italy), LV (Latvia), NO (Norway), PL (Poland), PT (Portugal), Romania (RO), SE (Sweden), Slovenia (SI) and SK (Slovakia). Each country-year cell represents the sum of manufacturing firms' gross output reported in Orbis data as a share of total official manufacturing gross output reported in Eurostat-SBS data.

\footnotetext{
${ }^{12}$ Online appendix C.1 provides details on the official aggregate data sets we use for comparison purposes.
} 
Table 2: European Coverage of the Manufacturing Sector Based on Gross Output

\begin{tabular}{cccc}
\hline \hline Year & $\begin{array}{c}\text { EU-unweighted } \\
(1)\end{array}$ & $\begin{array}{c}\text { EU-weighted } \\
(2)\end{array}$ & $\begin{array}{c}\text { EU-wide } \\
(3)\end{array}$ \\
\hline 2001 & 0.56 & 0.58 & 0.57 \\
2002 & 0.59 & 0.60 & 0.59 \\
2003 & 0.63 & 0.61 & 0.60 \\
2004 & 0.66 & 0.63 & 0.62 \\
2005 & 0.67 & 0.66 & 0.66 \\
2006 & 0.73 & 0.70 & 0.69 \\
2007 & 0.76 & 0.71 & 0.71 \\
2008 & 0.75 & 0.71 & 0.70 \\
2009 & 0.72 & 0.67 & 0.66 \\
2010 & 0.73 & 0.69 & 0.67 \\
2011 & 0.74 & 0.70 & 0.67 \\
2012 & 0.68 & 0.65 & 0.62 \\
\hline \hline
\end{tabular}

NotES: The columns of this table present EU averages of output-based coverage ratios that are constructed for each country-year cell presented in Table 1. EU averages are constructed following three alternative ways: Column (1) presents simple EU-unweighted means, Column (2) shows weighted averages where the corresponding country GDP acts as weight and Column (3) sums the gross output across all the firms included in the sample and compares to the corresponding gross output totals across the EU countries assuming no borders between countries.

The second step of our validation exercise is to show that our firms are not only covering a large part of aggregate economy, but they are also representative, that is, our data can mimic the official firm-size distribution provided by Eurostat-SBS. Table 3 presents the size distribution based on both gross output and employment in the manufacturing sector. We focus again on manufacturing sector because official statistics do not provide firm size distribution consistently over time for all the sectors for all our countries. As an example year, we picked 2006 as shown in this table. Both panels show that the firm size distribution in our data is very close to the official one provided by SBS, both in terms of output and employment. The table shows that most of the gross output and employment, in the manufacturing sector, are accounted for by SMEs, both in our data and in the official data. Some exceptions are Finland, the United Kingdom, and Slovakia with an under-representation of large firms, Greece with an over-representation of medium firms, and a slight under-representation of small firms in Italy and Slovenia.

\section{Application: New Facts on SMEs based on Orbis}

Having validated our data for the manufacturing sector, we provide new facts on the size distribution of firms in all sectors, based on Orbis information. Official Eurostat SBS statis- 
Table 3: Firm Size Distribution in the Manufacturing Sector: 2006

\begin{tabular}{|c|c|c|c|c|c|c|c|c|c|c|c|c|c|c|c|c|c|c|c|c|}
\hline \multicolumn{21}{|c|}{ Panel A:Based on Gross-output } \\
\hline & $\mathrm{AT}$ & $\mathrm{BE}$ & $\mathrm{CZ}$ & $\mathrm{DE}$ & EE & $\mathrm{ES}$ & FI & FR & GB & GR & $\mathrm{HU}$ & IT & LV & $\mathrm{NO}$ & $\mathrm{PL}$ & $\mathrm{PT}$ & $\mathrm{RO}$ & $\mathrm{SE}$ & SI & SK \\
\hline \multicolumn{21}{|l|}{ Orbis } \\
\hline 1 to 19 employees & 0.03 & 0.05 & 0.04 & 0.06 & 0.15 & 0.13 & 0.08 & 0.05 & 0.03 & 0.14 & 0.01 & 0.12 & 0.14 & 0.11 & 0.02 & 0.13 & 0.09 & 0.09 & 0.07 & 0.09 \\
\hline 20 to 249 employees & 0.23 & 0.3 & 0.32 & 0.23 & 0.67 & 0.4 & 0.38 & 0.23 & 0.23 & 0.55 & 0.14 & 0.49 & 0.62 & 0.4 & 0.32 & 0.44 & 0.32 & 0.26 & 0.32 & 0.33 \\
\hline $250+$ employees & 0.74 & 0.66 & 0.64 & 0.7 & 0.18 & 0.47 & 0.54 & 0.72 & 0.74 & 0.31 & 0.85 & 0.4 & 0.25 & 0.49 & 0.67 & 0.43 & 0.59 & 0.65 & 0.61 & 0.58 \\
\hline \multicolumn{21}{|l|}{ Eurostat SBS } \\
\hline 0 to 19 employees & 0.07 & 0.08 & 0.1 & 0.06 & 0.12 & 0.13 & 0.06 & 0.09 & 0.08 & 0.26 & 0.07 & 0.2 & 0.12 & 0.13 & 0.09 & 0.14 & 0.08 & 0.09 & 0.12 & 0.05 \\
\hline 20 to 249 employees & 0.32 & 0.27 & 0.31 & 0.22 & 0.6 & 0.38 & 0.21 & 0.27 & 0.29 & 0.26 & 0.21 & 0.41 & 0.54 & 0.36 & 0.28 & 0.42 & 0.31 & 0.28 & 0.32 & 0.23 \\
\hline $250+$ employees & 0.6 & 0.65 & 0.59 & 0.72 & 0.28 & 0.49 & 0.73 & 0.63 & 0.63 & 0.48 & 0.72 & 0.38 & 0.33 & 0.51 & 0.62 & 0.43 & 0.6 & 0.63 & 0.56 & 0.72 \\
\hline \multicolumn{21}{|c|}{ Panel B: Based on Employment } \\
\hline & AT & $\mathrm{BE}$ & $\mathrm{CZ}$ & $\mathrm{DE}$ & EE & ES & FI & FR & GB & GR & $\mathrm{HU}$ & IT & LV & $\mathrm{NO}$ & PL & $\mathrm{PT}$ & RO & $\mathrm{SE}$ & SI & SK \\
\hline \multicolumn{21}{|l|}{ Orbis } \\
\hline 1 to 19 employees & 0.08 & 0.13 & 0.05 & 0.05 & 0.15 & 0.25 & 0.16 & 0.1 & 0.01 & 0.13 & 0.02 & 0.13 & 0.19 & 0.18 & 0.03 & 0.26 & 0.12 & 0.17 & 0.08 & 0.06 \\
\hline 20 to 249 employees & 0.36 & 0.41 & 0.41 & 0.32 & 0.58 & 0.49 & 0.43 & 0.34 & 0.35 & 0.57 & 0.26 & 0.55 & 0.56 & 0.47 & 0.4 & 0.54 & 0.38 & 0.34 & 0.38 & 0.33 \\
\hline $250+$ employees & 0.56 & 0.45 & 0.53 & 0.63 & 0.27 & 0.26 & 0.41 & 0.56 & 0.64 & 0.3 & 0.72 & 0.32 & 0.25 & 0.35 & 0.57 & 0.2 & 0.5 & 0.48 & 0.55 & 0.61 \\
\hline \multicolumn{21}{|l|}{ Eurostat SBS } \\
\hline 0 to 19 employees & 0.17 & 0.18 & 0.19 & 0.15 & 0.17 & 0.31 & 0.14 & 0.19 & 0.19 & 0.5 & 0.2 & 0.4 & 0.18 & 0.2 & 0.21 & 0.32 & 0.12 & 0.18 & 0.18 & 0.1 \\
\hline 20 to 249 employees & 0.38 & 0.37 & 0.37 & 0.32 & 0.53 & 0.43 & 0.34 & 0.34 & 0.38 & 0.28 & 0.36 & 0.38 & 0.52 & 0.42 & 0.38 & 0.49 & 0.4 & 0.33 & 0.36 & 0.34 \\
\hline $250+$ employees & 0.46 & 0.45 & 0.44 & 0.53 & 0.3 & 0.26 & 0.51 & 0.47 & 0.43 & 0.22 & 0.44 & 0.22 & 0.3 & 0.38 & 0.41 & 0.19 & 0.48 & 0.49 & 0.45 & 0.55 \\
\hline
\end{tabular}

Notes: The country codes are AT (Austria), BE (Belgium), CZ (Czech Republic), DE (Germany), Estonia (EE), ES (Spain), FI (Finland), FR (France), GB (United Kingdom), GR (Greece), HU (Hungary), IT (Italy), LV (Latvia), NO (Norway), PL (Poland), PT (Portugal), RO (Romania), SE (Sweden), Slovenia (SI), and SK (Slovakia). Panel A reports the share of gross-output accounted for by each corresponding size bin in Orbis and Eurostat SBS. Panel B reports the share of employment accounted for by each corresponding size bin in Orbis and Eurostat SBS. 
Table 4: Firm Size Distribution in the Aggregate Economy: 2006

\begin{tabular}{|c|c|c|c|c|c|c|c|c|c|c|c|c|c|c|c|c|c|c|c|c|}
\hline \multicolumn{21}{|c|}{ Panel A:Based on Gross-output } \\
\hline & $\mathrm{AT}$ & $\mathrm{BE}$ & $\mathrm{CZ}$ & $\mathrm{DE}$ & $\mathrm{EE}$ & ES & FI & FR & GB & GR & $\mathrm{HU}$ & IT & $\mathrm{LV}$ & NO & PL & PT & RO & SE & SI & SK \\
\hline 1 to 19 employees & 0.16 & 0.15 & 0.15 & 0.16 & 0.35 & 0.26 & 0.24 & 0.15 & 0.07 & 0.22 & 0.07 & 0.21 & 0.36 & 0.29 & 0.07 & 0.31 & 0.24 & 0.26 & 0.17 & 0.27 \\
\hline 20 to 249 employees & 0.32 & 0.38 & 0.39 & 0.26 & 0.47 & 0.39 & 0.37 & 0.33 & 0.27 & 0.50 & 0.30 & 0.44 & 0.44 & 0.39 & 0.40 & 0.38 & 0.35 & 0.32 & 0.38 & 0.32 \\
\hline $250+$ employees & 0.52 & 0.47 & 0.46 & 0.58 & 0.18 & 0.35 & 0.39 & 0.52 & 0.66 & 0.28 & 0.63 & 0.35 & 0.20 & 0.32 & 0.53 & 0.31 & 0.41 & 0.42 & 0.45 & 0.42 \\
\hline \multicolumn{21}{|c|}{ Panel B: Based on Employment } \\
\hline & $\mathrm{AT}$ & $\mathrm{BE}$ & $\mathrm{CZ}$ & $\mathrm{DE}$ & $\mathrm{EE}$ & ES & FI & FR & GB & GR & $\mathrm{HU}$ & IT & LV & NO & PL & $\mathrm{PT}$ & $\mathrm{RO}$ & SE & SI & SK \\
\hline 1 to 19 employees & 0.15 & 0.25 & 0.13 & 0.08 & 0.32 & 0.30 & 0.29 & 0.21 & 0.03 & 0.17 & 0.04 & 0.17 & 0.32 & 0.33 & 0.06 & 0.39 & 0.28 & 0.32 & 0.13 & 0.15 \\
\hline 20 to 249 employees & 0.34 & 0.38 & 0.42 & 0.21 & 0.46 & 0.39 & 0.38 & 0.35 & 0.25 & 0.48 & 0.30 & 0.44 & 0.42 & 0.39 & 0.36 & 0.36 & 0.34 & 0.31 & 0.37 & 0.35 \\
\hline $250+$ employees & 0.51 & 0.36 & 0.45 & 0.72 & 0.22 & 0.30 & 0.33 & 0.45 & 0.72 & 0.34 & 0.66 & 0.39 & 0.25 & 0.28 & 0.58 & 0.25 & 0.38 & 0.36 & 0.50 & 0.50 \\
\hline
\end{tabular}

Notes: The country codes are AT (Austria), BE (Belgium), CZ (Czech Republic), DE (Germany), Estonia (EE), ES (Spain), FI (Finland), FR (France), GB (United Kingdom), GR (Greece), HU (Hungary), IT (Italy), LV (Latvia), NO (Norway), PL (Poland), PT (Portugal), RO (Romania), SE (Sweden), Slovenia (SI), and SK (Slovakia). Panel A reports the share of gross-output accounted for by each corresponding size bin in Orbis. Panel B reports the share of employment accounted for by each corresponding size bin in Orbis.

tics do not include all sectors of economic activity across countries. Column (1) in Table A.1 reports the relative importance, in output terms, of the sectors not included in SBS as a percentage of the total based on Orbis information. The percentages vary from country to country, but are not negligible. In most countries, official statistics are missing for sectors representing close to or more than $20 \%$ of total economic output. Similarly, Column (2) shows that while SBS reports information on the breakdown of employment and output by country-sector-size, there are many cells that lack this information. Again based on our sample in Orbis, we report that for example, in Spain, SBS provides the breakdown by sector and size for firms representing $43 \%$ of total output leaving out $57 \%$ of total output. The lack of consistent information across countries, sectors and size bins precludes the direct comparison of the Orbis database size distribution to that in SBS and therefore, we provide information based solely on Orbis.

Table 4 presents the size distribution based on gross output and employment in the aggregate economy based on the information provided in our Orbis sample of firms in 2006. Panels A and B show that most of the gross output and employment are accounted for by 
SMEs in the entire economy, mimicking the same fact we show for the manufacturing sector. Notice that this is a new fact shown by our data because as explained, official statistics on the firm size distribution are not available for all sectors and countries.

\section{Application: Trends in Industry Concentration}

Our second application regards the importance of firm representativeness in measuring the industry concentration trends in Europe. To illustrate the importance of using a representative data set, we report industry concentration measures using different sets of firms. We focus on the importance of the account type (i.e., consolidated vs unconsolidated financial accounts) and firm type (domestic or foreign owned). We use the standard measure of industry concentration, which is the market share of the top 8 (hereafter, MS8) firms in a given 2 -digit industry $s 2$, country $k$, and year $t$ relative to the population of all firms in the $s 2, k, t$ triplet. We also use market shares of the top 4 (hereafter, MS4) firms or Herfindahl industry concentration measures, obtaining similar results (see Figure A.4 in the appendix). ${ }^{13}$

We start with three different samples to calculate market shares of top 8 firms for the period 2001-2012 to illustrate the importance of firm representativeness: the sample of firms using all types of financial accounts, the sample of firms reporting unconsolidated accounts and the sample of firms reporting consolidated accounts. If a firm reports both types of accounts at the same time, we clean this double-counting before calculating the market share measures. In each sample, we "designate" top 8 firms by looking at the largest 8 firms based on operating revenue. In addition, we also calculate aggregate concentration measures for Europe, both a "EU-wide" measure and a "EU-country-weighted" measure. For the first measure, we use the market shares of the largest 8 firms in the pool of EU countries in a given sector-year. For the second measure, we aggregate each country's own concentration measure based on market shares of the top 8 firms using as weights a given country's GDP.

Orbis classifies firms' balance sheet information according to four types of accounts cor-

\footnotetext{
${ }^{13}$ We follow NACE level 1 and level 2 classifications to aggregate 4-digit industries to 1- and 2-digit industry level data. See online appendix Table A.6.2 for the NACE Revision 2, Level 2 Classification. Orbis assigns the company to a unique "primary" industry by the largest portion of its operating revenue; some companies might have multiple "secondary" codes (describing their additional activities). We use the primary code as the "sector" of a given company.
} 
responding to consolidation codes: ${ }^{14}$

- U1: Only unconsolidated accounts are available in Orbis.

- C1: Only consolidated accounts are available in Orbis.

- U2-C2: Both unconsolidated and consolidated accounts are available in Orbis. ${ }^{15}$

Consolidated statements are financial statements of an entity with multiple divisions or subsidiaries. It is obvious that using only unconsolidated or only consolidated accounts will change the total sales/revenue of the top 8 firms, biasing the concentration measures. Using unconsolidated accounts only might under-represent the true level of concentration if sales of the same consolidated group are recorded across different business units. This is especially important in the case of EU-wide concentration measures with foreign subsidiaries distributed across different EU countries. It is also misleading to use only consolidated accounts because many large companies do not report consolidated accounts, and hence this practice will bias the selection of top 8 firms. In fact, an overwhelming majority of companies in Orbis report unconsolidated accounts. An additional problem specific to the European setting is that regulatory changes after 2007 push company reporting to consolidated accounts. ${ }^{16}$ We checked our data and confirmed that cases that we detected switchers took

\footnotetext{
${ }^{14}$ In addition, Orbis contains companies with the account type LF with limited financial information, and NF with no financial items at all. Also, there are entities with "no recent accounts" (NRF) or "no recent limited financials" (NRLF), where "no recent" refers to last 3 years. By default, the Orbis media gives preference to the consolidated accounts, which can be changed via the Search settings. See Figure D.4.1 of online appendix D.4 for an example of how Orbis registers the multiple accounts of different types of Koç Holding Inc., the largest business group in Turkey.

${ }^{15}$ See section A.1 for full details on how we deal with different types of duplicates and double counting. All firms reporting under different consolidation codes share the same BvD ID number and differ on their last letter code reflecting $\mathrm{C} 1, \mathrm{U} 1, \mathrm{C} 2$ or $\mathrm{U} 2$, depending on the type of reporting consolidation code, respectively. To avoid double counting of sales, we eliminate duplicates based on BvD ID keeping the consolidated accounts when both consolidated and unconsolidated are reported (i.e., we drop the unconsolidated sales of headquarters). In spite of this approach, we cannot rule out the possibility that the sales of affiliates are double counted (i.e., included in the consolidated sales of the headquarter and separately, as unconsolidated sales of the affiliate). We deal with this concern by using the ownership information.

${ }^{16}$ The Council of the European Union adopted an International Accounting Standards (IAS) Regulation that requires listed companies including banks and insurance companies to prepare their consolidated accounts in accordance with IAS from 2005 onward. Member States may defer application until 2007 for those companies that are listed both in the EU and elsewhere and that currently use Generally Accepted Accounting Principles (GAAP) that is adopted by the U.S. (or other GAAP) as their primary basis of accounting, as well as for companies that have only publicly traded debt securities. Further details on this regulation is available in https://www.esma.europa.eu/convergence/ias-regulation.
} 
place mostly between 2007 and 2009 when the regulatory change came into effect. We correct for this to make sure we are not identifying switchers as different firms as explained in appendix A.2.

Figure 1 shows our main results. Panel A in Figure 1 shows the EU-wide concentration measures, while Panel B in Figure 1 shows the EU-country-weighted counterpart. Each figure shows concentration trends based on market shares of top 8 firms for the three samples we use as described above. Clearly, when one uses all firms and all accounts, the concentration is declining in Europe. However, when distinguishing between firms reporting unconsolidated accounts and those reporting consolidated accounts we can observe opposing trends especially after 2007 in both panels. When we use consolidated accounts, it seems like concentration declined during the period 2000-2007 and increased from 2007 on-wards, consistent with the results in Bajgar et al. (2019). The results are even more pronounced when we do not control the companies switching accounts due to the regulatory change, as shown in Figure A.1 in the appendix.

\section{Figure 1: MARKeT Share OF TOP 8 Firms}
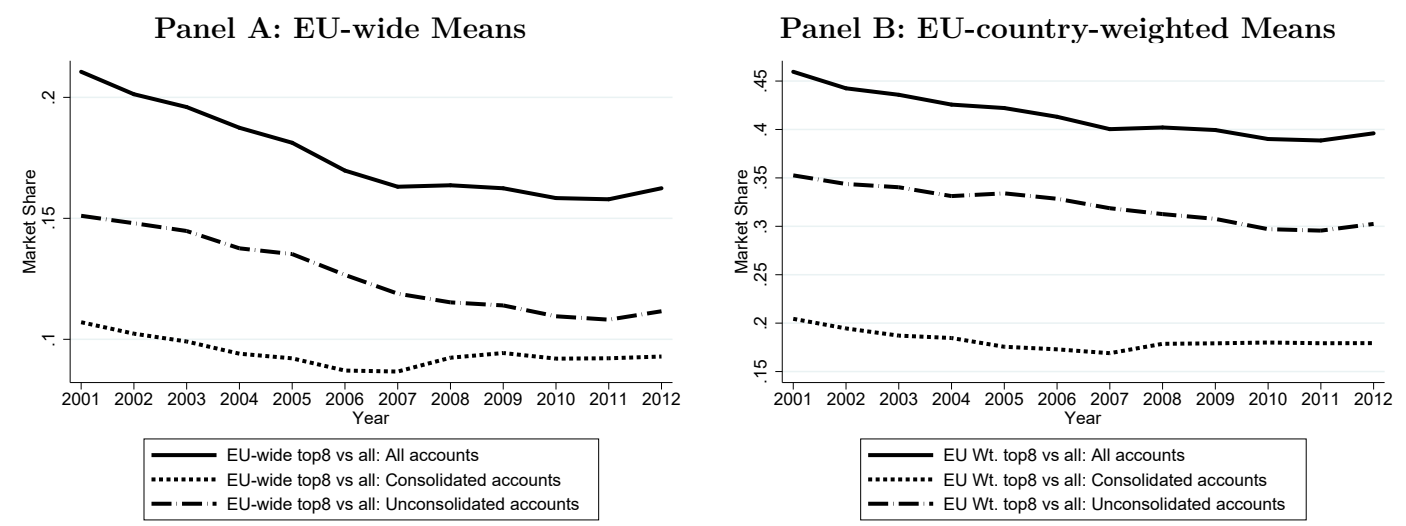

Notes: The figure plots market concentration in the total economy for the European countries in our sample from 2001 to 2012. Panel A plots "EU-wide" market shares over the period: we treat the EU as a single market and define market shares in all the EU countries in a given sector-year. We aggregate over sectors using sectoral value added as weights. In Panel B, we plot "EU-country-weighted" average market shares, using a given country's GDP as weight. In this panel we calculate each country's concentration measure separately, adding up sectors with sector value added and then add up countries with GDP weights. 
These concentration measures might be impacted by the fact that Orbis, although representative, does not cover the universe of firms in an economy. To show that this does not impact the declining concentration trend result, Figure 2 shows EU-wide concentration measures using three different denominators to calculate the market shares. Each denominator is a different proxy for total output of all the firms in an economy: Orbistotal, Orbis-100 (that is, the output from the top 100 firms in Orbis) and gross output aggregate reported in the OECD Structural Analysis (OECD STAN) database (available at http://stats.oecd.org/Index.aspx?DataSetCode=STAN08BIS). To make it comparable to the results in Bajgar et al. (2019) we report means as percentage change since the initial year (=100) over the period 2001-2012 and focus on the EU-wide means. ${ }^{17}$ Panel A shows results for the sample of all accounts while Panels B and $\mathrm{C}$ show results for unconsolidated and consolidated accounts, respectively. The declining trend during the entire sample period for the full sample as well as the unconsolidated accounts sample is clear in Panels A and B. In fact, there is almost no difference between the normalization by Orbis-100 sales and STAN gross output data. In fact, we prefer not to use the STAN denominator as the sector classification given that the STAN A64 classification does not fully correspond to the twodigit industry classification in Nace Rev. 2. ${ }^{18}$ Nevertheless, concentration in Europe declined by close to $10 \%$ when considering the full sample and $20 \%$ when considering the sample of firms reporting unconsolidated accounts, regardless of whether STAN or Orbis information is used.

Panel C shows a decreasing trend up to 2007, and an increasing trend thereafter, when we are to use the consolidated accounts sample. Concentration among firms reporting consolidated accounts increased by 2.5\% between 2001 and 2012 in Europe. As we already argued, this is driven by two factors: a) by not including unconsolidated accounts, important large firms will be missed in the top 8 group and b) the regulatory change in 2007 push certain set of firms to switch from reporting unconsolidated to consolidated. As we will show next, these firms who switch reporting and captured increasingly more so by the consolidated reporting happens to be foreign firms and they report consolidated as required by the regulation.

\footnotetext{
${ }^{17}$ Figure A.2 in the appendix shows the levels and the fact that the decreasing trend for unconsolidated accounts is robust to the denominator being top50, top100 or top1000 both for EU-wide and EU-countryweighted measures.

${ }^{18}$ For the exercise in Figure 2, we selected the overlapping sectors in both classifications.
} 
Figure 2: Market Share of Top 8 Firms: Different Denominators for 'All' FIRMS
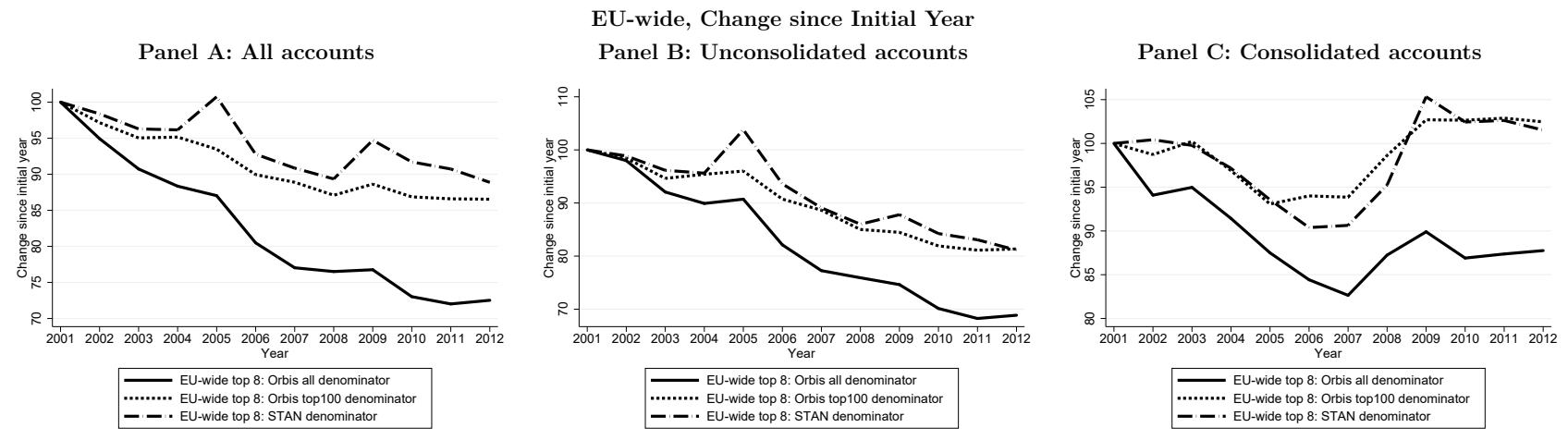

Notes: The figure plots market concentration in total economy for the European countries from 2001 to 2012. All panels plot "EU-wide" market shares as percentage change since the initial year $(=100)$ over this period: we treat the EU as a single market and calculate market share of top 8 firms in all the EU countries in a given sector-year as their aggregated output relative to: (1) the aggregated output of all firms (solid line); (2) the aggregated output of top 100 firms in the pool of EU countries (short-dashed line); (3) the EU-wide gross-output reported by the OECD STAN database for the same sector-year (long-dashed-dot line). We aggregate over sectors using sectoral value added as weights.

To show the importance of omitting large private firms that report unconsolidated accounts, we undertook an additional analysis. This analysis will also show that finding different concentration trends is not about Orbis data but about using "only" consolidated accounts. As shown in Figure 3, using consolidated accounts in Orbis or in Compustat Global (which consists only publicly-held companies) will also result in increasing concentration trends across European countries, especially in the post-2007 period due to changes in the regulation. Ali et al. (2008) argue that Compustat-based industry concentration measures are poor proxies for actual industry concentration. The correlation between the Compustat and U.S. Census-based Herfindahl indexes is only $13 \%$.

In order to dig deeper and understand what drives the increasing concentration trends when using consolidated accounts, we separate foreign and domestic top firms. ${ }^{19}$ The literature has shown that foreign/multinational companies are large and operate through a

\footnotetext{
${ }^{19}$ Any firm whose equity is owned by foreigners in excess of $10 \%$ is defined as a foreign-owned firm, following the balance-of-payments definition of the IMF.
} 


\section{Figure 3: Market Share of Top 8 Firms: Orbis vs. Compustat Global}

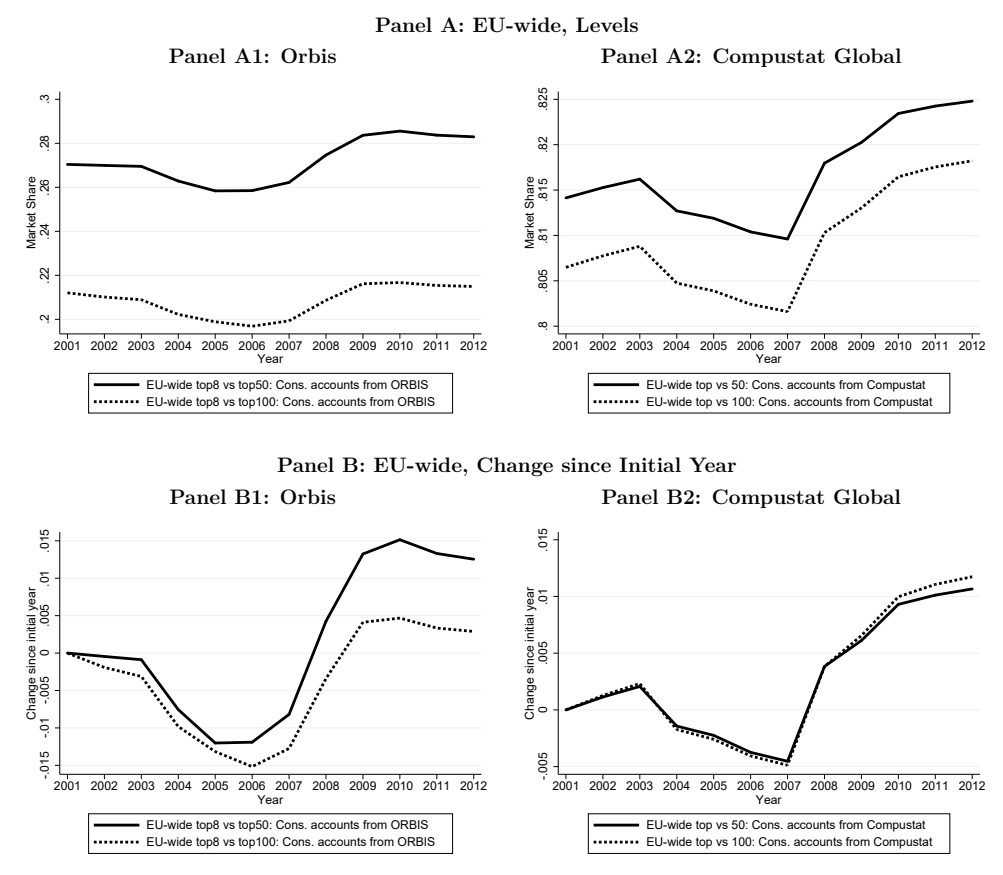

Notes: The figure plots market concentration in total economy for the European countries in the sample of consolidated accounts (from our sample-shown in Panels A1 and B1 and from Compustat-Global databaseshown in Panels A2 and B2) in the period 2001-2012. All panels plot "EU-wide" market shares over this period: we treat the EU as a single market and define market share of top 8 firms in all the EU countries in a given sector-year as their aggregated output relative to: (1) the aggregated output of top 50 firms (solid line); (2) the aggregated output of top 100 firms (short-dashed line). We aggregate over sectors using sectoral value added as weights.

network of subsidiaries and affiliates in several countries (e.g., Kalemli-Ozcan et al. (2014)).

First, to validate our data, we aggregate the activity of the foreign firms in our panel to the country-year level and compare these aggregated ownership numbers to the OECD data on the activities of foreign affiliates of multinationals from the Activity of Multinational Enterprises (AMNE) and the Activities of Foreign Affiliates (AFA) databases. ${ }^{20}$ Figure B.3.1

${ }^{20} \mathrm{AMNE}$ (available on the OECD data portal https://stats.oecd.org/Index.aspx?DataSetCode=AMNE_ IN) covers 28 OECD host countries from 2008 onward, although the coverage varies by country and over time. We base our comparison on the manufacturing sector because the earlier OECD data, reported in the AFA database, consistently provides information only from manufacturing sector (see http://stats.oecd. org/Index.aspx?DataSetCode=AFA_IN3). The OECD Foreign Affiliates Statistics (FATS) database provides detailed data on the activities of foreign affiliates operating in the services sector, although, for a smaller 
of online appendix B.3 graphically presents this comparison. The figure demonstrates that our data capture very well the share of multinational activity in total activity reported by the official statistics. ${ }^{21}$

To compute the concentration measures across the two groups, foreign and domestic, we keep the denominator fixed (i.e., it includes all firms in our sample) and we change the numerator by distinguishing between the sales of the top 8 foreign firms and the top 8 domestic firms. Figure 4 shows the results. We report EU-country-weighted averages to have a clear interpretation of foreign firms. BMW-Germany is considered a domestic firm in Germany while BMW-Spain is considered a foreign owned company in Spain. In a EU-wide measure they are both domestic. We show results first using all accounts and then using consolidated accounts, as changes from the initial year. ${ }^{22}$ As mentioned, the two panels share the same denominator (sales of all firms in the sample). ${ }^{23}$

Both panels show that the increase in industry concentration is driven by foreign firms, regardless of the account type used. Hence, any non-representative sample that gives larger weight to these foreign firms will register an increasing concentration trend over time. Using consolidated accounts is just one example of such non-representation because - especially in Europe with the regulatory changes in 2007 - using consolidated accounts will end up giving a higher weight to foreign firms.

sample of 25 OECD countries. OECD obtains their data from the Eurostat that conducts annual surveys on the activities of foreign-controlled enterprises and foreign affiliates abroad controlled by residents of the compiling country. Surveys are conducted, in most cases, by the national statistical office or the central bank of each country. While the key variables in the survey are common across countries, the target sample varies across countries. See online appendix B.2, for a description of the issues considered to maximize comparability across samples.

${ }^{21}$ Online appendix B.3 provides these statistics by country and other details of our validation exercise. Our advice on how to download and clean the foreign firms' data is described in detail in online appendix B.1.

${ }^{22}$ We classify foreign- and domestically-owned firms based on the ownership information on the first year of the sample; i.e., 2001 and, follow their market shares over time. Similar results are found based on the time-varying ownership information.

${ }^{23}$ Appendix Figure A.3 shows that the results are robust to considering the output of the top 100-firms in the denominator. 


\section{Figure 4: Market Share of Foreign and Domestic Firms within Top 8 Firms}

\section{EU-country-weighted, Change since Initial Year}

Panel A: All Accounts

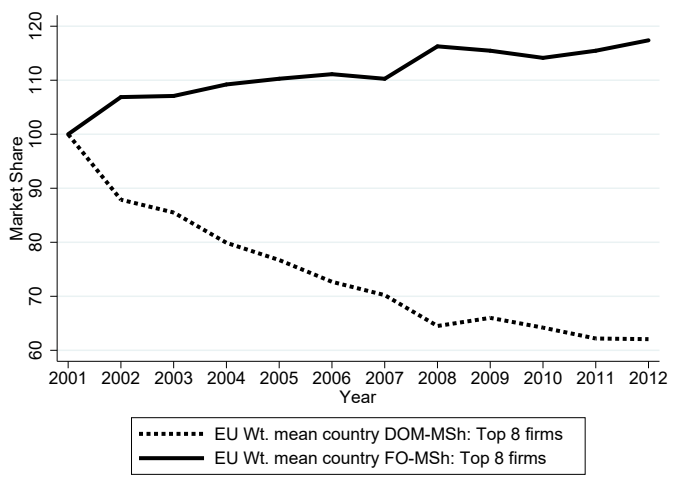

Panel B: Consolidated Accounts

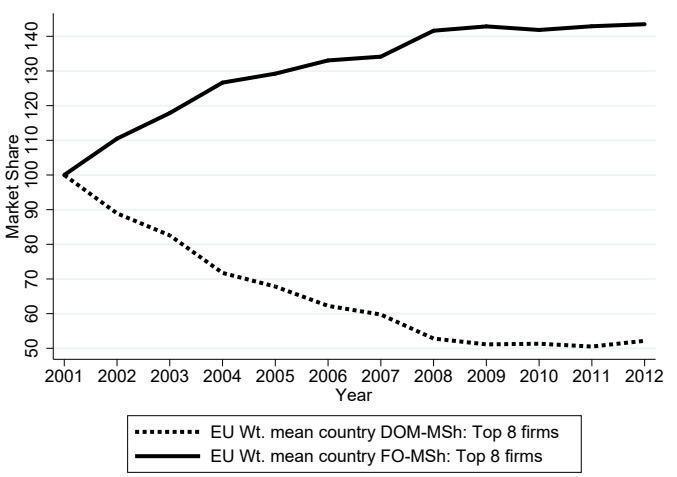

Notes: The figure plots market concentration of foreign and domestic firms within top 8 firms in the total economy for the European countries since 2001. Both panels plot "EU-country-weighted" market shares as percentage change since the initial year $(=100)$ over this period: we calculate each country's concentration measure separately, adding up sectors with sector value added and then add up countries with GDP weights. In both panels, being a foreign firm is determined based on official threshold of more than $10 \%$ foreign ownership in the initial year. 


\section{Conclusion}

We construct nationally representative firm-level longitudinal data for European countries using financial statements from the Orbis database. We provide a detailed "guide" on the construction for other researchers and we validate our data by comparing its coverage and firm size distribution to official statistics for the manufacturing sector.

To show the importance of firm representativeness, we showcase two applications, where representation is critical for understanding macro outcomes. First, we show that SMEs account for a large share of aggregate economic activity, regardless of the sector and country. This is a new fact because one can only obtain official statistics on firm size distribution for certain sectors. Hence, before our paper, we did not know if the larger role of SMEs in aggregate economic activity was specific to certain sectors. ${ }^{24}$ Second, we document that such firm-level representation is important for obtaining correct industry concentration trends over time in Europe. In a representative firm sample, one obtains a declining concentration trend. In a non-representative sample - focusing on large firms, or foreign firms or firms reporting using certain financial accounting types - the industry concentration is rising. In our application, which is for Europe, we show that all these examples of non-representation give more weight to large foreign firms, whose market shares clearly have gone up as part of the easing of cross-border regulations during the European integration process. These firms cannot represent economy-wide trends though, as we show that using nationally representative firm-level information industry concentration trends in Europe have declined.

\footnotetext{
${ }^{24}$ Of course, one can obtain the firm size distribution of every sector buy using the micro data from national census surveys for each country and re-defining the size categories to match the definition of SMEs. The official aggregate statistics from Eurostat do not do this, that is, they do not tell us the role of firms with less than 250 employees in aggregate economic activity for every sector and/or for the entire country. Note that even the Small Business Administration (SBA) in the U.S. with detailed data on SMEs only reports this statistic for the total of private sector in the U.S.
} 


\section{References}

Ali, Ashiq, Sandy Klasa, and Eric Yeung, "The limitations of industry concentration measures constructed with Compustat data: Implications for finance research," The Review of Financial Studies, 2008, 22 (10), 3839-3871.

Amiti, Mary and Sebastian Heise, "U.S. Market Concentration and Import Competition," Staff Reports 968, Federal Reserve Bank of New York May 2021.

Bajgar, Matej, Giuseppe Berlingieri, Sara Calligaris, Chiara Criscuolo, and Jonathan Timmis, "Industry Concentration in Europe and North America," Working paper 18, OECD 2019.

Besley, Timothy, Nicola Fontana, and Nicola Limodio, "Antitrust Policies and Profitability in Nontradable Sectors," American Economic Review: Insights, 2021, 3 (2), 25165.

Covarrubias, Matias, Germán Gutiérrez, and Thomas Philippon, "From Good to Bad Concentration? US Industries over the Past 30 Years," NBER Macroeconomics Annual 2019, volume 34, University of Chicago Press, 2017, pp. 11-62.

Crouzet, Nicolas and Janice Eberly, "Intangibles, investment, and efficiency," $A E A$ Papers and Proceedings, 2018, 108, 426-31.

De Loecker, Jan, Jan Eeckhout, and Gabriel Unger, "The Rise of Market Power and the Macroeconomic Implications*," The Quarterly Journal of Economics, 01 2020, 135 (2), 561-644.

Dottling, Robin, Germán Gutiérrez, and Thomas Philippon, "Is There an Investment Gap in Advanced Economies? If so, Why?," Conference proceedings, ECB Forum on Central Banking: Investment and Growth in Advanced Economies, 26-28 June, 2017.

Díez, Federico J., Jiayue Fan, and Carolina Villegas-Sánchez, "Global declining competition?," Journal of International Economics, 2021, 132, 103492.

Grullon, Gustavo, Yelena Larkin, and Roni Michaely, "Are US Industries Becoming More Concentrated?," Review of Finance, 04 2019, 23 (4), 697-743. 
Gutiérrez, Germán and Thomas Philippon, "Declining Competition and Investment in the US," Technical Report 2017.

Haltiwanger, John, Ron S Jarmin, Robert Kulick, and Javier Miranda, "1. High-Growth Young Firms," Measuring Entrepreneurial Businesses, University of Chicago Press, 2017, pp. 11-62.

Kalemli-Ozcan, Sebnem, Bent Sorensen, and Vadym Volosovych, "Deep financial integration and volatility," Journal of the European Economic Association, 2014, 12 (6), 1558-1585.

Reenen, John Van, "Increasing differences between firms: market power and the macroeconomy," CEP Discussion Papers dp1576, Centre for Economic Performance, LSE September 2018.

Rossi-Hansberg, Esteban, Pierre-Daniel Sarte, and Nicholas Trachter, "Diverging Trends in National and Local Concentration," NBER Macroeconomics Annual, 2021, 35, 115-150. 


\section{A APPENDIX}

\section{A.1 Dealing with Duplicates}

BvD assigns three generic variables i.e., "BvD Account Number," "BvD ID Number," and "Consolidation Code" to a given firm available in the data. The Consolidation code variable can take different values, corresponding to the type of financial statements reporting available to BvD. The codes reported by the variable Consolidation Code are as follows: C1: indicates that BvD has information on the firm's consolidated accounts only; U1: indicates BvD has information on the firm's unconsolidated accounts only; $\mathrm{C} 2$ : indicates that BvD has information on the firm's both consolidated and unconsolidated accounts and the associated to $\mathrm{C} 2$ are the consolidated ones; U2: indicates BvD has information on the firm's both consolidated and unconsolidated accounts and the associated to U2 are the unconsolidated ones; LF: indicates the firm reports limited financial information. The variable BvD Account Number is composed of three parts: the first two letters at the beginning of the string stand for the country code (BE for Belgium, US for the U.S., GB for the UK, and so on), the last character of the string refers to the type of consolidation code, based on values reported in the variable Consolidation code. The remaining numeric part in the middle of the string and the first two letters at the beginning of the string (identifying the country code) constitute the variable "BvD ID Number."

In the data set that we constructed using different vintages, we created our main company identifier ID_NUMBER, which is a copy of the BvD ID Number as well as our main account identifier CONSCODE2, which is a copy of the last letter of BvD Account Number. We fill CONSCODE2 with "C" or "U" according to the type of the firm's financial statements reporting available to BvD. Specifically, we fill CONSCODE2 with "C" if the financial information of the respective companies is available to $\mathrm{BvD}$ via $\mathrm{C} 1$ and/or $\mathrm{C} 2$ accounts. Similarly, we fill CONSCODE2 with "U" if the financial information of the respective companies is available to BvD via $\mathrm{U} 1$ and/or $\mathrm{U} 2$ accounts. Given that the original Consolidation Code is "LF" for the companies reporting limited financial information (for these companies all financial variables except sales and total assets are missing), we extract the information on account type from the last letter of the variable "BvD Account Number" 
and fill CONSCODE2 of such companies with that information accordingly. These generic variables enable us to track the the same company (the same ID_NUMBER) with multiple accounts of different types ( $\mathrm{U}$ or $\mathrm{C}$ ) in a given financial year. We tag those accounts as "duplicate accounts."

Duplicate accounts in Orbis data arises because companies may report both consolidated and unconsolidated statements in the same year or firms may switch the type of financial statements they report over time and when we combine information from different vintages we may end up with different accounts co-existing in the same firm-year in the merged data set. Such duplicate accounts appear in two cases:

1. A company reports two accounts with the same ID_NUMBER and different consolidation codes and different values of financial and real variables for each consolidation code in the same year.

2. A company reports two accounts with the same ID_NUMBER and different consolidation codes but the same values of financial and real variables for both consolidation codes.

To avoid duplicates (i.e., the same firm reporting under different consolidation codes) and have unique firm-year observations we make the following choices. Among Case 1 type duplicates (i.e., firms reporting different financial values under different consolidation codes) we give priority to those with consolidated accounts. To resolve the duplicates in Case 2 (i.e., firms reporting the same financial values under different consolidation codes), we implemented the following filters:

(i) For the duplicates belonging to companies that continuously report unconsolidated accounts in the period they are available in $\mathrm{BvD}$ data, we give priority to those with unconsolidated accounts.

(ii) For the duplicates belonging to companies that continuously report consolidated accounts in the period they are available in $\mathrm{BvD}$ data, we give priority to those with consolidated accounts. 
(iii) For the duplicates belonging to companies that report both consolidated and unconsolidated accounts with the same sales value but not consistently over the period they are available in BvD data, we checked and verified that the volume of sales over time was consistent with the consolidation code. Therefore, we give priority to the consolidated code classification and reclassify the time series as consolidated.

\section{A.2 Dealing with Switchers}

After getting rid of duplicates, in terms of reporting both consolidated and unconsolidated accounts or in terms of reporting the same financial variables under different consolidation codes, we keep track of "switchers." These are firms that change the reporting account type over time, so the financial information we have combines consolidated and unconsolidated sales of the corresponding firm. Given the change in legislation around 2007 with more firms reporting consolidated statements following international financial standards, we decided to drop these firms to have a consistent time series and minimize the artificial increase in sales that might arise from the change in legislation around 2007. Notice the change in regulation towards the consolidation reporting in accordance with International Accounting Standards (IAS) was supposed to take effect from 2005 onward. However, Member States could defer the application until 2007 for those companies that were listed both in the EU and elsewhere and that were using the US GAAP (or other GAAP) as their primary basis of accounting, as well as for companies that had only publicly traded debt securities. 


\title{
A.3 Appendix Tables \& Figures
}

\author{
Table A.1: Fraction of 'Missing' Output in Eurostat
}

\begin{tabular}{lccc}
\hline \hline & Missing Sector & Missing Sector-size \\
\cline { 2 - 2 } Country & $(1)$ & $(2)$ \\
\hline & 24 & 66 \\
Austria (AT) & 23 & 65 \\
Belgium(BE) & 16 & 56 \\
The Czech Republic (CZ) & 26 & 66 \\
Germany (DE) & 14 & 68 \\
Estonia (EE) & 16 & 57 \\
Spain (ES) & 22 & 65 \\
Finland (FI) & 20 & 65 \\
France (FR) & 36 & 68 \\
Great Britain (GB) & 16 & 74 \\
Greece (GR) & 16 & 60 \\
Hungary (HU) & 14 & 53 \\
Italy (IT) & 15 & 73 \\
Latvia (LV) & 21 & 66 \\
Norway (NO) & 14 & 55 \\
Poland (PL) & 18 & 66 \\
Portugal (PT) & 12 & 62 \\
Romania (RO) & 10 & 10 \\
Sweden (SE) & 12 & 54 \\
Slovenia (SI) & 16 & 16 \\
Slovakia (SK) & & \\
\hline \hline
\end{tabular}

Notes: The table shows the importance of missing sectors in Eurostat-SBS database based on Orbis information. Column (1) shows the share of unaccounted for output due to missing sectoral information in SBS. Column (2) shows the share of unaccounted for output due to missing sector-size information in Eurostat SBS database. 
Figure A.1: Market Share of Top 8 Firms: Sample of All Firms including SWITCHERS
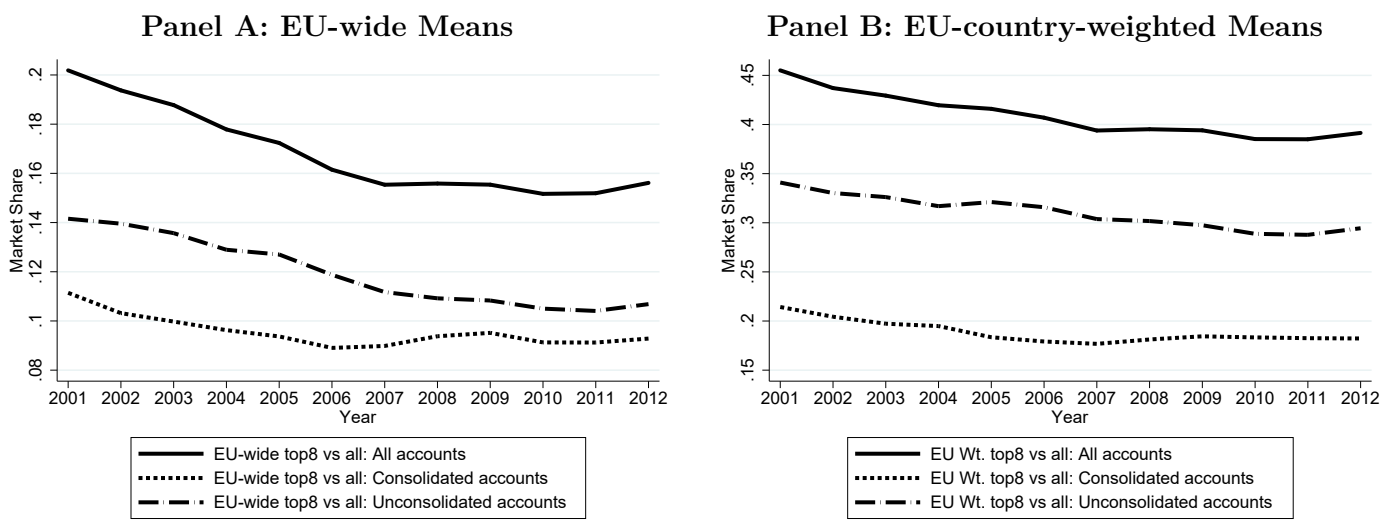

Notes: The figure plots market concentration in the total economy for the European countries in our sample from 2001 to 2012. Panel A plots "EU-wide" market shares over the period: we treat the EU as a single market and define market shares in all the EU countries in a given sector-year. We aggregate over sectors using sectoral value added as weights. In Panel B, we plot "EU-country-weighted" average market shares, using a given country's GDP as weight. In this panel we calculate each country's concentration measure separately, adding up sectors with sector value added and then add up countries with GDP weights. 
Figure A.2: Market Share of Top 8 Firms: Different Denominators for Time Coverage
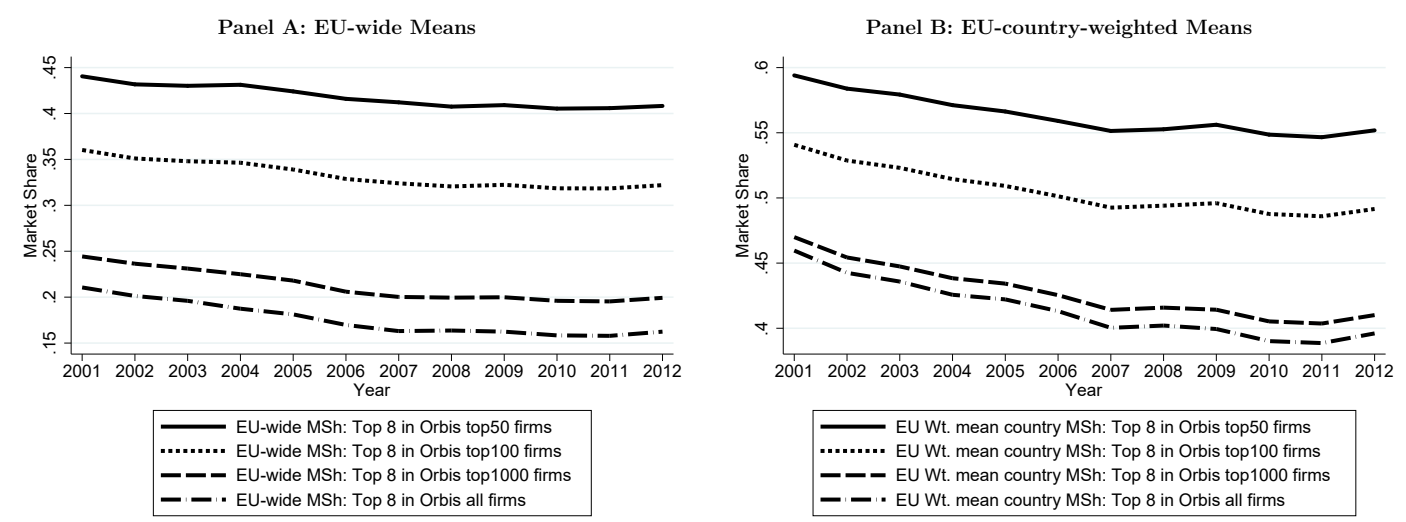

Notes: The figure plots market concentration in total economy for the European countries in different sub-samples of our sample from 2001 to 2012. Panel A plots "EU-wide" market shares over the period: we treat the EU as a single market and define market shares in all the EU countries in a given sector-year. We aggregate over sectors using sectoral value added as weights. In Panel B, we plot "EU-country-weighted" average market shares, using a given country's GDP as weight. In this panel we calculate each country's concentration measure separately, adding up sectors with sector value added and then add up countries with GDP weights. In both panels, we calculate market share of top 8 firms as their aggregated output relative to: (1) the aggregated output of Orbis top 50 firms (solid line); (2) the aggregated output of Orbis top 100 firms (short- dashed line); (3) the aggregated output of Orbis top 1000 firms (long-dashed line); and (4) the aggregated output of Orbis all firms (long-dashed-dot line). 
Figure A.3: Market Share of Foreign and Domestic Firms within Top 8 Firms, Top 100 Firms in Denominator

\author{
EU-country-weighted Means, Change since Initial Year
}

Panel A: All Accounts

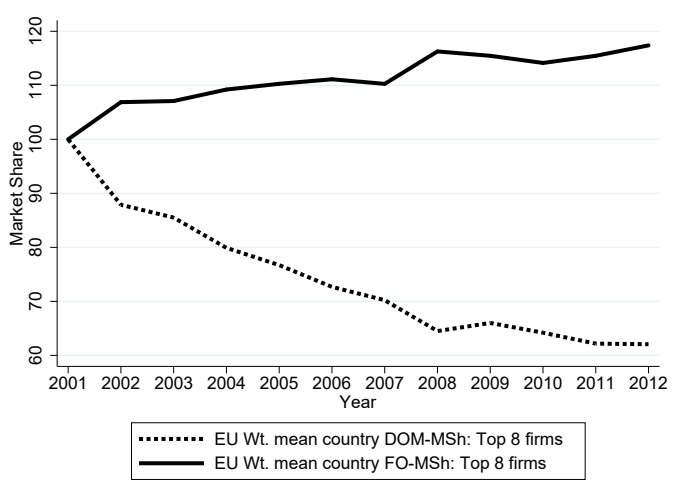

Panel B: Consolidated Accounts

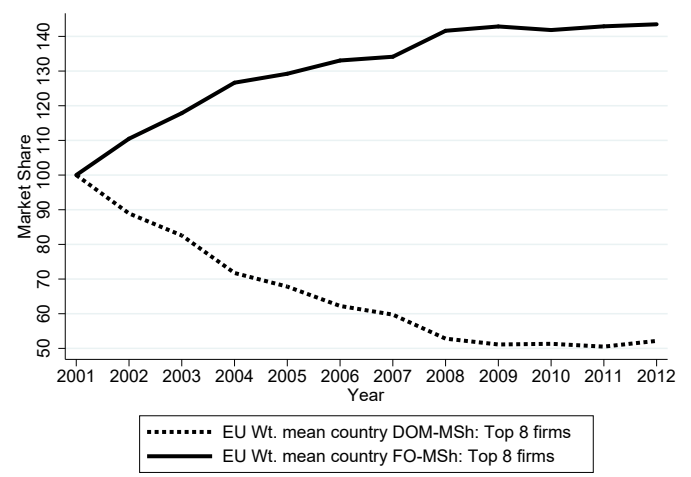

Notes: The figure plots market concentration of foreign and domestic firms within top 8 firms in the total economy for the European countries in different sub-samples of top 100 firms in our sample since 2001. Both panels plot "EU-country-weighted" market shares as percentage change since the initial year (=100) over this period: we calculate each country's concentration measure separately, adding up sectors with sector value added and then add up countries with GDP weights. In both panels, being a foreign firm is determined based on official threshold of more than $10 \%$ foreign ownership in the initial year. 


\section{Figure A.4: Alternative Measures of Industry Concentration}

Panel A: CR4

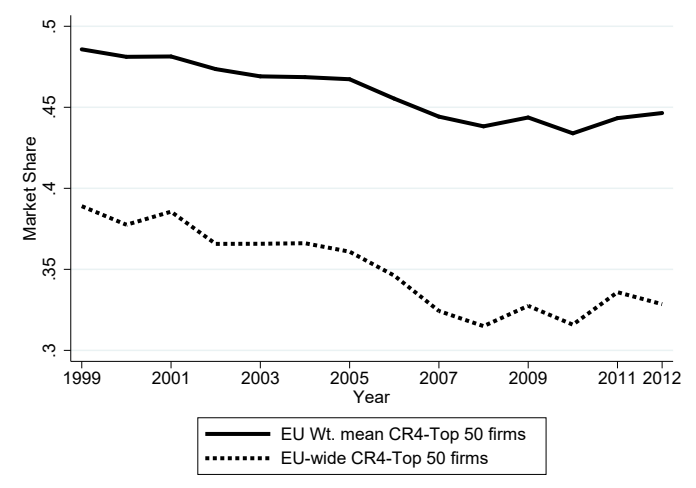

Panel B: Herfindahl

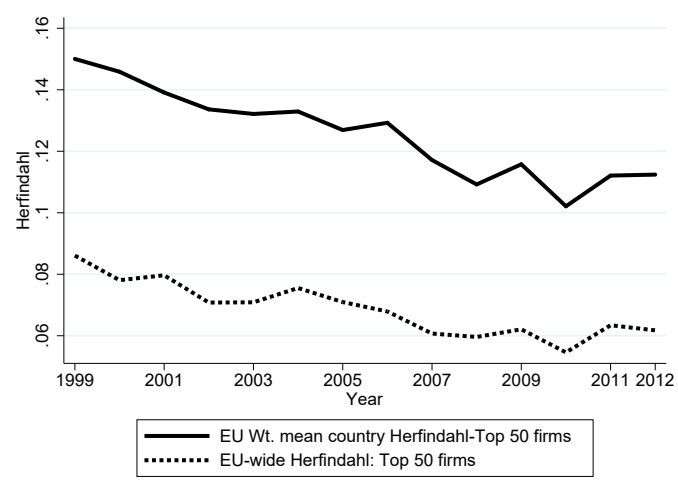

Notes: This figure replicates Chart 9 and Chart 10 in Dottling et al. (2017). We plot market concentration in non-financial corporate sector for the EU KLEMS countries in sub-sample of unconsolidated accounts of our sample from 1999 to 2012. The EU KLEMS countries are Austria (AT) Belgium (BE), Germany (DE), Spain (ES), Finland (FI), France (FR), Italy (IT) and Netherlands (NL). We exclude utilities (KLEMS segments D35 to D39), financial firms (segments D64 to D66) and real estate (segment D68) and industry segments D84 ("Public administration and defence; compulsory social security") and D99 ("Activities of extraterritorial organizations and bodies") from non-financial corporate sector. We measure market concentration over this period by the market shares of top 4 firms (henceforth, CR4) in top 50 firms-shown in Panel A and by Herfindahl index of top 50 firms-shown in Panel B. In both panels, we plot market concentration both on an EU-wide level and on a country level: we plot "EU-wide" market shares over the period (short-dashed lines): we treat the EU KLEMS countries as a single market and define market shares in all the EU KLEMS countries in a given sector-year. We aggregate over sectors using sectoral value added as weights. We plot "EU-country-weighted" average market shares (solid lines): we calculate each country's concentration measure separately, adding up sectors with sector value added. 


\section{Online Appendix}

to

How to Construct Nationally Representative Firm Level Data from the Orbis Global

Database: New Facts on SMEs and Aggregate Implications for Industry Concentration

by

Şebnem Kalemli-Özcan,

Bent Sørensen,

Carolina Villegas-Sanchez,

Vadym Volosovych,

Sevcan Yeşiltaş. 


\section{A Construction of the Dataset}

\section{A.1 Organization of Orbis and Amadeus Databases}

This appendix explains the practical aspects of constructing the panel data of financial and ownership information that is usable for research purposes based on Orbis and Amadeus datasets provided by BvD Electronic Publishing. In the following pages, we describe what we regard as the "best practice" for obtaining the most comprehensive financial- and ownership datasets over time.

\section{A.1.1 Accessing BvD Products}

BvD's two best known products for firm-level data are the global database Orbis and the European database Amadeus. There are other products which are either country specific or region specific (for example for the UK and for the Asia-Pacific region). All these products cover listed and unlisted firms. Amadeus was the original flagship product of BvD with many its features incorporated later on into Orbis database. In what follows, we will write about Orbis and stress the unique features of Amadeus separately.

A researcher can access Orbis and European Amadeus databases in three ways.

1. BvD proprietary browser online (orbis.bvdinfo.com and amadeus.bvdinfo.com).

2. BvD historic (CD/DVD-ROM, Blu-Ray) disks or a new related solution Orbis Historical with the linked historical data (www.bvdinfo.com/en-us/bvd-for-your-business/ academic described under "I need to research historical datasets and changes over time" QnA item). At the moment of writing of this paper, the Orbis Historical solution is still in the developing stage. Therefore, we focus on the steps required to work with the separate historic disks.

3. Through the Wharton Research Data Services (WRDS) from the Wharton School at the University of Pennsylvania (Amadeus only).

Each of the access methods has its benefits and costs for a researcher; the decision about 
which one is the most optimal depends on the research budget and the type of the data one expects to work with.

We refer to the information available from BvD disks as "vintages" of the BvD data. We use the same term when we talk about the data retrieved from an online access to BvD or WRDS at a given point of time. In each case, "vintage" will mean the release date of the disk or the time of online access, respectively.

Each product is split by the type of information provided. For example, Orbis contains the "sections" Orbis Financials with firm financial information and Orbis Ownership with ownership information. There are other sections in Orbis with valuable information such as Auditors and Advisors, Board Members, Patents, etc.

The users who obtain Amadeus through WRDS (Method 3) should be aware that the internal organization of the whole database (Amadeus Financials and Amadeus Ownership) consists of three non-overlapping files corresponding to three company size "tiers." The tiers are defined by BvD in terms of the size of company sales, operating revenue, and employment. The thresholds of these variables for the companies to be classified by BvD as Very Large \& Large, Medium, or Small vary by country (e.g., companies in Eastern Europe may have lower sales in order to be categorized as Very Large \& Large). This matters when querying and downloading the data with the SAS software available under the WRDS subscription.

\section{A.1.2 Financial Module}

The Orbis Financials sub-database includes detailed information about numerous balance sheet items, profit and loss account items, and financial ratios over time as well as static descriptive variables. The descriptive information includes, among other items, official national identification number, address (country, region, city, street), legal form, year of incorporation (entry), status of the company (active/liquidation/merger-acquisition), number of employees, quoted/unquoted indicator, industry and activity codes (4 digit level) and, when available, the description of the nature of the business in the local language and English. ${ }^{1}$

\footnotetext{
${ }^{1}$ The default option is to download textual information, such as company names, in the original format. We encountered problems with the encoding of non-Latin alphabets and non-standard national letters. The user should choose the available option to show the textual information in the international alphabet rather than the original alphabet before download.
} 
Historic (time-series) financial information can be downloaded from the web or from a single disk by selecting several historical years, although there are several issues to be aware of:

- Download speed and cap issue. BvD platforms or disks are not designed for the purposes of academic research involving large amounts of data. Extracting large amounts of data from any BvD platform is in general slow and BvD puts a cap on the amount of information researchers can download both from disks and also from its own website. Most of the time this cap does not turn into a termination of the download job, but rather the downloaded files will have missing information. WRDS is the most user-friendly platform because the imbedded WRDS browser allows researchers to run optimized queries and compresses the data at the time of download; WRDS also allows the researcher to retrieve the data by running a SAS for UNIX code directly at their servers. However, WRDS covers only Amadeus, and Orbis and Amadeus do not overlap 100 percent in terms of companies and variables even for a given European country (any country outside Europe will not be in Amadeus). ${ }^{2}$

- Survivorship bias. Both Orbis and Amadeus contain historic financial data for a number of years. However, the two databases follow somewhat different rules regarding the inclusion of companies and years. Amadeus provides at most the ten most recent reporting years for the same company while Orbis de facto reports data for the five most recent reporting years at most. Amadeus will delete a company from the database if the company did not report anything in the last 5 years, while Orbis will keep this company as long as the company is active in the business register.

- There is a reporting lag of about 2 years, on average, and there are differences in the coverage of particular variables depending on when the BvD product has been released. Hence, for the 2010 vintage, a company may not have the 2010 filings but the 2010 filings will appear in the 2012 vintage. BvD's data collection improves over time and hence this lag might vary by country and by data vintage.

\footnotetext{
${ }^{2}$ For the same company in a given year, it is possible to have more non-missing variables in Orbis than in Amadeus. It is also possible to obtain more firms for the same country and year in Orbis than Amadeus. We have confirmed that both cases are widespread.
} 
- Issues with the presentation format. Certain variables, such as employment, will not be on the balance sheet, but rather in memorandum items.

- Merging issues. BvD identifies each company by a unique company ID, which is designed to trace the same company across all BvD products. However, a researcher merging the time-series financial information coming from several BvD historic disks, or the online downloads done at various points of time, may encounter occasional $B v D$ ID changes over time. The BvD ID number incorporates either the national ID number or the ID provided by their information providers (IP). According to BvD, the ID numbers may change when the national ID numbers change in the official data sources or the BvD IPs decide to switch their ID numbers. The ID changes are related to changes of address, legal form, or M\&A activity. In acquisitions, acquiring company will keep its ID and the target's ID is blocked. BvD mentions that Spanish companies encounter a BvD ID change if they change legal form, while companies incorporated in Germany, Austria, or Italy in some cases see their BvD ID change if the company changes address. ${ }^{3}$ Finally, BvD itself can initiate the ID change when an entity is available on more than one product, or is provided by more than one IP, and BvD harmonizes the IDs across databases using a set of priority rules. As long as BvD does not know that a certain company is the same entity, it will have several different BvD ID numbers on Orbis . Because it is hard to keep track of all these idiosyncracies, the researcher should request the "correspondence table" of BvD IDs from their BvD representative. BvD ID changes can also be obtained by subscribing institutions via the dedicated BvD ID Change Lookup tool at idchanges.bvdinfo.com.

\section{A.1.3 Ownership Module}

Orbis Ownership sub-database contains information on each company's equity ownership structure: the names of owners, their respective ownership shares, the level of ownership (direct or ultimate cross-ownership), their countries of origin. For each owner of every target

\footnotetext{
${ }^{3}$ If a company moves from area 1 to area 2 and area 2 has a different office collecting the information, the company will get a new national ID, thus the BvD ID number changes. If in area 2, the same office is responsible for collecting information, the company keeps its national ID.
} 
firm there is one observation (we refer to such a record as an "ownership link"). There are two major issues of concern for the construction of time-series ownership information.

- The vintage issue for ownership. BvD proprietary browser online and WRDS contain only the latest available ownership information. If one were to access ownership information through the browser, through a specific vintage disk of Amadeus or Orbis or through WRDS, ownership information will be static ("as of date"). The only option to reconstruct the historic (time-series) ownership information is by purchasing the historic Orbis disks from BvD. It is possible to retrieve the historic ownership information through the BvD browser access (Method 1) or historic disks (Method 2) for individual companies by revealing the company's Standard report and then selecting "the Shareholders history - current, previous and archived data" option in the Ownership data menu. But this method is not practical if one is interested in large datasets. In addition, the extent of the survivorship bias through this method is not clear to us.

- Merging issues. The same issue related to BvD ID changes emerges if one downloads ownership data from several vintages of Orbis. The issue is more acute because one needs to rely on annual vintages to track annual ownership changes.

There is a separate BvD product that tracks all mergers and acquisitions, that is changes in ownership, at the transaction level over time (Zephyr). In principle, one can supplement the ownership stakes from Orbis Ownership with the transaction data from Zephyr, by adjusting the equity stakes reported in Orbis Ownership prior to transaction. The data we present in this paper incorporates such an adjustment.

Next, we propose a detailed approach to constructing the most comprehensive financial and ownership information for a representative set of firms over time.

\section{A.2 Downloading from Orbis and Amadeus Databases}

While Amadeus and Orbis have an impressive number of unique firm IDs, as many researchers have discovered, a large number of those IDs contain only information on company name and a few other variables. When a researcher requests some key variables, such as total assets, 
sales or employment, these turn out to be missing. As we detailed out above there are several reasons for this. It is necessary to download data in a non-standard way to overcome these problems. As we have explained in the previous chapter, there are three different ways to access BvD data:

1. Through BvD's proprietary web platform available by the direct subscription.

2. Through BvD's historical vintages, available on historic CD-ROM disks (or harddrives/blueray disks).

\section{Through WRDS archives.}

The standard and the most commonly used method is Method 3. To avoid the pitfalls mentioned above one must follow Method 2, however. Let us explain the advantages of Method 2 over other methods and how one can maximize the coverage and representation of small firms while recovering many financial variables by using Method 2 .

To maximize coverage (for European countries), a researcher must use both Orbis and Amadeus and several vintages from both databases. ${ }^{4}$ The reason is that these databases follow different rules regarding the inclusion of companies and years. ${ }^{5}$ Amadeus provides at most 10 recent years of data for the same company while Orbis, de facto, only reports data for up to 5 recent years, despite the possibility of choosing 10 years of data going back in the Orbis software. The justification given to us by BvD was that the global Orbis database contained much more information and the information included in a given vintage had to be limited because of the media capacity. Moreover, Amadeus drops firms from the database if they did not report anything during the last 5 years while Orbis keeps the information for these companies as long as companies are still in the business register. This problem makes it clear why Method 2 is superior to other methods. A company might file information with BvD for the last time in year 2007. However, in the business registry, this company is still active. Due to non-reporting in the last 5 years, in Amadeus-2013 vintage this company will

\footnotetext{
${ }^{4}$ For countries outside Europe, the only option is Orbis. Our instructions below related to Orbis will apply to other countries, such as the United States, in terms of maximizing coverage and representation.

${ }^{5}$ One also needs to keep in mind that Amadeus, being a regional database, includes some Europe-specific variables that the Orbis Global Standard Format may not contain. Plus some variables may be coded slightly differently in the two databases; for example, the type of owner is textual in Amadeus while in Orbis this variable contains standardized single-letter codes.
} 
not be included, but the same company's information for the period 2002-2007 will still be reported in Orbis-2013 disk. In addition, because there is a reporting lag of financial data of usually 2 years (it varies by country), the coverage of, for example, years 2007 and 2008 from the 2009 Orbis disk (or an online download done in the year 2009) will be very poor. For this purpose, again Method 2 will be better because recent database vintages will complement earlier ones and, hence, one can get more firms for the years 2007 and 2008 from the 2010 vintage (or the 2010 WRDS download). It is also the case that information is updated over time and some variables that were not available in early disks is made available in later vintages.

There are differences in coverage of certain variables across Orbis and Amadeus going back in time. The reason for this might be a combination of the issues mentioned above, or the fact that all the access methods will cap the amount of information one can download in one run (the number of firms and the number of variables). This cap unfortunately translates into missing observations in the resulting download instead of termination of the download job. This issue can also be dealt with, if we use Method 2. To illustrate the problem, consider a researcher who in April 2015 wants to obtain data on Spanish firms for the year 2006. The researcher goes to WRDS (Method 3) and downloads the data by choosing the year 2006. Table A.1.1 presents the distribution by size category in 2006 of firms in Spain in our data constructed based on the methodology we prescribe in this paper (RAW) and the same size distribution based on the data downloaded from WRDS on April 2015 for the year 2006 for Spanish companies. Panel A uses employment to measure firm size distribution, whereas Panel B uses wage bill. In Panel A, in column (1) we see that firms with less than 20 employees account for 25 percent of total employment, whereas firms who have between 20249 employees account for almost 50 percent and firms who have more than 250 employees account for 26 percent of employment. Panel B delivers a similar size distribution. The point we want to make is that if we use our data as shown in column (1), put together from several vintages using Method 2 for download, or we use direct download from WRDS for the year 2006, where we access WRDS on April 2015 as shown in column (2), we obtain a similar size distribution.

What is the problem then, if our data and a single shot download from WRDS delivers the same data? The problem starts when the researcher wants to have full information on a 
certain set of variables. For example, if we want to calculate total factor productivity, then we need to have the variables output, employment, capital stock and materials reported and, hence, we need to go down to a subset of firms that report all these variables. When we do that column (3), which is our data, performs very well and delivers a similar size distribution. However, column (4), which is the direct download from WRDS as of April 2015, performs clearly worse because there are practically no small firms reporting information on materials. This is an artifact of the one-time download from WRDS. As we show in Table 2, the size distribution based on our data for several countries (including the ones shown in Table A.1.1) matches the official size distribution provided by Eurostat based on national censuses.

Table A.1.1: Company coverage comparison in the Spanish manufacturing sector in 2006 obtained from our data (RAW) vs. Amadeus online from WRDS

\begin{tabular}{lcccc}
\hline \hline Sample & RAW & WRDS & RAW-TFP & WRDS-TFP \\
Panel A: Employment & & & & \\
$1-19$ & $24.7 \%$ & $24.0 \%$ & $24.2 \%$ & $0.6 \%$ \\
$20-249$ & $49.2 \%$ & $49.1 \%$ & $49.7 \%$ & $50.1 \%$ \\
$250+$ & $26.1 \%$ & $26.9 \%$ & $26.1 \%$ & $49.3 \%$ \\
Panel B: Wage Bill & & & & \\
$1-19$ & $19.6 \%$ & $18.0 \%$ & $19.2 \%$ & $0.6 \%$ \\
$20-249$ & $46.6 \%$ & $44.7 \%$ & $47.0 \%$ & $44.4 \%$ \\
$250+$ & $33.8 \%$ & $33.5 \%$ & $33.8 \%$ & $53.4 \%$ \\
& & & & \\
\hline \hline
\end{tabular}

Notes: RAW refers to the sample of firms after basic cleaning in our data. WRDS refers to the sample of firms as obtained from the WRDS after basic cleaning. TFP refers to the sample of firms after basic cleaning and with the required information to compute total factor productivity (TFP), i.e., non-missing values for employment, output, capital stock, and materials. WRDS-TFP refers to the sample of firms in WRDS after basic cleaning, with available information to compute TFP.)

In order to maximize the coverage of firms and variables by country over time, our download strategy (Method 2) for financials makes use of several vintages of BvD products: Orbis disk 2005, Orbis disk 2009, Orbis disk 2013, Amadeus online 2010 (from WRDS; accessed in May), and Amadeus disk 2014. We chose these vintages to ensure a time overlap to get around the reporting rules in Amadeus and Orbis.

For ownership our download strategy is more involved because, as we explained, any 
of the three access methods - browser access (Method 1 or 3), or the current vintage at hand (Method 2) — would give access to the ownership information "as of date." We use the Method 2 download strategy, but construct the historic (time-series) ownership information by purchasing the historic Orbis disks from BvD for every year. Because we prefer to record the ownership information as of the end of each calendar year, we choose the Orbis disk issued as closely as possible to the end of the desired year. For example, to obtain the ownership as of end of 2010, we use the Orbis disk issued in January 2011, and so on (disks are issued monthly but firms report yearly, though ownership can change within a year). To take full advantage of slight differences in ownership data in Amadeus and Orbis, we combine bi-annual vintages of Amadeus Ownership with annual vintages of Orbis Ownership. These differences will be discussed in Section B.1.

\section{A.3 Financial Reporting in BvD Databases}

\section{A.3.1 Time Stamp}

Before downloading, one has to choose how to time stamp the year of financial data. One option is the conventional "absolute years," where the year of the financial accounts explicitly refers to calendar years, 2006, 2007, and so on. An alternative is the so called "relative years," where the most recent year of non-missing financials (as available to the BvD) is referenced as the "Latest Year" and the earlier observations are referenced as the Latest Year -1, Latest Year -2 , and so on.

We advise to download financials via the "relative years" option. While it a priori seems counter intuitive, the relative year option is superior to the absolute year option, because of the reporting lag and the survivorship bias-issues detailed above. The distinction in the date option is extremely important for the companies which report irregularly, with gaps in their time series. For such companies, 5 relative years might cover a longer calendar period than 5 years requested explicitly (recall that Orbis de facto reports only the most recent 5 years of a given company, with a reporting lag of 1-2 years). For example, consider a company reporting data for year 2007, and then again for each year between 2009 and 2012. Then, asking for the 5 latest absolute years 2008-2012 would leave us with just 4 
observations (2009-2012), while asking for 5 relative years would retain the 2007 value (the 2007 is referenced as "Latest Year -4 " in this case). To obtain the correct assignment of the relative years in terms of calendar years, we use the special BvD index variable (Closing date, Latest Year; Closing date, Year -1 and so on).

\section{A.3.2 Consolidation of Subsidiaries}

For a given company, the BvD databases report one or more financial statements, whose type is specified by the "Consolidation Code." Most of the large companies with good coverage report either consolidated accounts (the statement of a parent company integrating the statements of its controlled subsidiaries) or unconsolidated accounts (the statement not integrating the statements of the controlled entities). Some companies report both kinds of accounts. Finally, there are entities with limited financial data, no recent financials (where the last available accounts are more than 48 months old), and the combination of the two. In most of these cases, only the number of employees and the operating revenue are available. The type of account reported is related to country filing requirements for particular size or legal type of companies, as detailed in Table A.6.1 (e.g., the non-independent branches (establishments) are often included in Orbis for the United States). To speed-up the process, we download the data separately for non-limited financial accounts (which includes most companies) and limited financials accounts. We download both consolidated and unconsolidated accounts and, so far, use unconsolidated accounts in all of our applications. Any user can choose which account to use by looking at the "U" or "C" letters at the end of the firm ID (or by using the $\mathrm{BvD}$ consolidation code) for unconsolidated and consolidated statements, respectively. Consolidated accounts will involve double counting when both consolidated account of the parent (with all its subsidiaries) and the unconsolidated account of the parent (without subsidiaries) are reported.

\section{A.3.3 Units and Currency of Financials}

Balance sheet financial variables are book values. Care should be exercised when choosing how the financial data will be downloaded both in terms of the monetary units and currency. By default, the formatted export from BvD disks will be in the units and currency in which 
a particular company originally filed its financials. This means that a given company may report in thousands in some years and in millions in other years. To avoid spurious jumps in the data, the best practice is to choose the units (units, thousands, millions) in the Formatted Export Wizard explicitly, rather that use the default. In case the default was chosen, the variable UNITS lists the units a given observation is recorded in (the values are textual in Orbis and numeric powers of 10 in Amadeus). In the latter case, the harmonization is achieved by the transformation $x=x * 10^{\text {UNITS }}$. But note that the UNITS variable might have errors in certain disks, as we have discovered and, therefore, the best practice is to force the download to be in specific units (such as thousands) and not use the default. ${ }^{6}$

We choose the data in the original currency filed by the company, which might be the national currency of the country or sometimes a foreign currency. The currency of the given account is available in the variable "Account published in currency." It is tempting to use the available BvD variable "Exchange Rate" in order to convert the data from all companies into a single currency. We advise against using this variable, because different products use it for different purposes. In the Orbis or Amadeus disks, once we choose to download the data in "local currency" the values of the variable "Exchange Rate" are always set to 1. However, in the Amadeus downloads from WRDS, this variable contains the actual exchange rate of the currency of account against the U.S. dollar. Hence, in general, the variable "Exchange Rate" does not contain the rate versus, say, the U.S. dollar (as was the case with WRDS Amadeus), but has the exchange rate of the currency of an account in relation to the currency chosen by the person downloading the data.

\section{A.4 Data Selection and Exporting}

Before discussing the merging and cleaning steps, we touch upon some other subtle issues in the setup of the download process. The process starts from selecting the sample of companies in a given $\mathrm{BvD}$ disk, typically by country. ${ }^{7}$ To overcome the download limits, large countries

\footnotetext{
${ }^{6}$ By errors, we mean the cases when the value of the UNITS switches from, say, thousands to millions, but the corresponding financial variables do not show the 1000x decrease in the order of magnitude. We describe a filter we developed to check for these issues in Section A.5.2.

${ }^{7}$ One must chose industrial companies from the start since there are also banks and insurance companies in Orbis. "Type" variable helps this selection. In addition global format is what is available for private firms whereas detailed format is available for listed firms.
} 
may be downloaded by regions. An alternative is to use sectoral splits in a given country. The software then displays the set of the selection criteria, combined by the "AND" expression, and the resulting number of unique companies satisfying all the criteria. One can replace the "AND" expression to adjust the selection criteria and/or display the list of companies. Regardless of the variable used for splitting the large country data for separate downloads, it is necessary to watch out for the cases when the variable used for splitting is not available for a subset of companies. For that, one needs to select the criterion of the entire country (such as "all companies in the U.S.") and add the criterion where all regions or sectors are explicitly listed, but precede the latter condition with the "NOT" expression (AND NOT "companies in sectors A, B, C..."). ${ }^{8}$

To download from the older disks (issued prior to January 2012 for Orbis or December 2010 for Amadeus) one has to navigate to the Formatted Export menu (File $>$ Export $>$ Formatted Export To on the upper-left) in order to adjust the default list of variables; the user does not need to display the list of companies after this. In the Formatted Export menu one can also choose the time period of the data (absolute/relative years), currency, units of financials, and then the export layout. See Section E.1 for illustration of this interface. An alternative, "List Export" method is accessible from the list of companies. To adjust the default list of variables and make other choices, one has to navigate to Options $>$ List Format $>$ New Format menu. We do not discuss this method, because we did not see a clear advantage over the Formatted Export method in older BvD disks. If anything, a potential disadvantage is the increase in waiting time for the list of companies to be displayed before the download can start.

In newer disks (issued after January 2012 for Orbis or December 2010 for Amadeus), which emulate the BvD online interface (Method 1), more download options are available after the resulting number of unique companies satisfying the criteria is revealed. After selecting the Formatted Export menu on the right, one now needs to further choose from the Database export, Statistical export (not useful), or Custom export. The closest analog to the Formatted Export interface in the older disks is the Custom Export where one can adjust the variables, data time stamp (absolute/relative years), units, currency, and layout. Section E.2

\footnotetext{
${ }^{8}$ This additional download can be ignored if the number of companies lost due to the missing splitting variable is negligible.
} 
shows the details of its interface. However, for unknown reasons the list of variables one can choose from does not include all the variables available in Orbis. ${ }^{9}$ In particular, none of the ownership data is available. A potential remedy is the Database Export (another subheading of Formatted Export), specifically designed for downloading large amounts of data according to BvD. For the interface of this method, see Section E.3. Database Export lets one choose all the variables in Orbis, currency, and units. The download works much faster than other methods, which is an advantage for large downloads such as ownership data. In our experiments, we saw roughly a twofold time gain compared to other methods. However, a serious drawback of the Database Export is the inability to download financials with the option of "relative" years (it only downloads in terms of "absolute years"). For this reason, we have to choose the Custom Export option as the only way to force the relative years download. For ownership downloads the Database Export is acceptable because, as we explained in Section A.2, the time dimension is irrelevant given the availability of ownership data as a snapshot in a given release. A final option is the List Export, illustrated in Section E.4. One can chose absolute and/or relative years and all of the variables under the List Export option. Hence, this method works for both financial and ownership data downloads. The only drawback of List Export is the extra time needed to first reveal the list of companies before the download can commence.

\section{A.5 Building Financial Panel Data}

\section{A.5.1 Vintage Raw Data}

The following are the key steps we take in constructing the firm-level financial database. We execute these steps for each vintage of the BvD database we use.

1. Extract the data from Orbis with the 5 latest "relative years" in ASCII commaseparated value format, ${ }^{10}$ transform it to Stata using Statransfer, name and label the variables using the database codes and names. The data comes in Stata wide format

\footnotetext{
${ }^{9}$ Because all the variables were available in older disks under Formatted Export, we believe the reason they are not under Custom Export (which is a sub-heading of Formatted Export) is due to space limitations in the newer disks due to the increase in the amount of information given more years.

${ }^{10}$ For Amadeus data, we select 10 relative years for the reasons explained in Section A.2.
} 
with the rows consisting of unique records (lines) per company consisting of BvD ID and similar non-time varying data, the last available year per firm LASTYEAR; and the blocks of time-varying variables in the form $X$ in the Latest Year, $X$ in Latest Year -1 , and so on, until $X$ in the Latest Year -4 . We rename the variables using internal BvD codes to become, correspondingly, $X 1, \ldots, X 5$.

2. Delete the observations with just a name of company and no other information and the observations with missing $\mathrm{BvD}$ ID or BvD Account number (the main account identifier).

3. Notice that at this stage the data does not have a harmonized time variable showing the precise calendar year of each data point. In order to reshape the data from Stata wide format to the convenient long format, we use the row number as the cross-section identifier and specify in Stata that the number following the stub $X$ of the time-varying variables $X 1, \ldots, X 5$ has to be treated as the "fake" time identifier YEAR. The resulting YEAR variable is a mere marker of the observation per firm because it does not account for the possible gaps in reporting that we have discussed in Section A.3.1. There are also a lot of redundant empty observations because the -reshape- command creates a full panel and the observations in the periods when a given firm does not report the data will be empty.

4. Use the variable "Account Closing Date" CLOSEDATE to correctly assign the calendar year. We re-construct the YEAR variable based on the following convention. If the closing date is after or on June 1st, the current year is assigned (if CLOSEDATE is 4th of August, 2003, the year is 2003). Otherwise, the previous year is assigned (if CLOSEDATE is 25th of May, 2003, the year is 2002). ${ }^{11,12}$

\footnotetext{
${ }^{11}$ The raw data may contain duplicates in terms of ID-YEAR. These duplicates arise for two reasons: i) The presence of both quarterly and annual reports. ii) Firms switching from presenting their end of accounting year balance sheet information in one month to some other month (from December to May, for example). We would like to keep the most recent reports for these companies. One way to handle duplicates is to retain the data for the closing date closest conceptually to the end of year. An additional step to handle duplicates is to use a flow variable with good coverage such as Operating Revenue to identify potential quarterly reports (quarterly sales should be much lower than yearly sales). Then we drop duplicates whose revenue are less than the maximum per firm-year. For example, in 2005 vintage, there are around 34 thousand duplicates like that out of over 18 million observations. We eliminate a small number of remaining duplicates for which we cannot know whether these remaining reports refer to annual or monthly data.

${ }^{12}$ One might think that $\mathrm{BvD}$ correctly marks the lags in relative years taking into account the possible
} 
5. Create our main company identifier ID_NUMBER, which is a copy of the BvD ID number. The difference between the BvD account number and the BvD ID number is the single letter, $\mathrm{U}$ or $\mathrm{C}$, in the end of the $\mathrm{BvD}$ account number, reflecting what account type the record represents (consolidated and unconsolidated). If the $\mathrm{BvD}$ account number is missing, we concatenate the BvD ID number with the first letter of non-missing BvD Consolidation Code, following the BvD convention for the BvD account numbers ( $\mathrm{U}$, $\mathrm{C}$ and nothing for limited financials accounts). We create the country code based on the first two letters of the ID_NUMBER which by BvD convention starts by a two-letter country code (BE for Belgium, US for the U.S., GB for the UK, and so on).

6. All the financial variables are transformed from strings into numeric data type. In the vintages where we downloaded the data in the "original units," we transform the variable UNITS from textual form to the integer power of ten to express all financials in the same units. We developed a filter to check for mistakes in the UNITS variables as explained below.

7. Clean the raw vintage data.

- Drop duplicates in terms of ID_NUMBER and YEAR. ${ }^{13}$

- Drop observations with no financial information. We verified that these companyyear points do not have an account closing date and are mostly missing observations generated during the reshaping stage.

- Drop observations for which country code created based on the BvD ID numbers does not correspond to BvD's country ISO code. ${ }^{14}$

- Drop observations with missing currency.

time gaps in financial data. As we discovered, this is not the case. Hence it is essential that one downloads the CLOSEDATE variable, together with BvD ID number, BvD account number, and the last available year variable.

${ }^{13}$ These will have the same financial data but different industry codes. In Orbis the first observation per duplicate represents the main industry, hence, we keep the main industry per company for companies that had multiple industries reported.

${ }^{14}$ As we mentioned, BvD IDs start from the 2-letter code corresponding to the company's country. BvD country ISO code is the same for all the companies in a given country. Hence, if a company has a different country code, we interpret this as a mistake. This can also be a tax front. Note that these are not the multinationals since the country code attached to BvD ID numbers reflect where the company operates. If the company is part of a multinational, this will be reflected in the ownership variables not in the ID numbers. 
- Drop observations with missing Account Closing Date.

\section{A.5.2 Merging Vintages}

At this stage each observation in each vintage is uniquely identified by the variables ID_NUMBER and YEAR. The following steps are performed at each consecutive merge, with vintage specifics highlighted.

1. As explained in Section A.1.2, in some instances the unique company identifiers change over time which would affect the success of the merge. Before the merge, we replace the old IDs for the countries which had their ID changed over time with the most recent ones. We retain the old "legacy IDs" on the data.

A slight complication emerges for IDs in former Yugoslavia, coming from earlier Orbis disks. The same companies "belong" to Yugoslavia in the early 2000s (country code and the first two letters of IDs are YU), then to Serbia-Montenegro (CS) in disks from the mid2000s, then to, separately, Serbia (RS) and Montenegro (ME), or even Kosovo (KV). In the IDs of these companies only the letter part changes over years - the numeric part does not. Where it is possible, we assign YU and CS to RS and ME using the numeric part of IDs; where we do not know, we assume they are in RS. We do this after the replacement of IDs using the correspondence table, because some firms with ID from CS are present in that table and are already assigned to RS or ME.

2. Before the merge, we harmonize the names of the variables across vintages and products.

3. Before the merge, we check the consistency of the Units of Financials variable (UNITS). Recall that at this stage the financial data is reported in various units of local currency (units, thousands, etc.) for different companies and even for the same company over time. This is due to BvD non-harmonization across products. Downloading in "default" option for the units requires the researchers to use the UNITS variable to harmonize the units. Another way is to force the download to be in a particular unit such as units or thousands. We employ the following strategy to deal with this issue if the researcher downloads the data with the "default" option. For each company we 
check if the moment of switch in units coincides with a "reasonable" move of total assets (can also do other financial variables); if not-we drop the entire firm. For the lower threshold of assets growth, we choose $-99 \%$ because the $1000 \mathrm{x}$ decrease (due to a change in the UNITS variable) of otherwise unchanged assets is $-99.9 \%$ growth. For the upper bound of assets growth, we choose 19,800\% because the 1000x increase of otherwise unchanged assets is $99900 \%$ growth. If we allow the company to have a large (70 percent) drop in assets in the year when the units switch $1000 \mathrm{x}\left(\mathrm{x}^{*} 0.3^{*} 1000\right)$, this is close to $19900 \%$ growth. ${ }^{15}$

Then we calculate the actual growth of assets and verify if this growth lies outside of these thresholds in the years when UNITS change. We drop the entire company where the moment of switch in UNITS does not coincide with the reasonable move in assets. ${ }^{16}$ One can keep the companies which are marked by BvD as "inactive" because the assets of those firms can genuinely go down to (almost) zero. ${ }^{17}$

4. Before the merge, we express all financial variables in harmonized units by the transformation $x=x \cdot 10^{\text {UNITS }}$, except in the 2013 Orbis vintage that is downloaded with the explicit "in units of local currency" option. The UNITS variable is then discarded.

5. Before the merge, we create the textual identifier for the vintage to keep track of the vintage which contributes to a given observation after all merging steps are done.

6. An additional methodological complication arises when we combine the 2013 Orbis vintage with earlier vintages. This is related to the change in sectoral classification in 2008 from NACE Rev 1.1 to NACE Rev 2 by the Eurostat. ${ }^{18}$ In 2005 and 2009 Orbis vintages, the sector is identified by the "NACE Rev. 1.1, Core code (4 digits)" (NACECD); in 2010 WRDS Amadeus, 2013 Orbis, and 2014 Amadeus vintages it is already "Rev.

\footnotetext{
${ }^{15}$ Recall that all the balance sheet values are book values for the non-listed firms.

${ }^{16} \mathrm{As}$ a result, we eliminate about $3 \%$ of observations in the 2005 and 2009 Orbis vintages; less than $1 \%$ in the 2010 WRDS Amadeus vintage; and less than 0.5\% in the 2014 Amadeus vintage.

${ }^{17}$ The variable Status takes the values Dissolved, Dissolved (merger or take-over), In liquidation, Inactive (no precision), Dissolved (liquidation), Dissolved (merger or take-over), Inactive (no precision), Bankruptcy, Dissolved (bankruptcy), Dissolved (demerger) or some peculiar active types Active (default of payments), Active (dormant), Unknown.

${ }^{18}$ Table A.6.2 lists sectors classified by NACE Rev 2, Level 2. For space considerations we do not report the 4-digit industry classification.
} 
2 Core code (4 digits)" (NACEREV2CCODE). Both codes are unique per company. ${ }^{19}$ We prefer to use the more recent NACE Rev. 2 classification in our data.

We went through a detailed process of matching the industry classifications pre- and post-2008. We start from the official Eurostat correspondence table between NACE Rev 1.1 and NACE Rev 2. To supplement the official correspondence table in a way that we have a one-to-one match for every sector, we proceed as follows. Most often, multiple NACE Rev 2 codes correspond to a given NACE Rev 1.1 code. In the official correspondence tables, when multiple NACE Rev 2 codes are matched to a unique NACE Rev 1.1, they are sorted in the ascending order of the numeric NACE Rev 2 code. The first code is the most closely related sector to the one in NACE Rev 1.1 classification. We retain the first NACE Rev 2 code provided in the official table and discard the rest. ${ }^{20}$ This approach attains a good match for manufacturing sectors (codes 10 and higher in NACE Rev 1.1) but not as good a match for agricultural sectors (codes below 10 in NACE Rev 1.1). We manually match codes by reading the long descriptions of the codes. We do the same if there are sectors that are completely missing in the official correspondence tables. Our own correspondence table is available upon request.

Before merging with the 2013 Orbis vintage we merge the earlier vintage data with our sector correspondence table. We keep the original sector classification from each vintage just in case.

7. Care should be exercised when combining the disk data from Orbis with Amadeus downloads from the WRDS (in our case, we used the 2010 download of Amadeus from the WRDS), mostly with respect to the harmonization of variable names. Here are some peculiarities which the users are advised to verify. i) As we explain above, the "Exchange Rate" variable of WRDS should not be used. ii) In May 2010 WRDS Amadeus , the label of the core sector variable NACECD states NACE Revision 1.1. but we dis-

\footnotetext{
${ }^{19}$ There are numerous "secondary" codes in BvD. All of the above is for the "main" code. We also keep the alternative unique industry codes such as SIC and NAICS.

${ }^{20}$ For example, the NACE Rev 1.1. code 10.20: Mining and agglomeration of lignite is matched to three NACE Rev 2 codes: 05.20: Mining of lignite; 09.90: Support activities for other mining and quarrying; 19.20: Manufacture of refined petroleum products. We retain the first line from the correspondence table and matches "10.20: Mining and agglomeration of lignite" to "05.20: Mining of lignite."
} 
covered from observing the values that it is in fact Revision 2. We verified this with WRDS, who in turn confirmed this by contacting BvD. For this reason, no sector correspondence table needs to be applied to this vintage. iii) In WRDS, the listed company identifier is a binary variable ("Quoted company" LISTED) while in Orbis it is textual having the values like "Delisted," "Listed," "Unlisted." We add the textual variable to WRDS Amadeus vintage before merging with the other data.

8. We use the values from the later vintages to supplement missing values. A non-missing value, however, will never be replaced with a missing. (In Stata language, we merge with update and replace options). Depending on the order of merge and the computing power (RAM) availability the users may merge all the vintages at once or, if the data gets big to fit the RAM, merge countries one-by-one and then append (stack) the country data.

9. Check for duplicates by ID and YEAR and, in case of duplicates, retain only observations coming from the most recent vintage.

\section{A.5.3 Cleaning Merged Data}

After we merge the financial data from individual vintages, we perform some further data harmonization and very mild cleaning for obvious data mistakes.

1. Companies in several countries report financials in multiple currencies. We always retain the accounts in major currencies, such as, U.S. dollar, Euro, UK Pound, but delete the observations with missing or unreasonable currencies which probably are mistakes (for example South African Rand or Canadian dollar for European companies).

2. We express the financial variables in real dollars 2005 base. To convert from the units of the nominal currency of accounts we i) convert the currency of accounts to the official currency of the country; ii) deflate the series by the national GDP deflator with the 2005 base from the World Bank; and iii) divide by the exchange rate of the official currency to the U.S. dollar in the year 2005. A number of complications arise at this stage. 
Because companies in several countries report in multiple currencies in order to add the official exchange rate, we do not use the country code but the currency code. ${ }^{21}$ The problem with the World Bank data (or the IMF's IFS data) is that the source does not report the ISO currency code even if the country changes the currency; we just observe a jump in the exchange rate. We obtain the Compustat Global exchange rates, which use currency ISO symbols (USD, GBP, etc.) as the main identifier of the existing and legacy currencies. We also supplement and harmonize the Compustat currency series rates with currencies actually observed in our data in particular country-years. In case the legacy currencies are missing in Compustat in some years (e.g., in the former Soviet Union, in Yugoslavia, etc.), we refer to the national central banks' data.

For the conversion step i), we need to make sure that the currency of financials for all firm-years is the "official" local currency as of today and not other currencies. This is important because we will use the deflator in the official local currency. In particular, we need to decide what official currency to use with the recent Eurozone members in conjunction with the GDP deflator data. In our sample, Estonia, Slovenia, Slovakia, and Malta are such countries; Latvia who adopted the euro on 1 January 2014 is still marked as having currency as Latvian Lats in our data. Consider Slovenia as an example. The country adopted the euro on 1 January 2007. In Slovenian data we observe the companies which report the data in single currency (Euro or Slovenian Tolar) in all years, pre- and post-2007. The note to the WB GDP deflator data for Slovenia says "A simple multiplier is used to convert the national currencies of EMU members to euros. The following irrevocable euro conversion rate entered into force on January 1, 2007: 1 euro $=239.64$ Slovenian Tolar." This implies that the deflator is effectively in Tolar (SIT) until 2007 because it is a ratio of year 2006 to year 2005 (the base year in WB data) and both of these years are multiplied by the same number 239.64 (the fixed parity rate). Hence, the official currency of Slovenia is considered to be SIT before 2007, and all financial data is recalculated to SIT before 2007. From 2007 the deflator reflects the dynamics of local prices in Euros, and we express all the

\footnotetext{
${ }^{21}$ As we explained in Section A.3, the BvD variable "Exchange Rate" is useless for conversion of the data downloaded in the "original currency." Users may choose to download the raw data in some other currency, such as U.S. dollars, in which case the Exchange Rate might report the exchange rate to the currency of accounts. We prefer to convert the data ourselves and not rely on the internal BvD data convertor.
} 
financials of Slovenia in euro.

3. Drop company-years with missing information on total assets and operating revenue and sales and employment (simultaneously).

4. Drop the entire company (all years) if total assets is negative in any year.

5. Drop the entire company if employment (in persons) is negative in any year and companies with employment larger than that of Walmart (2 million) in any year.

6. Drop the entire company if sales are negative in any year. Of note, we do not perform this filter in terms of Operating Revenue because this P\&L account item is equal to sales + Other operating revenues + Stock variations. While sales cannot be negative, revenue can be negative if a company has a sizable financial loss (say, loss due to hedging, etc.). For countries, like Denmark, whose firms do not report sales but only operating revenue, we cannot use this filter.

7. Drop the entire company when reporting in any year a value of employment per million of total assets larger than the 99.9 percentile of the distribution.

8. Drop the entire company when reporting in any year a value of employment per million of sales larger than the 99.9 percentile of the distribution.

9. Drop the entire company when reporting in any year a value of sales to total assets larger than the 99.9 percentile of the distribution.

10. Drop the entire company if Tangible Fixed Assets (such as buildings, machinery, etc.) is negative in any year.

11. For a given company ID year, we replace missing strings which are unlikely to change over time with values for this company for other years. We complement information on country, company name, city, region, postal code, legal form, and date of incorporation with lagged/lead values in the years where such info is present. This is reasonable because if a company changes the legal form it obtains a new BvD ID and will be treated as a new entity. If information is missing in all years, they remain missing. 


\section{A.6 Filing Requirements and Sector Correspondence}

\section{Table A.6.1: BvD Company Filing Requirements and Data Providers for Se- LECTED COUNTRIES}

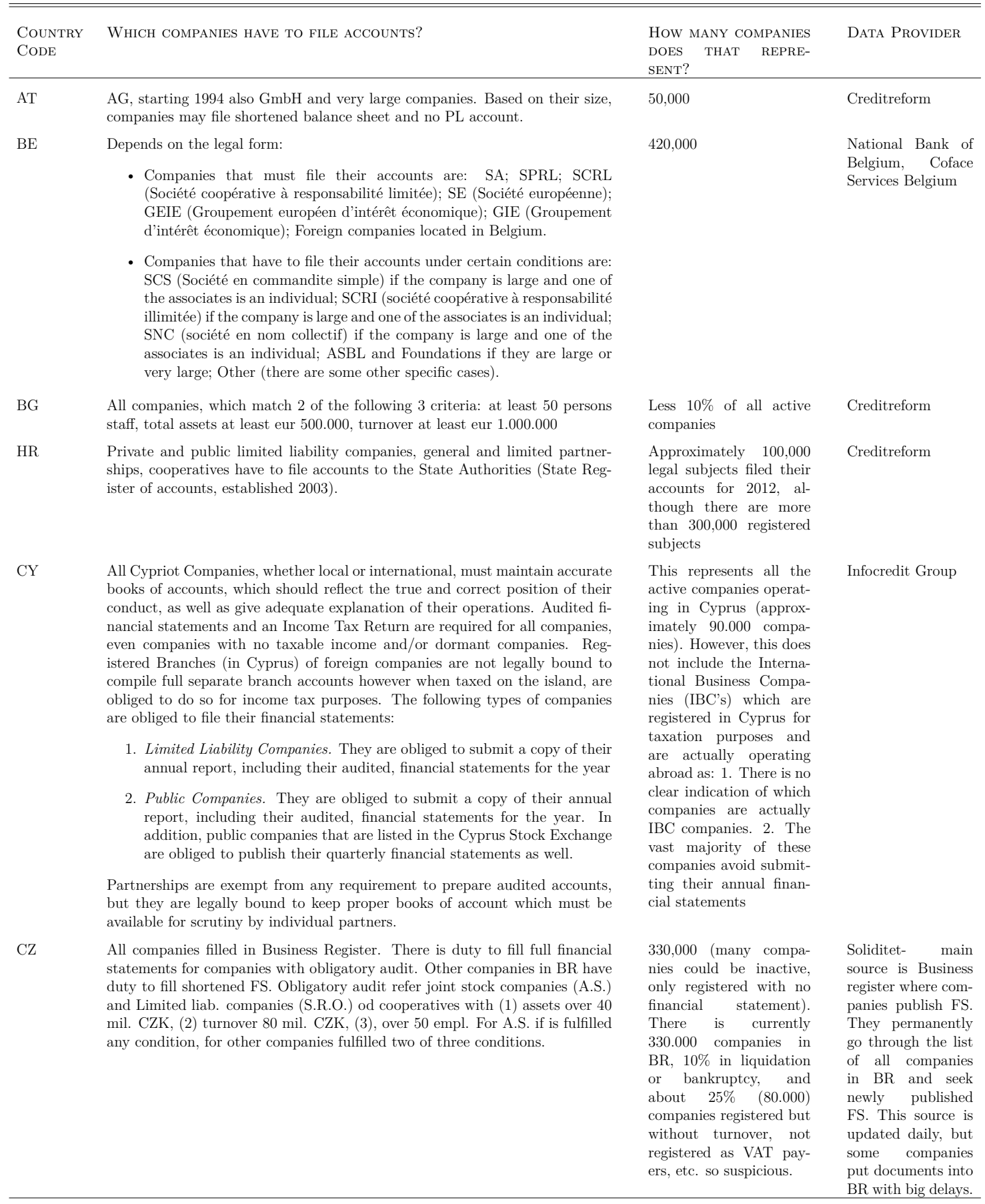

Notes: Filing requirements were taken from the Orbis Online Manual on February 3d, 2014. 


\section{Table A.6.1 (Cont'd.): Filing Requirements and Data Providers}

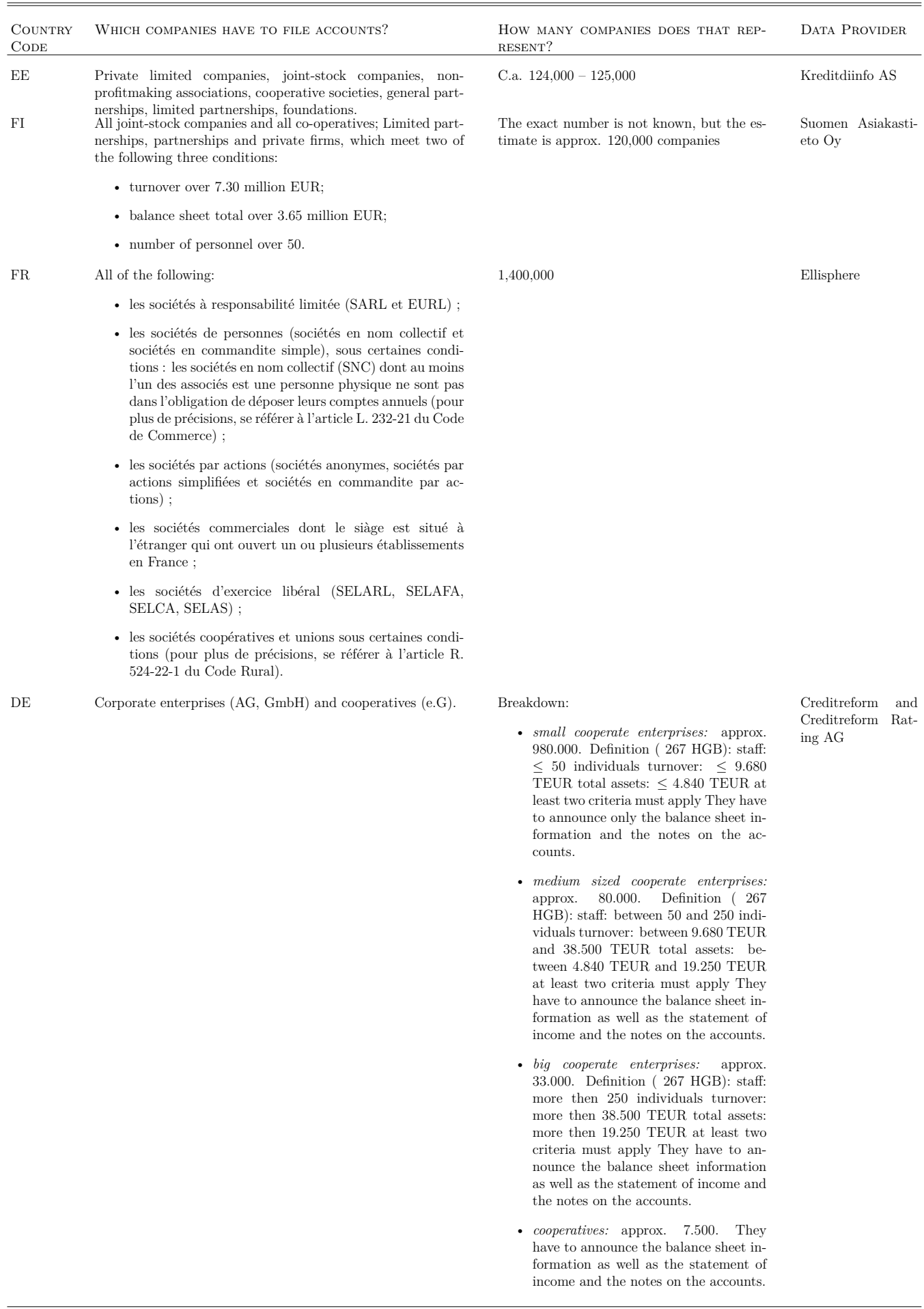




\section{Table A.6.1 (Cont'd.): Filing Requirements and Data Providers}

\begin{tabular}{|c|c|c|c|}
\hline $\begin{array}{l}\text { COUNTRY } \\
\text { Code }\end{array}$ & WHICH COMPANIES HAVE TO FILE ACCOUNTS? & $\begin{array}{l}\text { HOW MANY COMPANIES DOES THAT REP- } \\
\text { RESENT? }\end{array}$ & Data Provider \\
\hline GB & Limited, PLC, LLP, LP. & $1,000,000$ & Jordans Limited \\
\hline GR & Societe Anonyme and Limited Liability Companies. & $\begin{array}{l}\text { The Societe Anonyme and Limited Liability } \\
\text { Companies that publish Balance Sheets rep- } \\
\text { resent approximately the } 5 \% \text { of the total ac- } \\
\text { tive Business Universe in Greece. }\end{array}$ & ICAP \\
\hline $\mathrm{HU}$ & $\begin{array}{l}\text { All companies have to file accounts, except private enterprises. } \\
\text { The companies have to send the accounts to the Ministry of } \\
\text { Justice and to the Registry Court. The one-person firms and } \\
\text { the limited deposit companies do not have to send it to the } \\
\text { Ministry of Justice. }\end{array}$ & About $40 \%$. & Creditreform \\
\hline IS & $\begin{array}{l}\text { Sameignarfélag (fulfil two out of the three following prerequi- } \\
\text { sites : total assets }>230 \text { ML ISK, operating revenue }>460 \\
\text { ML ISK, average number of employees }>50 \text {, or if the mother } \\
\text { company has to file accounts), Samvinnufelag, Samlagsfelag } \\
\text { (if mother company has to file accounts), Einkahlutafélag, } \\
\text { Hlutafélag. }\end{array}$ & $\begin{array}{l}\text { Approx. } 20,000 \text { companies were to file their } \\
\text { accounts. }\end{array}$ & Icecredit Info. \\
\hline IE & Limited. & 100,000 & Jordan Limited \\
\hline IT & $\begin{array}{l}\text { Includes: } \\
\text { - S.p.A. (Società per Azioni), } \\
\text { - S.r.l. (Società a responsabilità limitata), } \\
\text { - Sapa (Società in accomandita per azioni), } \\
\text { - Società Cooperative, } \\
\text { - Società Consortili, } \\
\text { - G.e.i.e, Società di persone (only consolidated accounts), } \\
\text { - Consorzi con qualifica di Confidi. } \\
\text { - Società a responsabilità a socio unico e società per azioni } \\
\text { a socio unico. }\end{array}$ & Approximately 900,000 & \\
\hline LV & $\begin{array}{l}\text { All companies, except sole proprietor enterprises, peasant } \\
\text { farms and fishers farm whose annual turnover does not ex- } \\
\text { ceed LVL } 200.000 \text { (EUR } 284.6 \text { thousand). }\end{array}$ & Approximately 100,000 . & Creditreform \\
\hline LT & $\begin{array}{l}\text { Includes: } \\
\text { - Limited liability companies; } \\
\text { - Joint stock companies; } \\
\text { - State enterprises; } \\
\text { - Municipal enterprises; } \\
\text { - Agricultural companies; } \\
\text { - Cooperative companies. }\end{array}$ & $\begin{array}{l}79,823 \text { (excluding bankrupted, liquidating } \\
\text { and inactive companies). }\end{array}$ & Creditreform \\
\hline $\mathrm{LU}$ & Public (S.A.), limited (S.A.R.L.) & $\begin{array}{l}\text { Not possible to find out : there are in to- } \\
\text { tal about } 25,000 \text { companies and } 15,000 \text { Hold- } \\
\text { ings, total } 40,000 \text {. }\end{array}$ & Creditreform \\
\hline
\end{tabular}




\section{Table A.6.1 (Cont'd.): Filing Requirements and Data Providers}

\begin{tabular}{|c|c|c|c|}
\hline $\begin{array}{l}\text { COUNTRY } \\
\text { CODE }\end{array}$ & Which COMPANIES HAVE TO FILE ACCOUNTS? & $\begin{array}{l}\text { HOW MANY COMPANIES DOES THAT } \\
\text { REPRESENT? }\end{array}$ & Data Provider \\
\hline NL & $\begin{array}{l}\text { All limited companies (B.V.s and N.V.s) and some sole traders and } \\
\text { cooperations. }\end{array}$ & 680,000 & $\begin{array}{l}\text { LexisNexis } \\
\text { Benelux, Gray- } \\
\text { don and Chambers } \\
\text { of Commerce }\end{array}$ \\
\hline NO & Limited. & Approximately $120,000$. & Creditreform \\
\hline PL & $\begin{array}{l}\text { Filing of the accounts: All companies registered at the National } \\
\text { Court Registry (KRS): joint-stock companies (S.A.), limited liabil- } \\
\text { ity companies (Sp. z o.o.), cooperatives, state enterprises, etc., ex- } \\
\text { cept for general partnership (sp.j.), professional partnership (sp.p.) } \\
\text { that do not reach the annual turnover of } 800,000 \text { EUR. } \\
\text { Publishing of the accounts: Joint-stock companies, banks, insurance } \\
\text { companies, investment funds, plus others (limited liability compa- } \\
\text { nies, cooperatives, large private companies, etc.) complying with } \\
2 \text { of the following criteria: i) average annual employment }>50 \text {; ii) } \\
\text { total assets at the end of a financial year }>2.5 \text { million euro; iii) } \\
\text { annual net profit }>5 \text { million euro. }\end{array}$ & $\begin{array}{l}\text { About } 200,000 \text { companies. Among } \\
\text { these companies, approx. } 10,000 \text { com- } \\
\text { panies are also obliged to publish ac- } \\
\text { counts. }\end{array}$ & $\begin{array}{l}\text { InfoCredit, collects } \\
\text { information from } \\
\text { National Court } \\
\text { Registry, journals } \\
\text { for entities and } \\
\text { cooperatives, Judi- } \\
\text { cial and Business } \\
\text { Journal "Monitor } \\
\text { Sdowy i Gospodar- } \\
\text { czy," directly from } \\
\text { the companies, } \\
\text { as well as other } \\
\text { alternative sources, } \\
\text { if necessary). }\end{array}$ \\
\hline PT & $\begin{array}{l}\text { The Portuguese law compels all the companies to deposit the Bal- } \\
\text { ance Sheet. Therefore, about } 57,500 \text { balance sheets are public in- } \\
\text { formation. }\end{array}$ & $\begin{array}{l}\text { These } 57,500 \text { balance sheets correspond } \\
\text { to a small percentage of the totality of } \\
\text { Portuguese companies, if we verify that } \\
\text { the totality number of the universe has } \\
\text { about } 800.000 \text { companies. That means } \\
\text { that practically the companies do not } \\
\text { deliver financial information. }\end{array}$ & Coface MÓPE. \\
\hline RO & $\begin{array}{l}\text { Joint stock companies, partnerships limited by shares, limited lia- } \\
\text { bility companies, state owned concerns, co-operative companies. }\end{array}$ & 500,000 & $\begin{array}{l}\text { Chamber of Com- } \\
\text { merce and Industry } \\
\text { of Romania }\end{array}$ \\
\hline RU & $\begin{array}{l}\text { All juridical persons have to represent their accounts (individual } \\
\text { entrepreneurs (manufacturers) and farms are not juridical persons) }\end{array}$ & $\begin{array}{l}\text { Approximately } 40 \% \text { of all active com- } \\
\text { panies file their accounts. So, if there } \\
\text { are } 1,500,000 \text { registered active compa- } \\
\text { nies in Russia, the accounts are avail- } \\
\text { able for approximately } 800,000 \text { compa- } \\
\text { nies. Most of these are included in Rus- } \\
\text { lana. }\end{array}$ & \\
\hline SK & All companies filed in Business Register. & $\begin{array}{l}\text { About } 70-80,000 \text { (many companies } \\
\text { could be inactive, only registered with } \\
\text { no financial statement). Many compa- } \\
\text { nies do not file their accounts, there are } \\
\text { no penalties for it. }\end{array}$ & Soliditet, s.r.o. \\
\hline SI & All companies and sole proprietors & Around 160,000 companies. & Coface Slovenia \\
\hline ES & S.A., S.L. & 776,000 & INFORMA \\
\hline SE & Limited companies. & About 348,000 . & $\mathrm{UC} \mathrm{AB}$ \\
\hline $\mathrm{CH}$ & $\begin{array}{l}\text { There are no legal requirements to file their accounts in Switzerland } \\
\text { (like in the UK). Public quoted companies make their financial } \\
\text { statements available and all are collected, analysed and provided } \\
\text { to the Orbis database. }\end{array}$ & $\mathrm{N} / \mathrm{A}$ & Worldbox AG \\
\hline UA & $\begin{array}{l}\text { All local companies and trade or representative offices of foreign } \\
\text { companies have to file accounts (except companies mentioned in } 3 \text {.) } \\
\text { Notes: In the database of the Central Statistical Department there } \\
\text { are about } 330,000 \text { accounts of the biggest Ukrainian companies. } \\
\text { The remaining companies are split in } 800 \text { regional Departments of } \\
\text { Statistics: there are currently no means by which we can get them } \\
\text { for the time being. }\end{array}$ & $\begin{array}{l}\text { There are more than } 1,000,000 \text { com- } \\
\text { panies and trade representative offices } \\
\text { registered. }\end{array}$ & Creditreform \\
\hline
\end{tabular}


Table A.6.2: NACE Revision 2, Level 2 Classification.

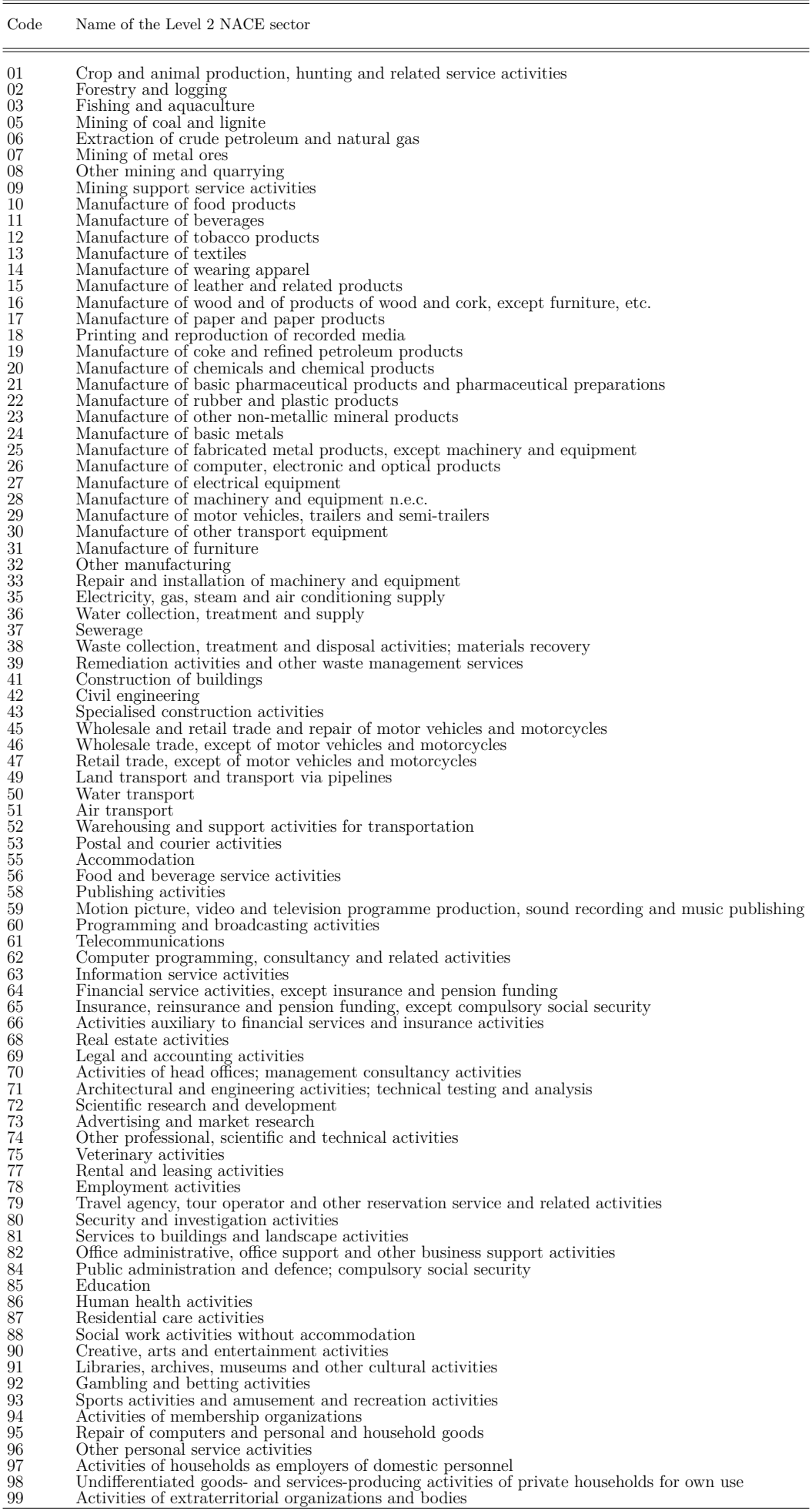




\section{B Foreign Ownership}

\section{B.1 Building Foreign Investment Panel Data}

\section{B.1.1 Vintage Raw Data}

The following are the key steps we take in constructing the firm-level ownership database. In some respect, the process of preparing the raw vintage data is more straightforward than that for the financials because each vintage corresponds to a single time observation. However, compared to the financial data, the ownership data has more than two identifiers (the company ID and year). In the case of ownership, the additional dimension comes from the fact that each company could have multiple owners or subsidiaries.

The raw ASCII data has rows consisting of non-time varying data and the blocks of variables corresponding to the groups in Orbis Ownership database. They are company's shareholders, domestic ultimate owners (UOs), global UOs, and subsidiaries. In order to have the data for a given country in one file, we download data using the Formatted Export method in older disks and the List Export method in newer disks, as discussed in Section A.2. Of note, we download some variables describing the company itself such as name, BvD ID, size category, type of company, location information, core industry, and three key financials (employment, total assets, and operating revenue) in the original currency of accounts and in the last available year, together with Units and Currency Code in case we would need these to identify the company better. The key identifier is still the company BvD ID.

Assume a Company A has 2 shareholders, 1 global UO, and 3 subsidiaries. The data for this company will have 3 observations (rows) in a given vintage, corresponding to the largest number of observations across the groups in Orbis Ownership database:

\begin{tabular}{|c|c|c|c|c|c|c|c|c|}
\hline NAME* & BvD ID* & $\begin{array}{l}\text { Core } \\
\text { Industry* }\end{array}$ & $\begin{array}{l}\text { Shareholder } \\
\text { Name }\end{array}$ & $\begin{array}{l}\text { Shareholder } \\
\text { \% Stake Direct }\end{array}$ & $\begin{array}{l}\text { GUO } \\
\text { Name }\end{array}$ & $\begin{array}{l}\text { GUO } \\
\% \text { Stake }\end{array}$ & $\begin{array}{l}\text { Subsidiary } \\
\text { Name }\end{array}$ & $\begin{array}{l}\text { Subsidiary } \\
\text { \% Stake }\end{array}$ \\
\hline $\begin{array}{l}\text { Company A } \\
\text { Company A } \\
\text { Company A }\end{array}$ & $\begin{array}{l}\text { ZZ1234U } \\
\text { ZZ1234U } \\
\text { ZZ1234U }\end{array}$ & $\begin{array}{l}6123 \\
6123 \\
6123 \\
\end{array}$ & $\begin{array}{l}\text { Company B } \\
\text { Mr. Smith }\end{array}$ & $\begin{array}{l}70 \\
30\end{array}$ & Company B & 100 & $\begin{array}{l}\text { Company C } \\
\text { Company D } \\
\text { Company E }\end{array}$ & $\begin{array}{l}100 \\
90 \\
\text { WO }\end{array}$ \\
\hline
\end{tabular}

The variables marked with $\left({ }^{*}\right)$ are unique per company-vintage. Because we export the data asking the disk to repeat each single item all these variables will be repeated for each 
company record in the raw downloads. The order of the non-unique variables corresponds to the internal order in the Orbis Ownership or Amadeus Ownership databases.

We execute the following steps for each vintage of the Orbis Ownership or Amadeus Ownership database we use.

1. We extract the data in ASCII comma-separated value format, transform it to Stata using Statransfer, name and label the variables following the database names.

2. Delete observations with only a company name and no other information.

3. Generate the YEAR variable for the year in which the ownership information is recorded in a given vintage of $\mathrm{BvD}$ product following our assumption that YEAR takes the value of one less the year when the Orbis disk was issued. Recall that we choose the vintages that are closest, but subsequent to that year. For example, the ownership data coming from the Orbis disk no. 27 issued in January 2011 is assigned to YEAR 2010, and so on.

4. As in case of financial data, we create our main identifier ID_NUMBER, which is a copy of the $\mathrm{BvD}$ account number. It is a copy of the $\mathrm{BvD}$ ID number if the BvD account number is missing.

5. To keep the file size manageable we split the data generating a separate file for a given country in a given year and the group of variables in Orbis Ownership database. As a result we have the following files per country-year.

- In the file with the information about the company itself, we keep all the identifiers mentioned above, removing the duplicates in terms of all remaining variables and then removing duplicates by ID and Employment.

- In the file with information on company shareholders, we keep ID, YEAR and all variables from this group, dropping observations with missing information on owners and then removing the duplicates in terms of all remaining variables.

- We do the same in the file with separate information for company's immediate shareholders, for its domestic ultimate owners, for its global ultimate owners, and for its subsidiaries. 


\section{B.1.2 Merging and Cleaning Ownership Data}

In this section, we illustrate how we create the country panels of company shareholder data; that is, the information on the direct ownership of the equity rights for the universe of companies covered in the Orbis Ownership data set. The preparation of other ownership variables involves similar steps. We first describe how we prepare the company panels of "direct ownership links;" that is, the data where the unit of observation is the companyshareholder pairs in a given year. After that, we discuss how we build the company-year level data where the links information is aggregated to the company level each year.

\section{B.1.3 Data with Company Shareholder Links}

Each of the following steps is performed for individual country ownership files coming either from the Orbis Ownership or the Amadeus Ownership database.

1. Combine (stack) all annual ownership data files for a given country. Recall that we have bi-annual vintages of Amadeus Ownership since 2000 and annual vintages of Orbis Ownership since 2005.

2. Create the country code based on the first two letters of the ID_NUMBER, which by BvD convention should start from two-letter country code (BE for Belgium, US for the United States, GB for the UK and so on).

3. Convert the character variables Percentage Owned Direct (ODIRECT) and Percentage Owned Total (OTOTAL) into numeric format, replacing some special character values they may take in the raw data. In particular, we replace percentage with a leading $<,>, \pm$ with the percentage after the symbol; eliminate possible $\%$ sign; replace special codes "WO" (wholly owned) with 100\%, "MO" (majority owned) with $50.01 \%$ (because by the GAAP practice the majority ownership involves $50 \%$ plus one share but the smallest stakes reported by BvD are $0.01 \%$ ), "CQP1" (50\% plus 1 share) with $50.01 \%$, "NG" (negligible) with $0.01 \%$ (again, the smallest observed stake according to BvD), "-" (not significant) or "n.a." (not available) with missing; "BR" (branch, Orbis Ownership only) with 100\%; "JO" (jointly owned, Amadeus Ownership only) 
with $50 \%$ (our exploration of such cases shows that there is always exactly two owners in case of the JO code). We keep the character versions of these variables.

4. Implement company ID changes following the procedure described in Section A.5.2 for financial data, saving the legacy IDs on the dataset.

5. To determine the total foreign ownership at the company level, we proceed as follows. Whenever the variable Shareholder Country ISO code (OCOUNTRY in Amadeus or SHARCOUN in Orbis ) is different from the company own Country code we consider the link foreign. By default, we assume that the shareholder with missing country code or with SHARCOUN taking the values of "-" and "n.a." is located in the same country as the given company as it is done in the literature.

6. For Amadeus Ownership, we further improve the above simple rule by manual assignments by country, based on the variable Shareholder Name (ONAME). That variable contains some indication of whether the owner is foreign. ${ }^{22}$ We determine the unique values of ONAME and then manually replace the ownership links which have the missing OCOUNTRY. One can further try to compare the company country code to the first two letters of the available Shareholder BvDEP ID number (OID in Amadeus or SHARSIR in Orbis ), but not every shareholder has the BvD ID available. In addition, one can investigate the values of the variable Shareholder Type (the textual variable OTYPE in Amadeus or the standardized letter code SHARTYPE in Orbis), assuming that certain owner types are domestic (such as company employees or management, or the entries like "private individual(s)" or "unnamed private shareholders", and so on) unless it is clear from the name they are foreign (for example, "foreign investors").

7. Combine shareholder information from our Amadeus Ownership and Orbis Ownership, making sure we do not have duplicates in overlapping years. In overlapping years, we establish which database has more recorded shareholders with non-missing direct ownership stakes for a given company-year (non-missing variable Shareholder - Percentage of ownership, direct, SHARDPER and use the record with more data. ${ }^{23}$ In case of an ex-

\footnotetext{
${ }^{22}$ We make this assignment mostly based on the parts of the names reflecting the legal type of the shareholder. We compare that to what is typical for the company's own country.

${ }^{23}$ We encountered the case when the same observation (ownership links) got the value "-" in Amadeus
} 
act match, we use Orbis but retain the variable Shareholder NACE Rev. 2 Core Code (ONACE) and other useful information available only in Amadeus. Actual elimination of the duplicates is done later, because we use some information across two products in a given year to supplement the data.

8. Supplement the missing textual information (Shareholder Type in textual form from Amadeus and 1-letter code from Orbis; Shareholder NACE Rev. 2 Core Code) using the unique shareholder IDs and shareholder names. Supplement missing Shareholder Type in textual form from Amadeus using non-missing 1-letter code from Orbis and vice versa.

9. Because we first establish the foreign ownership link status at the individual vintage level, we can take advantage of the full panel and revise the foreign link status based on other years when this info is available for a given company ID. As above, using the unique shareholder IDs and shareholder names, we replace links ever found to be as foreign in at least one year as such in all the years.

10. After all the information across products has been used, we delete the duplicated observations (all the links for a given company-year) from Orbis and Amadeus keeping the ones with the best coverage. We save the data files of direct ownership links for individual countries.

\section{B.1.4 Direct Ownership Types}

Once we have the shareholder links data for country-years, we can aggregate it in the variety of ways because each link record has a number or variables describing not only the equity stake held by a given (direct) investor but also investor's location, type, or industry.

For illustration, we will discuss our work to aggregate ownership stakes by foreign/domestic status, further split by the type of the shareholder involved. In particular, this data can be

Ownership and the value of exactly $0 \%$ in Orbis Ownership. We think that in Amadeus Ownership, the code "-" actually means "negligible" while it means "missing" in Orbis Ownership . Because we could not confirm or refute this distinction, we recoded "-" as missing. Because the $0 \%$ stakes do not bear any useful information, we treat the observations with Shareholder Percentage $=0 \%$ as missing when counting the shareholders with available ownership stake. 
merged with the financials data panel, described in part A.5, also uniquely identified by the company ID (IDNUMBER) and YEAR. Each of the following steps is performed over individual country data files.

1. We start from the ownership links data obtained as described in section B.1.3 and delete the link records which have no usable information.

2. Identify foreign and domestic links, specific to the owners of a particular type. The exercise is similar to what we did to find foreign/domestic links, but here we use the information on whether a link is foreign or domestic and, in addition, take advantage of the information in the variable Shareholder Type (the textual variable OTYPE in Amadeus or the standardized letter code SHARTYPE in Orbis). Recall that in the codes preparing raw links data we supplemented the values of both variables with one another and across all the years. In particular we define the following indicators:

- Foreign (Domestic) Owner-Industrial Type, $=1$ if Foreign (Domestic) owner has the (textual) type Industrial company, Corporate, Self-owned, Branch, or types reflecting the individuals working for the company (such as, employees, personnel, managers, directors, self-ownership) because these owners are likely to bring similar types of "expertise" as industrial owners for the majority of the companies in our financials database. ${ }^{24}$

- Foreign (Domestic) Owner-Financial Type, $=1$ if Foreign (Domestic) owner has the type Bank, Financial company, Insurance company, Other financial institution, Mutual \& Pension Fund/Nominee/Trust/Trustee, Foundation/Research Institute, Private Equity firms, Venture capital, Hedge funds.

- Foreign (Domestic) Owner-Government Type, $=1$ if Foreign (Domestic) owner has type Governments, State, Public authority.

- Foreign (Domestic) Owner-Individuals Type, =1 Foreign (Domestic) owner has the "individuals" type with known names. Besides single private individuals or families, this category includes shareholders designated by more than one named

\footnotetext{
${ }^{24}$ Orbis has some companies in the financial intermediation and insurance sector. Our assumption is less valid for such entities.
} 
individual or families (the entries like "Mr Gregory Edward Bailey \& Mrs Margaret Ethel Bailey" or "Mme Bringaud et son fils". The idea behind this is that they would probably exert their voting power alone or together.

- Foreign (Domestic) Owner-Other Types, $=1$ if Foreign (Domestic) owner has the aggregated types including unnamed individuals, the entries indicating that there are more than one private shareholders, collectively designated (for example, "Individual(s) or family(ies)"), unknown types of owners ("Unnamed private shareholders, aggregated", Miscellaneous; Undefined company, Unknown, "n.a.", NA), or simply missing owner type.

- Owner is Public, $=1$ if the company is owned by numerous shareholders, collectively designated as "public." The owner type "Public" is possible only for publicly quoted companies. ${ }^{25}$

3. In addition we specify two sub-types of the owners of financial type:

- Foreign (Domestic) Owner-Active Financial Type, $=1$ if Foreign (Domestic) owner has the type Financial company, Insurance company, Other financial institution, Mutual \& Pension Fund/Nominee/Trust/Trustee, Foundation/Stichting, Private Equity firms, Venture capital, Hedge funds. ${ }^{26}$

- Foreign (Domestic) Owner-Passive Financial Type, =1 if Foreign (Domestic) owner has the type Bank.

4. Once we identify the stakes held by the direct investors of certain type with the help of those dummies, we can generate the company-level foreign and domestic ownership variables out of the links data. We "collapse" data by summing up the stakes of the same owner type, separately domestic and foreign, by year and company ID. We also generate the simple count of number of owners, foreign owners as well as dummies

\footnotetext{
${ }^{25}$ Notice, that for public companies BvD may report some owners of more specific types (banks, individuals, industrial companies, etc.) with their corresponding stakes, as long as those stakes are known. We do not assign the owners designated collectively as "Public" to either foreign or domestic type because we do not know how the shareholder base is split.

${ }^{26}$ Unfortunately, we cannot separate such arguably passive types of institutional investors as pension funds from the combined type "Mutual \& Pension Fund/Nominee/Trust/Trustee" or corresponding code SHARTYPE="E".
} 
identifying all owner types at the company-year level. For convenience we also create the variable "Check 100 Ownership" which is the sum of all known ownership stakes. If this variable is less than 100, we have unassigned ownership percentages in certain company-years which we assign as domestic. After summation by collapse, the ownership stake percentages larger than $100 \%$ are possibly due to rounding and replacing of some special codes such as "NG" with $0.01 \%$, or "WO" with $100 \%$, or simply due to ownership data mistakes. Hence, we perform some cleaning steps.

5. We round all the direct ownership percentages to the second digit after the decimal (to repeat, the smallest stake observed by Orbis is $0.01 \%$ ).

6. Remove duplicates in terms of ID_NUMBER and YEAR by retaining that of the two duplicates which has larger number of ownership observations, hoping that there is a bigger chance it provides useful data for percentages, etc.

7. After this, we delete the observations with the ownership percentages larger than $103 \%$ and then replace the values "slightly more" than $100 \%$, that is in $(100,103]$ range, with exactly $100 \%$. At this stage, we have constructed an unbalanced country panel of company-level direct ownership data.

8. The ownership panel is merged with financials panel by ID_NUMBER and YEAR.

9. In the combined dataset, we fill in the missing ownership time series, regardless of the time coverage of financials. In particular, we supplement ownership data in missing years using previous or consecutive non-missing values (using Stata -carryforwardcommand) assuming the following: 1. We use the existing earliest value of ownership to carry forward until i) the new non-missing value is reached or ii) the end of the time-series is reached for that company. 2. For the missing initial years of ownership, we assume that it is the same as in the first observation of non-missing data. ${ }^{27}$

10. After we filled in ownership data using lags and leads, we assign the companies with financial data but no ownership data to the category of companies with Domestic Industrial ownership.

\footnotetext{
${ }^{27}$ We can keep track of the filled-in ownership data by using the "Check 100 Ownership" variable which will be missing for filled-in observations.
} 


\section{B.2 OECD Official Data Sources}

We compare our ownership panel to alternative source on inward and outward activities of multinationals. The OECD provides data on the activities of foreign affiliates of multinationals in OECD countries in the AMNE (Activity of Multinational Enterprises) database available on the OECD data portal https://stats.oecd.org/Index.aspx?DataSetCode=AMNE_IN. The key variables presented are production, employment, value added, research and development, labor compensation, and exports. The data is broken down by country of origin of the ultimate owner (inward investment), location (outward investment), and main sector of economic activity of the multinational company following the ISIC revision 4 sector classification. AMNE covers 28 OECD host countries from 2008 onwards, although the coverage varies by country and over time.

The historical data is available from two prior databases that use the ISIC revision 3 classification: AFA (Activities of Foreign Affiliates) and FATS (Foreign Affiliates Statistics). The AFA database presents detailed data on the performance of foreign affiliates in the manufacturing industry for 28 OECD countries. The FATS database gives detailed data on the activities of foreign affiliates in the services sector for 25 OECD countries. These databases can be accessed at http://stats.oecd.org/Index.aspx?DataSetCode=AFA_IN3 and https://stats.oecd.org/Index.aspx?DataSetCode=FATS_IN3_SERV .

The OECD databases consist of data reported to the OECD by Eurostat based on annual surveys on the activities of foreign-controlled enterprises and foreign affiliates abroad controlled by residents of the compiling country. Surveys are conducted, in most cases, by the national statistical office or the central bank of each country. While the key variables in the survey are common across countries, the target sample varies across countries. In order to compare the $\mathrm{BvD}$ ownership data to the official OECD data, the following issues have to be considered:

- Both AMNE and Orbis report data at the firm level, while AFA-FATS, covering the pre-2008 period, report the "number of enterprises or establishments." Therefore, in certain countries, the number of foreign affiliates is not comparable with Orbis data because establishments (plants) are not included in the BvD database. All other key variables refer to a firm in all data sets. 
- The notion of Foreign Affiliate is based on the concept of the "controlling interest." According to AFA-FATS, a single institutional unit (another corporation, a household, or a government body) secures control over a corporation by owning more than half the voting shares or otherwise controlling more than half the shareholder voting power. However, the definition of controlling interest varies across countries. In most countries, controlling interest is based on direct majority ownership (50\%) while others (Hungary and the United States) also consider minority control (between $10 \%$ and $50 \%$ ). Moreover, some countries also include indirectly owned foreign affiliates. In Table B.2.1, we provide a summary of the characteristics of the AMNE database by country, whether indirect foreign control is considered, multiple owners and the main data source.

- In AMNE database, starting in 2008, the total economy is defined as sectors B-N at the ISIC revision 4. Prior to 2008, the total economy includes additional sectors.

- As shown in Table B.2.1, in the OECD databases, some countries do not sample all firms and the inclusion of firms in the surveys depends on certain economic thresholds. We always use all information available in Orbis, regardless of the firm size.

- In all cases, OECD aggregates the entire output of the entities designated as "foreign" and expresses them in national currency (Euro for Eurozone countries) or, additionally in the AFA database, as the ratio of the total manufacturing output in a given country. 


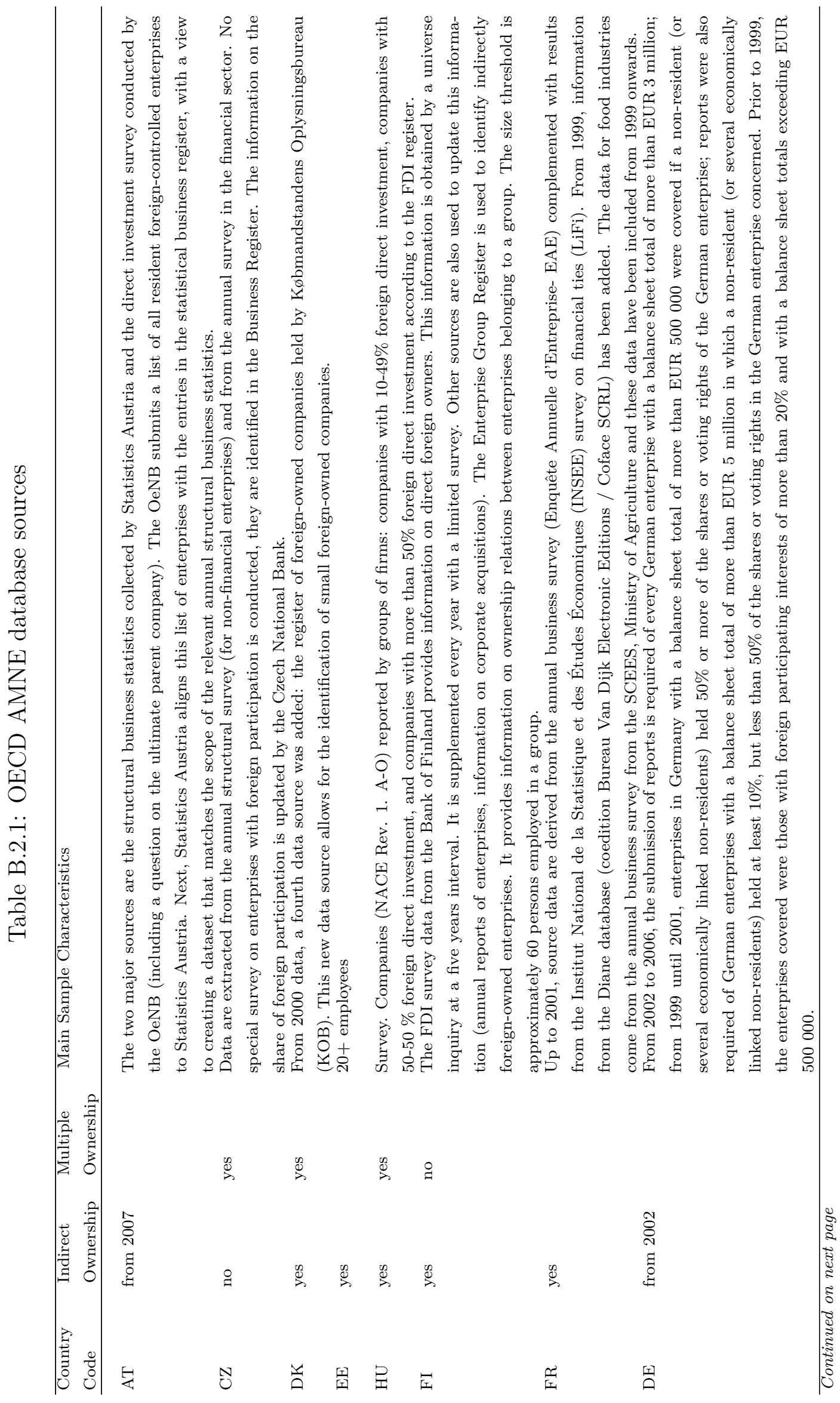




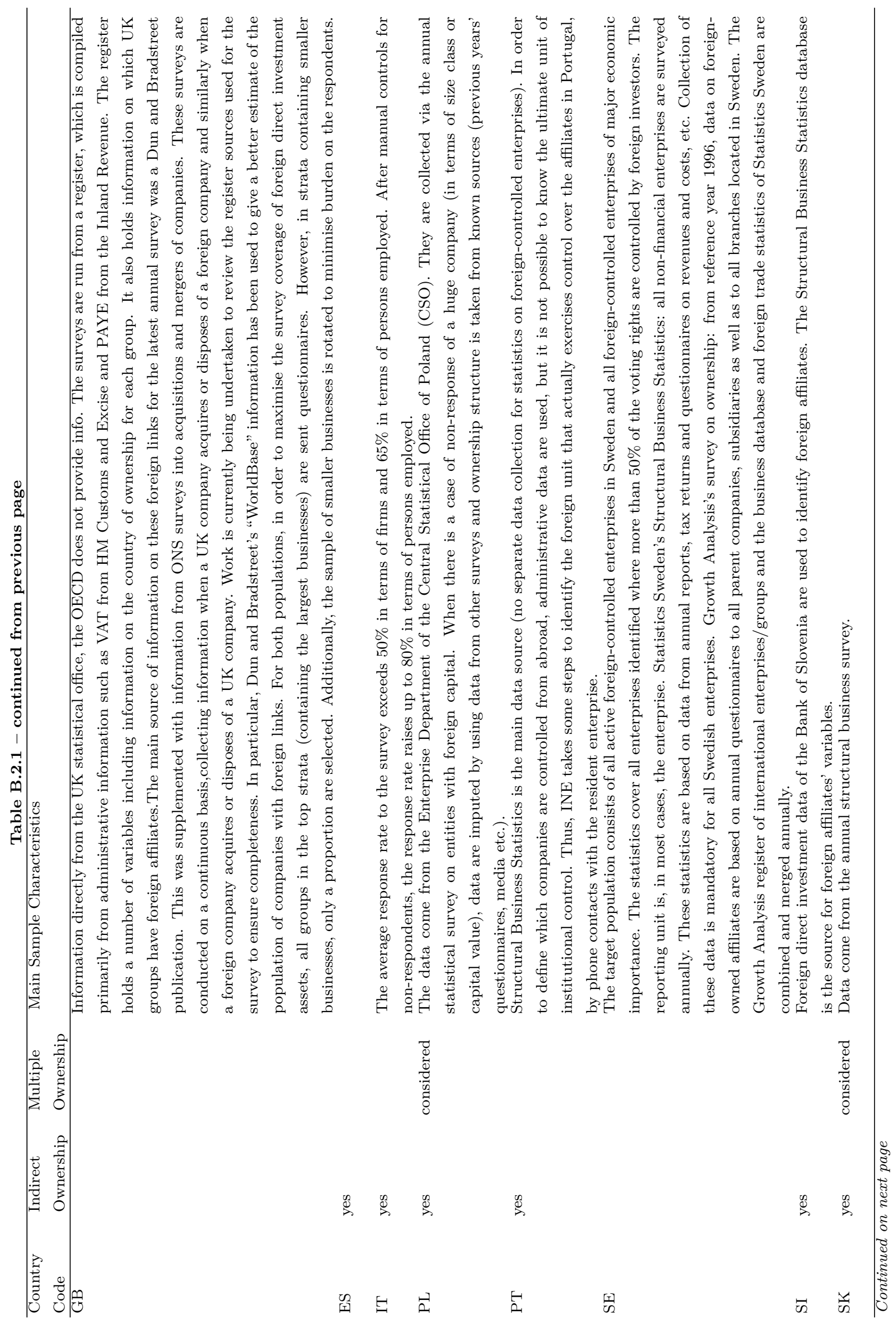




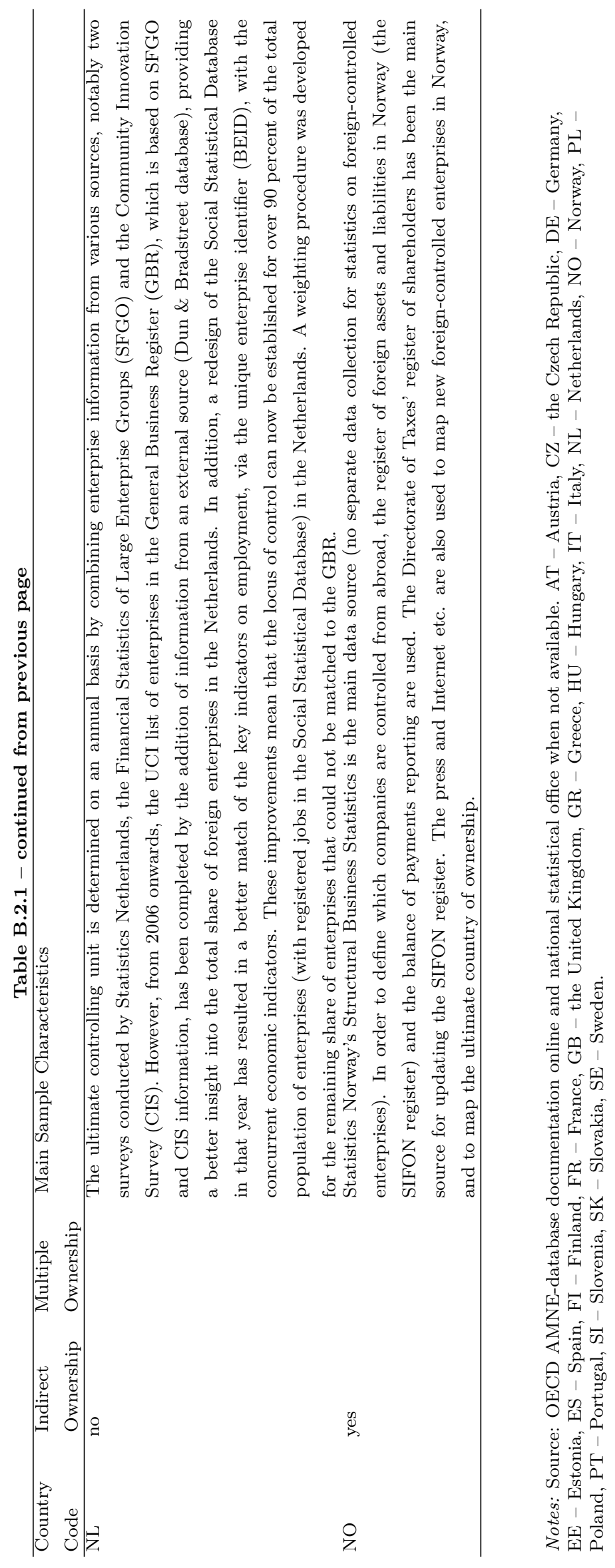




\section{B.3 Coverage of Foreign Ownership}

Bearing all these caveats in mind, we proceed with the comparison of the data we compile from Orbis-Amadeus to the data collected by the OECD in the AMNE, FAS, and FATS databases. In our data comparison, we measure output by total turnover and we limit ourselves to manufacturing because this 1-digit sector has been covered for the longest period of time in the most OECD countries.

For the OECD data, we take the multinational turnover data from the AFA and AMNE databases, expressed in a single currency using the end-of-period exchange rates from Bloomberg, divided by the total manufacturing turnover taken from the OECD STAN database.

As said before, to stay as consistent as possible with the OECD data we identify the companies in our Orbis-Amadeus database as foreign if 10 or more percent of their equity is owned directly or, in case all direct owners are domestic over all years, ultimately by one or several foreign entities. We compute the country's foreign output share in our data as the ratio of total output aggregated over all identified foreign firms to total output of all firms in a given country.

Table B.3.2 reports these ratios by country and year. We select all the OECD memberstates and Switzerland, but the Swiss data is not available in AMNE-AFA databases. We present the countries by groups, including Eurozone and non-Eurozone member states as of 2012 (Estonia became a member in 2011). Averages are simple means of ratios in columns over all years. As seen, some countries have short time series in the OECD database, either because of data privacy issues (such as Belgium or Ireland) or due to their later inclusion in the OECD (such as Hungary, Latvia, Slovenia, or Slovakia).

To facilitate the comparison of averages, Table B.3.3 reports country average shares, the average by two groups, and the overall average in a balanced sample of countries that report the data to the OECD in every year over the 2003-2012 period.

Both tables show that foreign activity makes up at most 40 percent of the total activity on average. The averages mask a lot of cross-country heterogeneity, however. In many larger European economies, the average share of foreign sales is much smaller than the group averages, being around 20 percent in Germany, France, or Italy, or 30-40 percent 
in Spain, the UK, and Sweden. Interestingly, some advanced economies with well-known MNCs, such as Denmark or Finland, have average shares of around 20 percent. In other countries the average share is larger than the group averages; OFCs such as Luxembourg, and emerging markets Czech Republic, Estonia, Slovak Republic, Hungary, and Poland all have multinational sales amounting to more than half of total manufacturing sales. Table B.3.2 also makes it clear that OFCs, such as Ireland, Luxembourg, or the Netherlands display the largest differences between our data and the OECD data. This is not surprising, because our data exclude this type of financial FDI.

Table B.3.1 shows the foreign affiliate turnover as a share of total turnover in total economy (all sectors) for the firms covered by our data, both for non-Eurozone and Eurozone countries. Each cell is the ratio of the value of total output produced by our firms, which have at least 10 percent foreign ownership, relative to the value of total output produced by all firms with non-missing data in Orbis in the corresponding year and country. Some countries report data as early as the late 1980s, but the coverage in earlier years is poor. To keep the sample consistent with the following exercise, comparing coverage of Orbis with the OECD data, we limit ourselves to the 1999-2012 period.

Table B.3.1 shows the variation in multinational activity over time and across countries. In larger advanced economies, such as Germany, France, and Italy, the turnover share of foreign owned firms is in the range of 15-25 percent (and less in some years). Some countries have low shares below 10, as in Malta, Bosnia, and Belarus, while other have larger shares close to or exceeding 40 percent, as in Belgium, Estonia, Luxembourg, the Netherlands, and Slovakia. Generally, smaller economies and emerging markets in Eastern Europe have larger multinational presence at around 30 percent or more. Some of these, such as Luxembourg, Switzerland, Cyprus, and the Netherlands, are offshore financial centers (OFC), known for large round-tripping of foreign investment or regulatory/tax regimes favoring multinational affiliation. According to the recognized definition, OFC is a center which provides some or all of the following services: low or zero taxation; moderate or light financial regulation; banking secrecy and anonymity (Aykut et al., 2017).

There is sizable time variation in foreign activity for some economies. In Iceland, turnover designated as "foreign" jumped to 71 percent of total turnover in 2005 only to collapse to 
5 percent in 2009, after the Global Financial Crisis (GFC) of 2008-09. Such volatility is not common, although Cyprus displays a similar pattern. In general, however, more stable economies with less questionable data quality have fairly stable shares of foreign activity over time, resembling the time averages. In almost all economies, the multinational sales share declined following the GFC from the peak in the mid-2000s. All in all, the patterns of the foreign turnover across countries reassure the reliability of our data. 


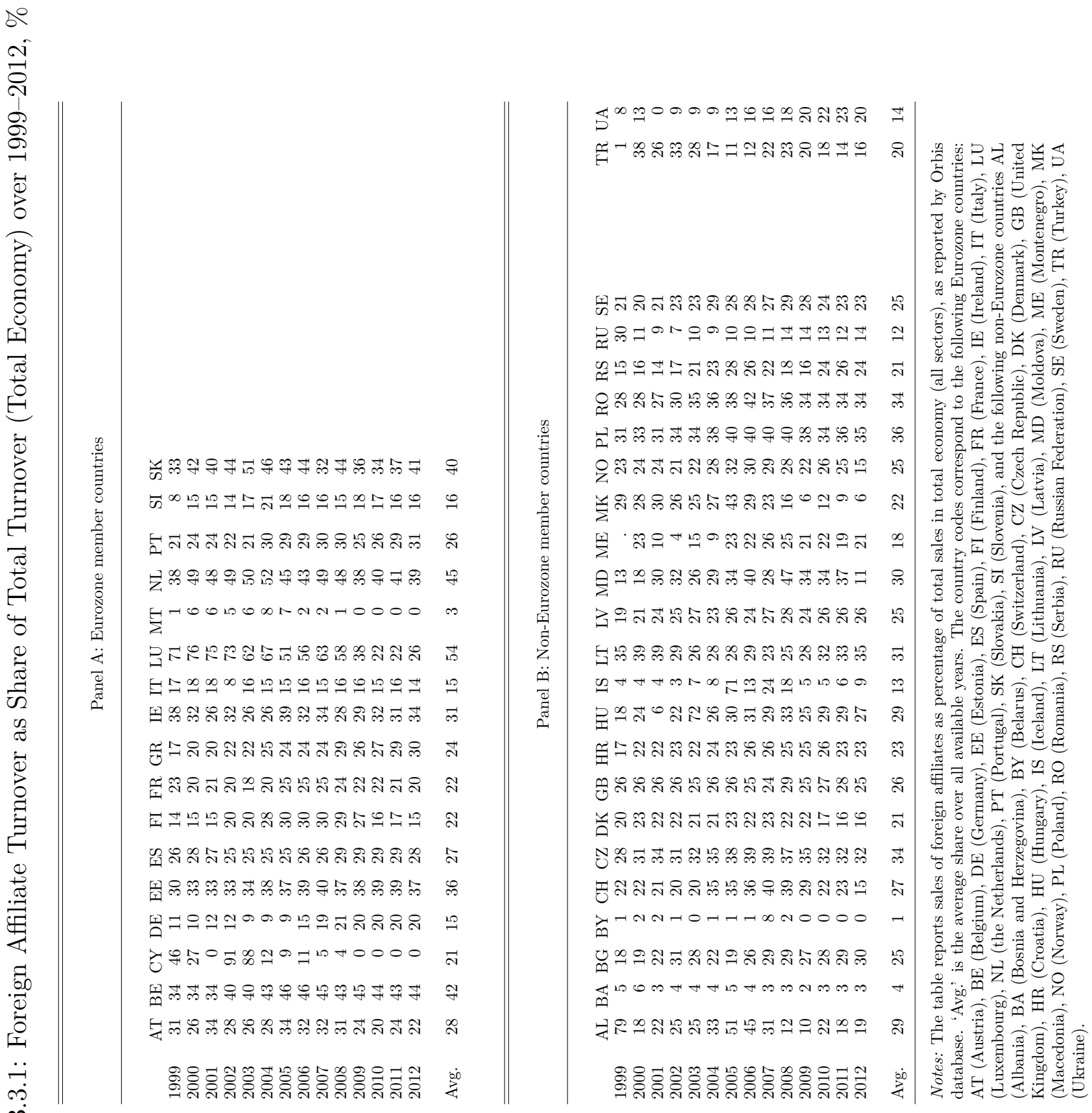


됭

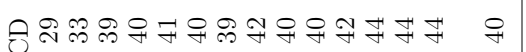

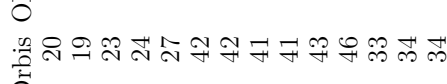

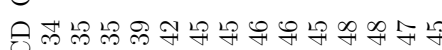
1 동

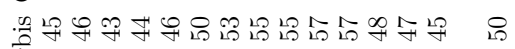
完

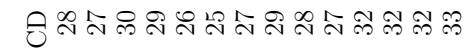
$\circ$

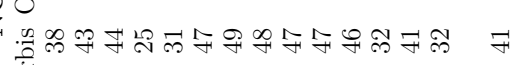
oิ

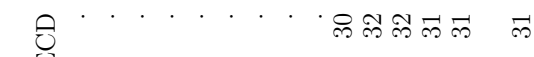
寻年

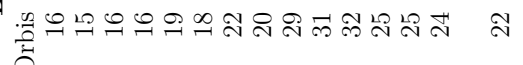

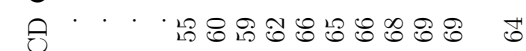
농

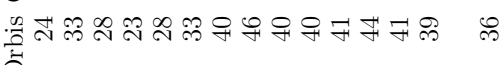

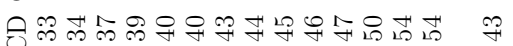
옹

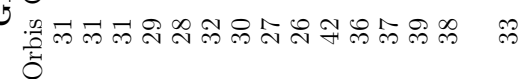
ชิ고옥 농

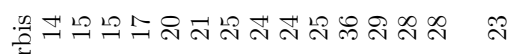

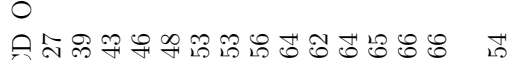
잉

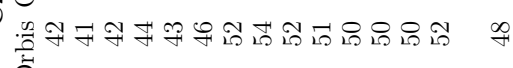

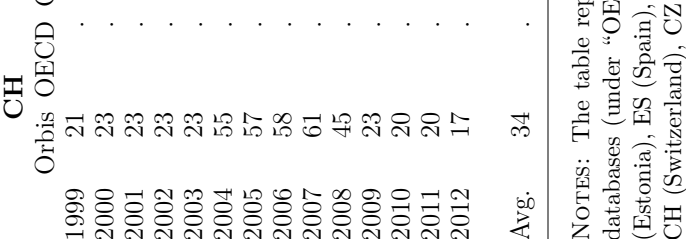


Table B.3.3: Average Foreign Affiliate Turnover as A Share of Total Turnover (Manufacturing), \%, 2003-2012

\begin{tabular}{|c|c|c|c|}
\hline Country & Country Code & Orbis & OECD \\
\hline Austria & $\mathrm{AT}$ & 30 & 37 \\
\hline Germany & $\mathrm{DE}$ & 22 & 28 \\
\hline Estonia & $\mathrm{EE}$ & 55 & 54 \\
\hline Spain & ES & 39 & 32 \\
\hline Finland & $\mathrm{FI}$ & 31 & 18 \\
\hline France & $\mathrm{FR}$ & 26 & 31 \\
\hline Italy & $\mathrm{IT}$ & 21 & 19 \\
\hline Luxembourg & $\mathrm{LU}$ & 60 & 55 \\
\hline Netherlands & NL & 34 & 45 \\
\hline Portugal & $\mathrm{PT}$ & 25 & 26 \\
\hline Slovenia & SI & 21 & 28 \\
\hline Slovak Republic & SK & 65 & 74 \\
\hline Average Eurozone & & 36 & 37 \\
\hline Czech Republic & $\mathrm{CZ}$ & 50 & 60 \\
\hline Denmark & DK & 26 & 26 \\
\hline Great Britain & GB & 33 & 46 \\
\hline Hungary & $\mathrm{HU}$ & 39 & 64 \\
\hline Norway & $\mathrm{NO}$ & 42 & 29 \\
\hline Poland & PL & 51 & 46 \\
\hline Sweden & $\mathrm{SE}$ & 38 & 42 \\
\hline Average Other & & 40 & 45 \\
\hline Average OECD & & 38 & 41 \\
\hline
\end{tabular}

Notes: The table reports sales of foreign affiliates in manufacturing as percentage of total manufacturing sales as reported in the Orbis database (under Orbis) and the OECD's AFA and AMNE database (under $O E C D$ ). The sample is balanced, with data for all countries available in all years 2003-2012. The numbers for each country represent the average share over all available years, while the group averages are computed over all countries and years. 

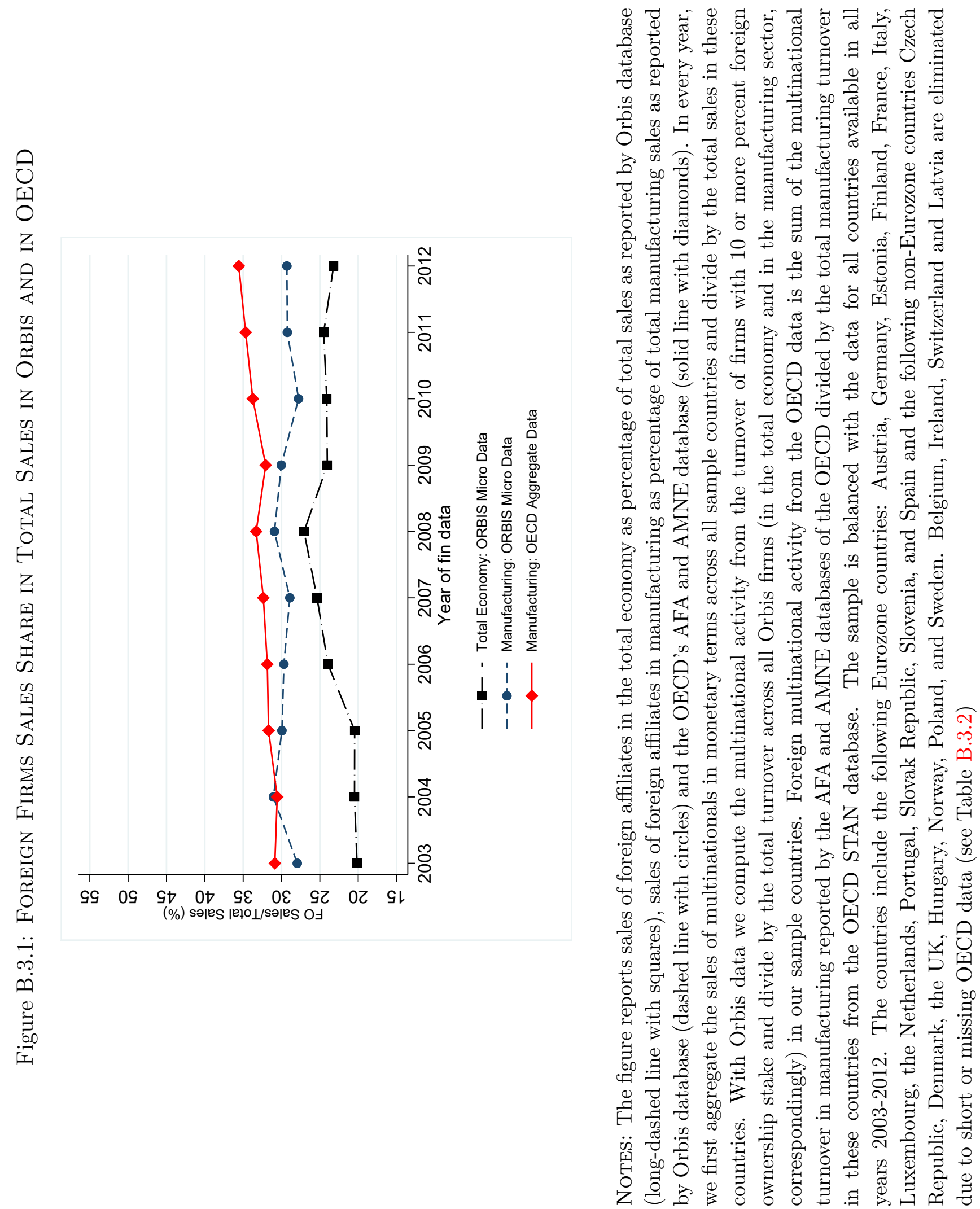


\section{Aggregate Comparison}

\section{C.1 Eurostat Data for Aggregate Economic Activity}

Eurostat provides data on main economic indicators as well as some additional variables for all EU member states, Norway, Switzerland, and some candidate and potential candidate countries. The data is collected either by national statistical agencies via surveys or by drawing on business registers and/or other administrative sources. Eurostat has multiple sub-databases categorized according to different themes. To serve for our purpose, we focus on the following two: Structural Business Statistics (SBS) and Business Demography (BD). Both databases cover variables related to business demography, while their scope differs in some aspects. So, before presenting the details on our comparison exercises, we firstly describe basic characteristics of these two databases and then explain how we utilize them in turn to compare the Eurostat data with our data obtained from Orbis-Amadeus.

Starting in 1995, the SBS data provides information that describes the structure, conduct, and performance of economic activities at a very fine level of detail (several hundred economic sectors). ${ }^{28}$ The SBS coverage was limited to Sections C to K of NACE Rev. 1.1 until 2007. Starting from the reference year 2008, the data is available for sectors B to N and sub-sector S95 of NACE Rev. 2 classification. Some of these sectors, such as NACE Rev. 2 sector K and NACE Rev. 1.1. sector J are only partially covered with data for insurance services, credit institutions, and pension funds but not all financial intermediation activities.

The main variables in the SBS data are business demographic variables (e.g., number of enterprises), "output related" variables (e.g., turnover, value added), "input related" variables such as labor input (e.g. employment, hours worked), goods and services input (e.g., total purchases), and capital input (e.g., material investments). This information is available for different size categories. Among all, we use "TOTAL," "0-19 employees," "20-249 employees," and "250+ employees" for our purpose.

In 1997, the BD data started to collect variables mostly related to the demography of the business population. ${ }^{29}$ The BD data is not as detailed in terms of variables as SBS data,

\footnotetext{
${ }^{28}$ See http://ec.europa.eu/eurostat/cache/metadata/en/sbs_esms.htm for a detailed description.

${ }^{29}$ See http://ec.europa.eu/eurostat/cache/metadata/EN/bd_esms.htm for a detailed description.
} 
which enables it to cover a larger number of sectors. Starting with the reference year 2008, the BD data covers NACE Rev. 2 sections B to N (excluding activities of holding companies, K64.2). Data for sections $\mathrm{P}, \mathrm{Q}, \mathrm{R}$ and $\mathrm{S}$ are provided on a voluntary basis. NACE Rev. 1.1 was used up to the reference year 2007 covering the data for sections $\mathrm{C}$ to $\mathrm{K}$ (excluding activities of holding companies-K74.15). Sectors M, N, and O were reported on a voluntary basis and, therefore, not available for all countries.

The main indicators of the BD data category include population of active enterprises, number of enterprise births, number of enterprise survivals up to five year, number of enterprise deaths, related variables on employment, derived indicators such as birth rates, death rates, survival rates and employment shares, and an additional set of indicators on high-growth enterprises and "gazelles" (high-growth enterprises that are up to five years old). This information is available for firms of different size and legal form. The three main categories by size are All, Zero, $10+$.

As it is immediately seen, there are several differences between the BD data and the SBS data, important for our purposes. The BD data counts only active enterprises. Unlike the BD data, the SBS data counts both active and inactive companies. Moreover, the SBS data provides the information for multiple firm size groups based on employment, whereas the firm size categories are limited in the BD data. Another advantage of the SBS data over the BD data is that the SBS data provides information on monetary values such as turnover, wage bill, investment, etc., and all these variables are available for multiple firm size categorizes. The BD data covers more sectors but contains less variables. In addition, the BD data provides information separately for "Zero" firm size category that counts selfemployed workers. Having these differences in mind, if we do comparison based on number of enterprises and employment for "Total" or "Zero" categories, we always use the BD data. In case, we do comparison based on gross output, we always use the SBS data. For all other cases where we do comparison for SMEs, we always use the SBS data. We cannot use the BD data for comparisons based on employment for SMEs because, as mentioned above, the BD data lacks employment information for SMEs. In what follows, we present the details of the comparison of our data to statistics computed using Eurostat data. 


\section{C.2 Comparison of Orbis-Amadeus to Eurostat Data: Implemen- tation Details}

There are structural differences between Orbis-Amadeus and Eurostat. Given this, we follow some steps in order to make Eurostat data sets and our BvD data comparable before conducting comparison exercises. The details on these steps are given in below:

1. We identify Eurostat sectors based on NACE Rev. 2 classification because our OrbisAmadeus data uses this classification (see step 6 in Section A.5.2). In order to do this, we go through the process of matching the industry classifications pre- and post-2008 within each Eurostat data category. We first create a variable NACE1 in both Rev. 1.1. and Rev. 2 files. We then fill in the values of this variable by values of NACE Rev. 2 codes based on our augmented BvD sector variable (NACEREV2CCODE) using the official NACE Rev. 2 Level 1 classification. For example, we replace NACE1 with C if it is coded as D in NACE Rev. 1.1. file. Then, we merge these two files by NACE1 for each country-year-company category (company category is based either on size and/or legal form). Thus, this common NACE1 variable in Orbis-Amadeus and Eurostat enables us to compare them based on any sector defined at NACE Rev. 2 Level 1 classification.

2. We determine overlapping sectors across Orbis-Amadeus and Eurostat SBS data sets based on the NACE1 variable. While Orbis-Amadeus data, by construction, covers all sectors for a given country-year, Eurostat data provides information for the business economy with the exception of some sectors. Table C.2.2 lists the sectors with available information in Eurostat data sets. However, this list is differential based on the variable of interest. For example, the variable Turnover provided by Eurostat SBS data is not available for all sectors given in Table C.2.2. The availability of this variable differs across country-sector-year triplets, and this should be taken into account especially in total economy comparison exercises.

To exemplify, Eurostat data sets provide information for the construction sector (NACE Rev. 2 sector F) between 1995-2012. However, according to Table C.2.3, Eurostat SBS data lacks information on gross-output for this sector in Belgium for the years 2008, 2009, 2011 and 2012. If we had disregarded such detail and had computed total 
gross output over $\mathrm{BvD}$ Belgium firms for all overlapping sectors by just considering the correspondence given in Table C.2.2, we would have inflated the BvD aggregate for 2008, 2009, 2011 and 2012. To put it differently, since BvD aggregates are used as numerators in the ratios we use to construct percentages, overlooking such details would produce artificial higher percentages. In order to avoid such mistakes, we instead follow the sector correspondence given in Table C.2.3, and construct the percentages accordingly. To be more exact, in case we compute the percentage based on gross output for Belgium in 2009, we aggregate gross-output over the sectors which have non-missing gross output in both Eurostat SBS and BvD data sets. We label those sectors with 1 in Table C.2.3.

3. As stated above, Eurostat SBS data provides information on economic activity (i.e., gross-output and employment) for different size categories. Among all, we use "TOTAL," "0-19 employees," "20-249 employees," and "250+ employees" to compare size distribution for total economy and manufacturing sector. BvD provides firm-level information on economic activity for all sectors of a given European country-size category in any year of interest, whereas Eurostat SBS data provides information on the corresponding measure in a given size category for selected sectors, which are labelled with 1 in Table C.2.4. So, to make sure we do not create measurement error we construct a "hypothetical aggregate" economy based on aggregating the sectors where official data by size class is provided by the Eurostat. Doing this, we compare exact sectors, then compute the percentages in Table 2, accurately.

4. Eurostat BD data provides information on the main indicators for the categories of different firm size and legal form. Among the legal form categories, we are forced to use "Total" which refers to all firms with different legal forms assuming that BvD collects data from firms of all legal firms. We do not want to deal with legal firm issue since it is hard to identify the legal form information for each country in Orbis-Amadeus data given differential filing policy across countries (See Table A.6.1). Among the size categories, we use "Total" and "Zero" to construct a new size category i.e. "AllminusZero" which refers to all firms excluding the self employed workers. This enables us to compare manufacturing employment of Orbis-Amadeus to that of Eurostat BD in the most 
appropriate manner since BvD excludes self-employed workers by construction.

Eurostat SBS data provides information only for different size categories. However, it doesn't provide information under "Zero" size category, which forced us to use "Total" size category in all comparison exercises where Eurostat SBS data was used.

5. In our comparison exercises, we use two main indicators to measure economic activity: employment and gross-output. Eurostat data provides multiple variables related to economic activity and the related variables are different in terms of definition. So, in order to precisely compare the coverage based on economic activity, we pick Eurostat variables that have close definitions with those of BvD data. To illustrate, in our comparison exercises based on gross-output we use OPRE from BvD and V12110-Turnover from Eurostat SBS data. We express these financial variables in real dollars 2005 base using original values in Eurostat SBS data (see Step 2 in Chapter A.5.3). Additional correspondences as well as the variable definitions are given in Table C.2.1.

6. In comparison exercises based on number of enterprises, we use either Eurostat SBS or Eurostat BD data. In case we used the BD data, we drop inactive companies checking the variable STATUS in our data because the BD data counts only active companies. ${ }^{30}$

7. We construct two different samples using our BvD data and repeat our comparison exercised for each sample: Total Sample and TFP Sample. The Total Sample consists of firms that report data with positive values of the corresponding measure (i.e. employment (EMPL) and gross output (OPRE)), whereas the TFP Sample consists of firms that report positive values on employment (EMPL) or wage bill (STAF), and tangible fixed assets (TFAS), gross output (OPRE), materials (MATE).

8. For a given company, Orbis-Amadeus provides financial statements regarding different consolidation codes i.e. C1, C2, U1 and U2. ${ }^{31}$ Given this fact, we first drop C2 accounts

\footnotetext{
${ }^{30}$ If a given BvD company is read as "Inactive," "Dissolved," "In liquidation," and "Bankruptcy," we count it as inactive.

${ }^{31} \mathrm{C} 1$ : account of a company-headquarter of a group, aggregating all companies belonging to the group (affiliates, subsidiaries, etc.), where the company headquarter has no unconsolidated account, C2: account of a company-headquarter of a group, aggregating all companies belonging to the group (affiliates, subsidiaries, etc.) where the company headquarter also presents an unconsolidated account, U1: account of a company with no consolidated account, and U2: account of a company with a consolidated account.
} 
to avoid double accounting in our comparison exercises. For some specific cases, we further drop C1 accounts. To illustrate, in cases where we use the Total Sample, we drop C1 accounts for all countries except Spain and Italy. In the cases where we use the TFP Sample, we drop C1 accounts for all countries except Spain, Italy, Cyprus, Denmark, the UK, Greece, Ireland, and Lithuania.

9. As a final step, we want to make sure percentages in our comparison exercises are not inflated by outliers. So, we check distributions of the underlying economic activity measure within a given country-sector-year triplet and winsorize data if neccessary. ${ }^{32}$

We put Table C.2.1 as a guide for readers to help them follow the tables related to our comparison exercises.

\footnotetext{
${ }^{32}$ For space considerations, the list of the winsorized country-sector-year triplets as well as details on the amount of winsorizing (which varies between $0.01 \%$ and $0.5 \%$ ) are not reported here. All these details are available upon request.
} 
Table C.2.1: Details of Comparison Exercises

\begin{tabular}{|c|c|c|}
\hline \multicolumn{3}{|l|}{ Table 1} \\
\hline Data & Orbis-Amadeus & Eurostat SBS \\
\hline Year & $1999-2012$ & $1999-2012$ \\
\hline Variable & OPRE & V12110-Turnover \\
\hline Size & All & TOTAL - Total \\
\hline Sector & See Table C.2.3 & See Table C.2.3 \\
\hline \multicolumn{3}{|c|}{ Panel B of Table 2} \\
\hline Data & Orbis-Amadeus & Eurostat SBS \\
\hline Year & 2006 & 2006 \\
\hline Variable & OPRE & V12110-Turnover \\
\hline Size & $1-19,20-249,250+$ employees & $0-19,20-249,250+$ employees \\
\hline Sector & See Table C.2.4 & See Table C.2.4 \\
\hline \multicolumn{3}{|c|}{ Panel B of Table 2} \\
\hline Data & Orbis-Amadeus & Eurostat SBS \\
\hline Year & 2006 & 2006 \\
\hline Variable & EMPL & V16110 \\
\hline Size & 1-19, 20-249, $250+$ employees & $0-19,20-249,250+$ employees \\
\hline Sector & See Table C.2.4 & See Table C.2.4 \\
\hline
\end{tabular}

Notes: Table C.2.1 presents the details of the comparison exercises. The sectors are compared based on NACE Rev. 2 Level 1 Classification (NACE1). In Tables D.3.1-D.3.2, total economy in the reference country-year corresponds to all common available sectors with Eurostat BD and SBS data, respectively. The definitions of the variables are as follows: OPRE: Total operating revenues (Net sales + Other operating revenues+ Stock variations). The figures do not include VAT. Local differences may occur regarding excises taxes and similar obligatory payments for specific market of tobacco and alcoholic beverage industries; EMPL: Total number of employees included in the company's payroll, V16910: Number of persons employed in the population of active enterprises in t, V13310: Personnel costs are defined as the total remuneration, in cash or in kind, payable by an employer to an employee (regular and temporary employees, as well as home-workers) in return for work done by the latter during the reference period, V12110: Turnover comprises the totals invoiced by the observation unit during the reference period, and this corresponds to the total value of market sales of goods and services to third parties, V16110: Number of persons employed. In BvD data, for the construction of the TFP sample, we also used the variables STAF, TFAS, and MATE. STAF: All the employees costs of the company (including pension costs), TFAS: Book value of tangible fixed assets i.e. plant, equipment and machinery, and MATE: Material Costs. 
Table C.2.1 (Cont'd.): Details of Comparison Exercises

\begin{tabular}{|c|c|c|}
\hline \multicolumn{3}{|c|}{ Tables D.2.1 \& D.2.2 } \\
\hline Data & Orbis-Amadeus & Eurostat SBS \\
\hline Year & 1999-2012 & 1999-2012 \\
\hline Variable & OPRE & V12110-Turnover \\
\hline Size & All & TOTAL - Total \\
\hline Sector & $\mathrm{C}$ & $\mathrm{C}$ \\
\hline \multicolumn{3}{|c|}{ Tables D. 2.3 \& D. 2.2} \\
\hline Data & Orbis-Amadeus & Eurostat SBS \\
\hline Year & $1999-2012$ & $1999-2012$ \\
\hline Variable & EMPL & V16110 \\
\hline Size & All & TOTAL - Total \\
\hline Sector & $\mathrm{C}$ & $\mathrm{C}$ \\
\hline \multicolumn{3}{|c|}{ Panel A in Table D.2.5 } \\
\hline Data & Orbis-Amadeus & Eurostat SBS \\
\hline Year & 2006 & 2006 \\
\hline Variable & OPRE & V12110-Turnover \\
\hline Size & $1-19,20-249,250+$ employees & $0-19,20-249,250+$ employees \\
\hline Sector & $\mathrm{C}$ & $\mathrm{C}$ \\
\hline \multicolumn{3}{|c|}{ Panel B in Table D.2.5 } \\
\hline Data & Orbis-Amadeus & Eurostat SBS \\
\hline Year & 2006 & 2006 \\
\hline Variable & EMPL & V16110 \\
\hline Size & $1-19,20-249,250+$ employees & $0-19,20-249,250+$ employees \\
\hline Sector & C & $\mathrm{C}$ \\
\hline \multicolumn{3}{|c|}{ Table D.3.1 } \\
\hline Data & Orbis-Amadeus & Eurostat BD \\
\hline Year & $2007,2008,2009$ & $2007,2008,2009$ \\
\hline Variable & ID_NUMBER & V11910-Population of active enterprises in t \\
\hline Size & All & Country specific \\
\hline Sector & Total economy & Total economy \\
\hline \multicolumn{3}{|c|}{ Table D.3.2 } \\
\hline Data & Orbis-Amadeus & Eurostat SBS \\
\hline Year & $2007,2008,2009$ & $2007,2008,2009$ \\
\hline Variable & ID_NUMBER & V11110-Number of enterprises \\
\hline Size & All, 1-19, 20-249, $250+$ employees & TOTAL-Total, 0-19, 20-249, 250 + employees \\
\hline Sector & Total economy & Total economy \\
\hline
\end{tabular}




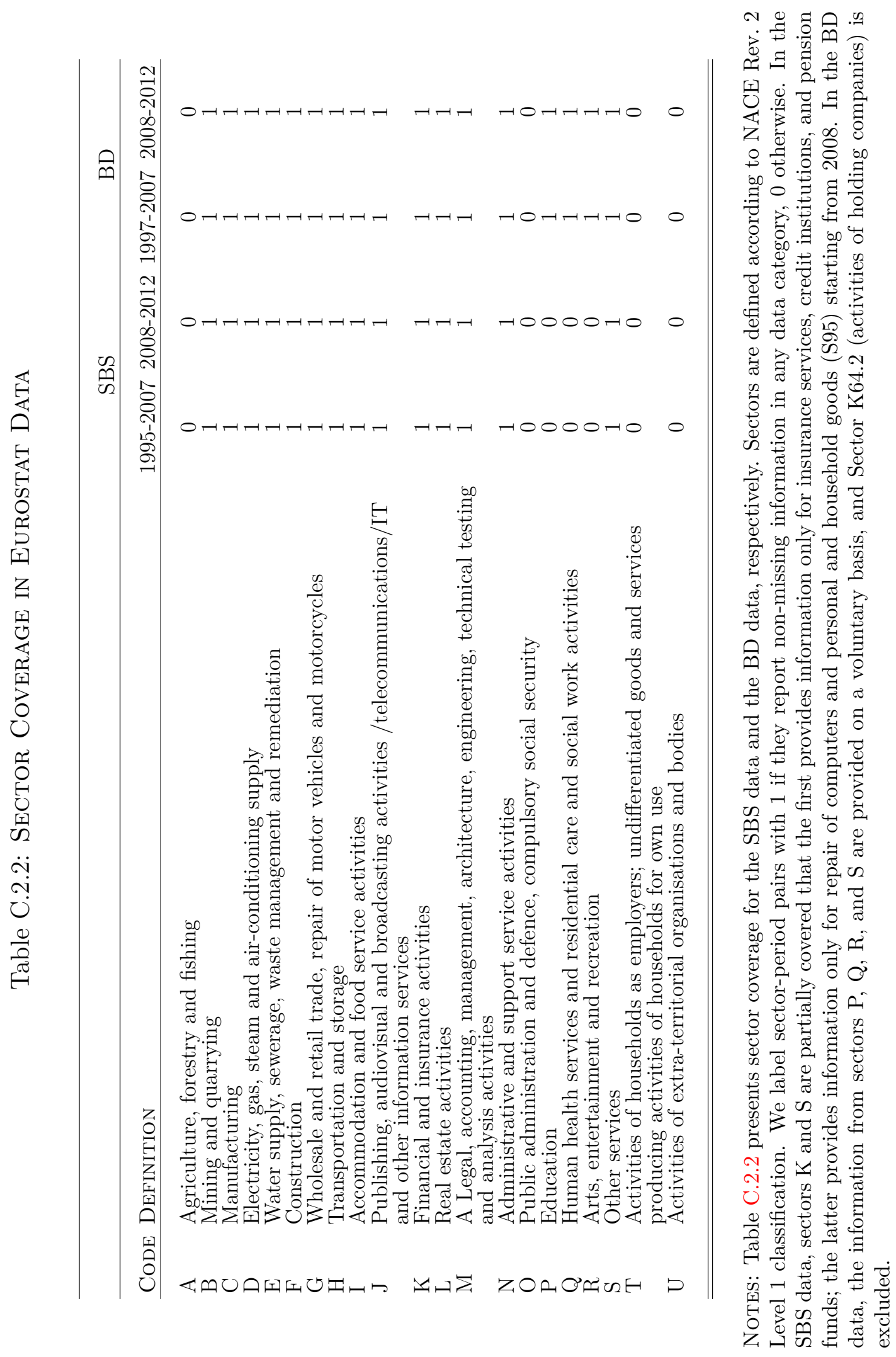


Table C.2.3: Sector Coverage of Eurostat Countries across Years: 1999-2012

\section{Based on Gross Output}

\begin{tabular}{lllllllllllllllll}
\hline AT & \multicolumn{10}{c}{10} \\
& 1999 & 2000 & 2001 & 2002 & 2003 & 2004 & 2005 & 2006 & 2007 & 2008 & 2009 & 2010 & 2011 & 2012 \\
\hline $\mathrm{B}$ & 1 & 1 & 1 & 1 & 0 & 0 & 0 & 0 & 0 & 0 & 0 & 0 & 0 & 0 \\
$\mathrm{C}$ & 1 & 1 & 1 & 1 & 1 & 1 & 1 & 1 & 1 & 1 & 1 & 1 & 1 & 1 \\
$\mathrm{D}$ & 1 & 1 & 1 & 1 & 1 & 1 & 1 & 1 & 1 & 1 & 1 & 1 & 1 & 1 \\
$\mathrm{E}$ & 0 & 0 & 0 & 0 & 0 & 0 & 1 & 0 & 0 & 1 & 1 & 1 & 1 & 1 \\
$\mathrm{~F}$ & 1 & 1 & 1 & 1 & 1 & 1 & 1 & 1 & 1 & 0 & 0 & 1 & 0 & 0 \\
$\mathrm{G}$ & 1 & 1 & 1 & 1 & 1 & 1 & 1 & 1 & 1 & 0 & 0 & 1 & 0 & 0 \\
$\mathrm{H}$ & 1 & 1 & 1 & 1 & 1 & 1 & 1 & 1 & 1 & 1 & 1 & 1 & 1 & 0 \\
$\mathrm{I}$ & 1 & 1 & 1 & 1 & 1 & 1 & 1 & 1 & 1 & 1 & 1 & 1 & 1 & 0 \\
$\mathrm{~J}$ & 0 & 0 & 0 & 0 & 0 & 0 & 0 & 0 & 0 & 1 & 1 & 1 & 1 & 0 \\
$\mathrm{~K}$ & 0 & 0 & 0 & 0 & 0 & 0 & 0 & 0 & 0 & 0 & 0 & 0 & 0 & 0 \\
$\mathrm{~L}$ & 1 & 1 & 1 & 1 & 1 & 1 & 1 & 1 & 1 & 1 & 1 & 1 & 1 & 0 \\
$\mathrm{M}$ & 0 & 0 & 0 & 0 & 0 & 0 & 0 & 0 & 0 & 1 & 1 & 1 & 1 & 0 \\
$\mathrm{~N}$ & 0 & 0 & 0 & 0 & 0 & 0 & 0 & 0 & 0 & 1 & 1 & 1 & 1 & 0 \\
$\mathrm{~S}$ & 0 & 0 & 0 & 0 & 0 & 0 & 0 & 0 & 0 & 0 & 0 & 0 & 1 & 0 \\
\hline
\end{tabular}

$\mathrm{BE}$

19992000200120022003200420052006200720082009201020112012

\begin{tabular}{lllllllllllllll}
\hline $\mathrm{B}$ & 0 & 0 & 0 & 0 & 0 & 0 & 0 & 0 & 0 & 0 & 0 & 1 & 0 & 0 \\
$\mathrm{C}$ & 1 & 1 & 1 & 0 & 1 & 1 & 1 & 1 & 1 & 1 & 1 & 1 & 1 & 1 \\
$\mathrm{D}$ & 1 & 1 & 1 & 0 & 1 & 1 & 1 & 1 & 1 & 0 & 0 & 1 & 1 & 1 \\
$\mathrm{E}$ & 0 & 0 & 0 & 0 & 0 & 0 & 0 & 0 & 0 & 1 & 1 & 1 & 1 & 1 \\
$\mathrm{~F}$ & 1 & 1 & 1 & 0 & 1 & 1 & 1 & 1 & 1 & 0 & 0 & 1 & 0 & 0 \\
$\mathrm{G}$ & 1 & 1 & 1 & 0 & 1 & 1 & 1 & 1 & 1 & 0 & 0 & 1 & 0 & 0 \\
$\mathrm{H}$ & 1 & 1 & 1 & 0 & 1 & 1 & 1 & 1 & 1 & 1 & 1 & 1 & 1 & 0 \\
$\mathrm{I}$ & 1 & 1 & 1 & 0 & 1 & 1 & 1 & 1 & 1 & 1 & 1 & 1 & 1 & 0 \\
$\mathrm{~J}$ & 0 & 0 & 0 & 0 & 0 & 0 & 0 & 0 & 0 & 1 & 1 & 1 & 1 & 0 \\
$\mathrm{~K}$ & 0 & 0 & 0 & 0 & 0 & 0 & 0 & 0 & 0 & 0 & 0 & 0 & 0 & 0 \\
$\mathrm{~L}$ & 1 & 1 & 1 & 0 & 1 & 1 & 1 & 1 & 1 & 1 & 1 & 1 & 1 & 0 \\
$\mathrm{M}$ & 0 & 0 & 0 & 0 & 0 & 0 & 0 & 0 & 0 & 1 & 1 & 1 & 1 & 0 \\
$\mathrm{~N}$ & 0 & 0 & 0 & 0 & 0 & 0 & 0 & 0 & 0 & 1 & 1 & 1 & 1 & 0 \\
$\mathrm{~S}$ & 0 & 0 & 0 & 0 & 0 & 0 & 0 & 0 & 0 & 1 & 0 & 0 & 0 & 0 \\
\hline
\end{tabular}

$\mathrm{BG}$

19992000200120022003200420052006200720082009201020112012

\begin{tabular}{|c|c|c|c|c|c|c|c|c|c|c|c|c|c|c|}
\hline B & 0 & 0 & 0 & 1 & 1 & 1 & 1 & 1 & 1 & 0 & 0 & 0 & 0 & 0 \\
\hline $\mathrm{C}$ & 0 & 0 & 0 & 1 & 1 & 1 & 1 & 1 & 1 & 1 & 1 & 1 & 1 & 1 \\
\hline D & 0 & 0 & 0 & 1 & 1 & 1 & 1 & 1 & 1 & 1 & 1 & 1 & 1 & 1 \\
\hline $\mathrm{E}$ & 0 & 0 & 0 & 0 & 0 & 0 & 1 & 0 & 0 & 0 & 0 & 0 & 0 & 1 \\
\hline $\mathrm{F}$ & 0 & 0 & 0 & 1 & 1 & 1 & 1 & 1 & 1 & 0 & 0 & 0 & 0 & 0 \\
\hline $\mathrm{G}$ & 0 & 0 & 0 & 1 & 1 & 1 & 1 & 0 & 1 & 0 & 0 & 1 & 0 & 0 \\
\hline $\mathrm{H}$ & 0 & 0 & 0 & 1 & 1 & 1 & 1 & 1 & 1 & 1 & 1 & 1 & 1 & 0 \\
\hline I & 0 & 0 & 0 & 1 & 1 & 1 & 1 & 1 & 1 & 1 & 1 & 1 & 1 & 0 \\
\hline $\mathrm{J}$ & 0 & 0 & 0 & 0 & 0 & 0 & 0 & 0 & 0 & 1 & 1 & 1 & 1 & 0 \\
\hline $\mathrm{K}$ & 0 & 0 & 0 & 0 & 0 & 0 & 0 & 0 & 0 & 0 & 0 & 0 & 0 & 0 \\
\hline $\mathrm{L}$ & 0 & 0 & 0 & 1 & 1 & 1 & 1 & 1 & 1 & 1 & 0 & 0 & 0 & 0 \\
\hline $\mathrm{M}$ & 0 & 0 & 0 & 0 & 0 & 0 & 0 & 0 & 0 & 1 & 1 & 1 & 1 & 0 \\
\hline $\mathrm{N}$ & 0 & 0 & 0 & 0 & 0 & 0 & 0 & 0 & 0 & 0 & 0 & 1 & 1 & 0 \\
\hline S & 0 & 0 & 0 & 0 & 0 & 0 & 0 & 0 & 0 & 0 & 0 & 0 & 0 & 0 \\
\hline
\end{tabular}

Notes: Table C.2.3 presents the coverage in the Eurostat SBS data by economic activity for given countryyears. The variable of interest is gross-output and the information is based on NACE Rev. 2 Level 1 categories. This table is used as reference for total economy comparisons based on gross-output. In the table, the corresponding country-year is labelled as 1 if information on gross-output is available, 0 otherwise. The country codes reported are as follows: AT (Austria), BE (Belgium), BG (Bulgaria), CZ (Czech Republic), DE (Germany), DK (Denmark), EE (Estonia), ES (Spain), FI (Finland), FR (France), GB (United Kingdom), GR (Greece), HR (Croatia), HU (Hungary), IE (Ireland), IT (Italy), LT (Lithuania), LU (Luxembourg), LV (Latvia), NL (Netherlands), NO (Norway), PL (Polø̄nd), PT (Portugal), RO (Romania), SE (Sweden), SI (Slovenia), and SK (Slovakia). 
Table C.2.3 (Cont'd.): Sector Coverage of Eurostat Countries across Years: 1999-2012

\section{Based on Gross Output}

\begin{tabular}{|c|c|c|c|c|c|c|c|c|c|c|c|c|c|c|}
\hline $\mathrm{CZ}$ & 1999 & 2000 & 2001 & 2002 & 2003 & 2004 & 2005 & 2006 & 2007 & 2008 & 2009 & 2010 & 2011 & 2012 \\
\hline B & 1 & 1 & 1 & 1 & 1 & 1 & 1 & 1 & 1 & 1 & 1 & 1 & 1 & 1 \\
\hline C & 1 & 1 & 1 & 1 & 1 & 1 & 1 & 1 & 1 & 1 & 1 & 1 & 1 & 1 \\
\hline D & 1 & 1 & 1 & 1 & 1 & 1 & 1 & 1 & 1 & 1 & 1 & 1 & 1 & 1 \\
\hline $\mathrm{E}$ & 0 & 0 & 0 & 0 & 0 & 0 & 1 & 1 & 1 & 1 & 1 & 0 & 1 & 1 \\
\hline $\mathrm{F}$ & 1 & 1 & 1 & 1 & 1 & 1 & 1 & 1 & 1 & 0 & 0 & 1 & 0 & ( \\
\hline $\mathrm{G}$ & 1 & 1 & 1 & 1 & 1 & 1 & 1 & 1 & 1 & 0 & 0 & 1 & 0 & ( \\
\hline $\mathrm{H}$ & 1 & 1 & 1 & 1 & 1 & 1 & 1 & 1 & 1 & 1 & 1 & 0 & 0 & ( \\
\hline I & 1 & 1 & 1 & 1 & 1 & 1 & 1 & 1 & 1 & 1 & 1 & 0 & 0 & ( \\
\hline $\mathrm{J}$ & 0 & 0 & 0 & 0 & 0 & 0 & 0 & 0 & 0 & 1 & 1 & 1 & 1 & ( \\
\hline K & 0 & 0 & 0 & 0 & 0 & 0 & 0 & 0 & 0 & 0 & 0 & 0 & 0 & ( \\
\hline $\mathrm{L}$ & 1 & 1 & 0 & 1 & 1 & 1 & 1 & 1 & 1 & 1 & 1 & 1 & 0 & ( \\
\hline M & 0 & 0 & 0 & 0 & 0 & 0 & 0 & 0 & 0 & 1 & 1 & 1 & 1 & ( \\
\hline $\mathrm{N}$ & 0 & 0 & 0 & 0 & 0 & 0 & 0 & 0 & 0 & 1 & 1 & 1 & 1 & ( \\
\hline $\mathrm{S}$ & 0 & 0 & 0 & 0 & 0 & 0 & 0 & 0 & 0 & 1 & 0 & 0 & 0 & ( \\
\hline
\end{tabular}

$\mathrm{DE}$

19992000200120022003200420052006200720082009201020112012

$\begin{array}{lllllllllllllll}\mathrm{B} & 1 & 0 & 0 & 0 & 0 & 0 & 0 & 0 & 0 & 0 & 0 & 0 & 0 & 0 \\ \mathrm{C} & 1 & 1 & 1 & 1 & 1 & 1 & 1 & 1 & 1 & 1 & 1 & 1 & 1 & 1 \\ \mathrm{D} & 1 & 1 & 1 & 1 & 1 & 1 & 1 & 1 & 1 & 1 & 1 & 1 & 1 & 1 \\ \mathrm{E} & 0 & 0 & 0 & 0 & 0 & 0 & 0 & 0 & 0 & 1 & 1 & 1 & 1 & 1 \\ \mathrm{~F} & 1 & 1 & 1 & 1 & 1 & 1 & 1 & 1 & 1 & 0 & 0 & 1 & 0 & 0 \\ \mathrm{G} & 1 & 1 & 1 & 1 & 1 & 1 & 1 & 1 & 1 & 0 & 0 & 1 & 0 & 0 \\ \mathrm{H} & 0 & 1 & 1 & 1 & 1 & 1 & 1 & 1 & 1 & 1 & 1 & 1 & 1 & 0 \\ \mathrm{I} & 1 & 1 & 1 & 1 & 1 & 1 & 1 & 1 & 1 & 1 & 1 & 1 & 1 & 0 \\ \mathrm{~J} & 0 & 0 & 0 & 0 & 0 & 0 & 0 & 0 & 0 & 1 & 1 & 1 & 1 & 0 \\ \mathrm{~K} & 0 & 0 & 0 & 0 & 0 & 0 & 0 & 0 & 0 & 0 & 0 & 0 & 0 & 0 \\ \mathrm{~L} & 0 & 1 & 1 & 1 & 1 & 1 & 1 & 1 & 1 & 1 & 1 & 1 & 1 & 0 \\ \mathrm{M} & 0 & 0 & 0 & 0 & 0 & 0 & 0 & 0 & 0 & 1 & 1 & 1 & 1 & 0 \\ \mathrm{~N} & 0 & 0 & 0 & 0 & 0 & 0 & 0 & 0 & 0 & 1 & 1 & 1 & 1 & 0 \\ \mathrm{~S} & 0 & 0 & 0 & 0 & 0 & 0 & 0 & 0 & 0 & 0 & 0 & 0 & 0 & 0 \\ \mathrm{DK} & & & & & & & & & & & & & & \end{array}$

19992000200120022003200420052006200720082009201020112012

\begin{tabular}{lllllllllllllll}
\hline $\mathrm{B}$ & 1 & 1 & 1 & 1 & 1 & 1 & 1 & 1 & 1 & 1 & 1 & 1 & 1 & 1 \\
$\mathrm{C}$ & 1 & 1 & 1 & 1 & 1 & 1 & 1 & 1 & 1 & 1 & 1 & 1 & 1 & 1 \\
$\mathrm{D}$ & 1 & 1 & 1 & 1 & 1 & 1 & 1 & 1 & 1 & 1 & 1 & 1 & 1 & 1 \\
$\mathrm{E}$ & 0 & 0 & 0 & 0 & 0 & 0 & 0 & 0 & 0 & 1 & 1 & 1 & 1 & 1 \\
$\mathrm{~F}$ & 1 & 1 & 1 & 1 & 1 & 1 & 1 & 1 & 1 & 0 & 0 & 1 & 0 & 0 \\
$\mathrm{G}$ & 1 & 1 & 1 & 1 & 1 & 1 & 1 & 1 & 1 & 0 & 0 & 1 & 0 & 0 \\
$\mathrm{H}$ & 1 & 1 & 1 & 1 & 1 & 1 & 1 & 1 & 1 & 1 & 1 & 1 & 1 & 0 \\
$\mathrm{I}$ & 1 & 1 & 1 & 1 & 1 & 1 & 1 & 1 & 1 & 1 & 1 & 1 & 1 & 0 \\
$\mathrm{~J}$ & 0 & 0 & 0 & 0 & 0 & 0 & 0 & 0 & 0 & 1 & 1 & 1 & 1 & 0 \\
$\mathrm{~K}$ & 0 & 0 & 0 & 0 & 0 & 0 & 0 & 0 & 0 & 0 & 0 & 0 & 0 & 0 \\
$\mathrm{~L}$ & 1 & 1 & 1 & 1 & 1 & 1 & 1 & 1 & 1 & 1 & 1 & 1 & 1 & 0 \\
$\mathrm{M}$ & 0 & 0 & 0 & 0 & 0 & 0 & 0 & 0 & 0 & 1 & 1 & 1 & 1 & 0 \\
$\mathrm{~N}$ & 0 & 0 & 0 & 0 & 0 & 0 & 0 & 0 & 0 & 1 & 1 & 1 & 1 & 0 \\
$\mathrm{~S}$ & 0 & 0 & 0 & 0 & 0 & 0 & 0 & 0 & 0 & 1 & 1 & 1 & 1 & 0 \\
\hline
\end{tabular}

EE

19992000200120022003200420052006200720082009201020112012

\begin{tabular}{lllllllllllllll}
$\mathrm{B}$ & 1 & 0 & 0 & 0 & 0 & 0 & 0 & 0 & 0 & 0 & 0 & 0 & 0 & 0 \\
$\mathrm{C}$ & 1 & 1 & 1 & 1 & 1 & 1 & 1 & 1 & 1 & 1 & 1 & 1 & 1 & 1 \\
$\mathrm{D}$ & 1 & 1 & 1 & 1 & 1 & 0 & 0 & 0 & 0 & 0 & 0 & 1 & 1 & 0 \\
$\mathrm{E}$ & 0 & 0 & 0 & 0 & 0 & 0 & 0 & 0 & 0 & 0 & 0 & 0 & 0 & 0 \\
$\mathrm{~F}$ & 1 & 1 & 1 & 1 & 1 & 1 & 1 & 1 & 1 & 0 & 0 & 1 & 0 & 0 \\
$\mathrm{G}$ & 1 & 1 & 1 & 1 & 1 & 1 & 1 & 1 & 1 & 0 & 0 & 1 & 0 & 0 \\
$\mathrm{H}$ & 1 & 1 & 1 & 1 & 1 & 1 & 1 & 1 & 1 & 1 & 1 & 1 & 1 & 0 \\
$\mathrm{I}$ & 1 & 1 & 1 & 1 & 1 & 0 & 0 & 0 & 0 & 0 & 1 & 1 & 1 & 0 \\
$\mathrm{~J}$ & 0 & 0 & 0 & 0 & 0 & 0 & 0 & 0 & 0 & 1 & 1 & 1 & 1 & 0 \\
$\mathrm{~K}$ & 0 & 0 & 0 & 0 & 0 & 0 & 0 & 0 & 0 & 0 & 0 & 0 & 0 & 0 \\
$\mathrm{~L}$ & 1 & 1 & 1 & 1 & 1 & 1 & 1 & 0 & 0 & 0 & 0 & 0 & 0 & 0 \\
$\mathrm{M}$ & 0 & 0 & 0 & 0 & 0 & 0 & 0 & 0 & 0 & 0 & 1 & 1 & 1 & 0 \\
$\mathrm{~N}$ & 0 & 0 & 0 & 0 & 0 & 0 & 0 & 0 & 0 & 0 & 1 & 1 & 1 & 0 \\
$\mathrm{~S}$ & 0 & 0 & 0 & 0 & 0 & 0 & 0 & 0 & 0 & 0 & 0 & 0 & 0 & 0 \\
\hline
\end{tabular}

Notes: See the notes above. 
Table C.2.3 (Cont'd.): Sector Coverage of Eurostat Countries across Years: 1999-2012

\section{Based on Gross Output}

\begin{tabular}{|c|c|c|c|c|c|c|c|c|c|c|c|c|c|c|}
\hline ES & 1999 & 2000 & 2001 & 2002 & 2003 & 2004 & 2005 & 2006 & 2007 & 2008 & 2009 & 2010 & 2011 & 2012 \\
\hline B & 0 & 0 & 0 & 0 & 0 & 0 & 0 & 0 & 0 & 0 & 0 & 0 & 0 & 0 \\
\hline $\mathrm{C}$ & 1 & 1 & 1 & 1 & 1 & 1 & 1 & 1 & 1 & 1 & 1 & 1 & 1 & 1 \\
\hline D & 1 & 1 & 1 & 1 & 1 & 1 & 1 & 1 & 1 & 1 & 1 & 1 & 1 & 1 \\
\hline $\mathrm{E}$ & 0 & 0 & 0 & 0 & 0 & 0 & 0 & 0 & 0 & 1 & 1 & 1 & 1 & 1 \\
\hline $\mathrm{F}$ & 1 & 1 & 1 & 1 & 1 & 1 & 1 & 1 & 1 & 0 & 0 & 1 & 0 & 0 \\
\hline G & 1 & 1 & 1 & 1 & 1 & 1 & 1 & 1 & 1 & 0 & 0 & 1 & 0 & 0 \\
\hline $\mathrm{H}$ & 0 & 1 & 1 & 1 & 1 & 1 & 1 & 1 & 1 & 1 & 1 & 1 & 1 & 0 \\
\hline I & 1 & 1 & 1 & 1 & 1 & 1 & 1 & 1 & 1 & 1 & 1 & 1 & 1 & 0 \\
\hline $\mathrm{J}$ & 0 & 0 & 0 & 0 & 0 & 0 & 0 & 0 & 0 & 1 & 1 & 1 & 1 & 0 \\
\hline K & 0 & 0 & 0 & 0 & 0 & 0 & 0 & 0 & 0 & 0 & 0 & 0 & 0 & 0 \\
\hline $\mathrm{L}$ & 1 & 1 & 1 & 1 & 1 & 1 & 1 & 1 & 1 & 1 & 1 & 1 & 1 & 0 \\
\hline $\mathrm{M}$ & 0 & 0 & 0 & 0 & 0 & 0 & 0 & 0 & 0 & 1 & 1 & 1 & 1 & 0 \\
\hline $\mathrm{N}$ & 0 & 0 & 0 & 0 & 0 & 0 & 0 & 0 & 0 & 1 & 1 & 1 & 1 & 0 \\
\hline $\mathrm{S}$ & 0 & 0 & 0 & 0 & 0 & 0 & 0 & 0 & 0 & 0 & 0 & 0 & 0 & 0 \\
\hline
\end{tabular}

FI 19992000200120022003200420052006200720082009201020112012

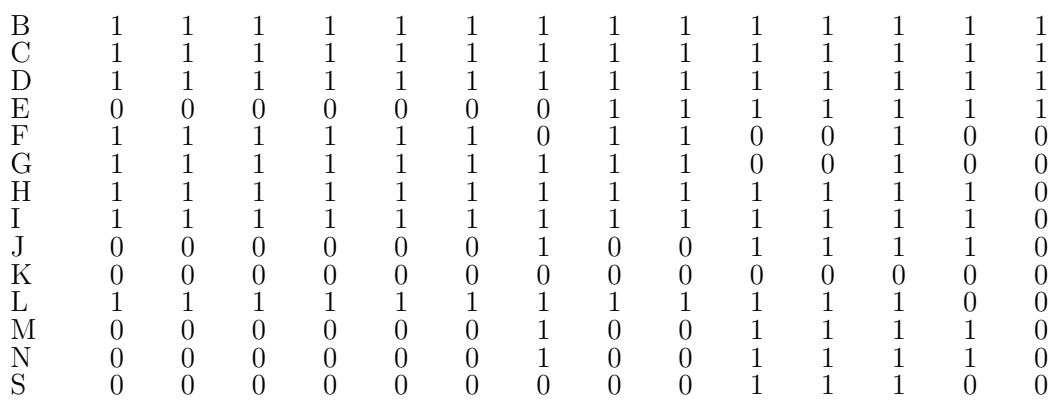

FR

19992000200120022003200420052006200720082009201020112012

\begin{tabular}{lllllllllllllll}
$\mathrm{B}$ & 1 & 0 & 0 & 0 & 0 & 0 & 0 & 0 & 0 & 0 & 0 & 0 & 0 & 0 \\
$\mathrm{C}$ & 1 & 1 & 1 & 1 & 1 & 1 & 1 & 1 & 1 & 1 & 1 & 1 & 1 & 1 \\
$\mathrm{D}$ & 1 & 1 & 1 & 1 & 1 & 1 & 1 & 1 & 1 & 1 & 1 & 1 & 1 & 1 \\
$\mathrm{E}$ & 0 & 0 & 0 & 0 & 0 & 0 & 0 & 0 & 0 & 1 & 1 & 1 & 1 & 1 \\
$\mathrm{~F}$ & 1 & 1 & 1 & 1 & 1 & 1 & 1 & 1 & 1 & 0 & 0 & 1 & 0 & 1 \\
$\mathrm{G}$ & 1 & 1 & 1 & 0 & 1 & 1 & 1 & 1 & 1 & 0 & 0 & 1 & 0 & 1 \\
$\mathrm{H}$ & 1 & 1 & 1 & 1 & 1 & 1 & 1 & 1 & 1 & 1 & 1 & 1 & 1 & 1 \\
$\mathrm{I}$ & 1 & 1 & 1 & 1 & 1 & 1 & 1 & 1 & 1 & 1 & 1 & 1 & 1 & 1 \\
$\mathrm{~J}$ & 0 & 0 & 0 & 0 & 0 & 0 & 0 & 0 & 0 & 1 & 1 & 1 & 1 & 1 \\
$\mathrm{~K}$ & 0 & 0 & 0 & 0 & 0 & 0 & 0 & 0 & 0 & 0 & 0 & 0 & 0 & 0 \\
$\mathrm{~L}$ & 1 & 1 & 1 & 1 & 1 & 1 & 1 & 1 & 1 & 1 & 1 & 1 & 1 & 1 \\
$\mathrm{M}$ & 0 & 0 & 0 & 0 & 0 & 0 & 0 & 0 & 0 & 1 & 1 & 1 & 1 & 1 \\
$\mathrm{~N}$ & 0 & 0 & 0 & 0 & 0 & 0 & 0 & 0 & 0 & 1 & 1 & 1 & 1 & 1 \\
$\mathrm{~S}$ & 0 & 0 & 0 & 0 & 0 & 0 & 0 & 0 & 0 & 0 & 0 & 0 & 0 & 0 \\
\hline
\end{tabular}

GB

19992000200120022003200420052006200720082009201020112012

\begin{tabular}{lllllllllllllll}
$\mathrm{B}$ & 0 & 0 & 0 & 0 & 0 & 0 & 0 & 0 & 0 & 0 & 0 & 0 & 0 & 0 \\
$\mathrm{C}$ & 1 & 1 & 1 & 1 & 1 & 1 & 1 & 1 & 1 & 1 & 1 & 1 & 1 & 1 \\
$\mathrm{D}$ & 1 & 1 & 1 & 1 & 1 & 1 & 1 & 1 & 1 & 1 & 1 & 1 & 1 & 1 \\
$\mathrm{E}$ & 0 & 0 & 0 & 0 & 0 & 0 & 0 & 0 & 0 & 1 & 1 & 1 & 1 & 1 \\
$\mathrm{~F}$ & 1 & 1 & 1 & 1 & 1 & 1 & 1 & 1 & 1 & 0 & 0 & 1 & 0 & 0 \\
$\mathrm{G}$ & 1 & 1 & 1 & 1 & 1 & 1 & 1 & 1 & 1 & 0 & 0 & 1 & 0 & 0 \\
$\mathrm{H}$ & 1 & 1 & 1 & 1 & 1 & 1 & 1 & 1 & 1 & 1 & 1 & 1 & 1 & 0 \\
$\mathrm{I}$ & 1 & 1 & 1 & 1 & 1 & 1 & 1 & 1 & 1 & 1 & 1 & 1 & 1 & 0 \\
$\mathrm{~J}$ & 0 & 0 & 0 & 0 & 0 & 0 & 0 & 0 & 0 & 1 & 1 & 1 & 1 & 0 \\
$\mathrm{~K}$ & 1 & 1 & 1 & 0 & 0 & 0 & 0 & 0 & 0 & 0 & 0 & 0 & 0 & 0 \\
$\mathrm{~L}$ & 1 & 1 & 1 & 1 & 1 & 1 & 1 & 1 & 1 & 1 & 1 & 1 & 1 & 0 \\
$\mathrm{M}$ & 0 & 0 & 0 & 0 & 0 & 0 & 0 & 0 & 0 & 1 & 1 & 1 & 1 & 0 \\
$\mathrm{~N}$ & 0 & 0 & 0 & 0 & 0 & 0 & 0 & 0 & 0 & 1 & 1 & 0 & 0 & 0 \\
$\mathrm{~S}$ & 0 & 0 & 0 & 0 & 0 & 0 & 59 & 0 & 0 & 0 & 0 & 0 & 0 & 0 \\
\hline \hline
\end{tabular}

Notes: See the notes above. 
Table C.2.3 (Cont'd.): Sector Coverage of Eurostat Countries across Years: 1999-2012

\section{Based on Gross Output}

\begin{tabular}{|c|c|c|c|c|c|c|c|c|c|c|c|c|c|c|}
\hline GR & 1999 & 2000 & 2001 & 2002 & 2003 & 2004 & 2005 & 2006 & 2007 & 2008 & 2009 & 2010 & 2011 & 2012 \\
\hline B & 0 & 0 & 0 & 0 & 1 & 1 & 1 & 1 & 1 & 1 & 1 & 1 & 1 & 1 \\
\hline $\mathrm{C}$ & 1 & 1 & 0 & 0 & 1 & 1 & 1 & 1 & 1 & 1 & 1 & 1 & 1 & 1 \\
\hline D & 0 & 0 & 0 & 0 & 1 & 1 & 1 & 1 & 1 & 0 & 1 & 1 & 1 & 1 \\
\hline $\mathrm{E}$ & 0 & 0 & 0 & 0 & 0 & 0 & 0 & 0 & 0 & 0 & 1 & 1 & 1 & 1 \\
\hline $\bar{F}$ & 0 & 0 & 0 & 1 & 1 & 1 & 1 & 1 & 1 & 0 & 0 & 0 & 0 & 0 \\
\hline G & 0 & 0 & 0 & 0 & 1 & 1 & 1 & 1 & 1 & 0 & 0 & 0 & 0 & 0 \\
\hline $\mathrm{H}$ & 0 & 0 & 0 & 0 & 1 & 1 & 1 & 1 & 1 & 1 & 1 & 1 & 0 & 0 \\
\hline I & 0 & 0 & 0 & 0 & 1 & 1 & 1 & 1 & 1 & 1 & 1 & 1 & 0 & 0 \\
\hline $\mathrm{J}$ & 0 & 0 & 0 & 0 & 0 & 0 & 0 & 0 & 0 & 1 & 1 & 1 & 0 & 0 \\
\hline K & 0 & 0 & 0 & 0 & 0 & 0 & 0 & 0 & 0 & 0 & 0 & 0 & 0 & 0 \\
\hline $\mathrm{L}$ & 0 & 0 & 0 & 0 & 1 & 1 & 1 & 1 & 1 & 1 & 1 & 1 & 0 & 0 \\
\hline M & 0 & 0 & 0 & 0 & 0 & 0 & 0 & 0 & 0 & 1 & 1 & 1 & 0 & 0 \\
\hline $\mathrm{N}$ & 0 & 0 & 0 & 0 & 0 & 0 & 0 & 0 & 0 & 1 & 1 & 1 & 0 & 0 \\
\hline S & 0 & 0 & 0 & 0 & 0 & 0 & 0 & 0 & 0 & 1 & 0 & 1 & 0 & 0 \\
\hline
\end{tabular}

HR

19992000200120022003200420052006200720082009201020112012

\begin{tabular}{lllllllllllllll}
$\mathrm{B}$ & 0 & 0 & 0 & 0 & 0 & 0 & 0 & 0 & 0 & 0 & 1 & 1 & 1 & 1 \\
$\mathrm{C}$ & 0 & 0 & 0 & 0 & 0 & 0 & 0 & 0 & 0 & 1 & 1 & 1 & 1 & 1 \\
$\mathrm{D}$ & 0 & 0 & 0 & 0 & 0 & 0 & 0 & 0 & 0 & 0 & 0 & 1 & 1 & 1 \\
$\mathrm{E}$ & 0 & 0 & 0 & 0 & 0 & 0 & 0 & 0 & 0 & 1 & 1 & 1 & 1 & 1 \\
$\mathrm{~F}$ & 0 & 0 & 0 & 0 & 0 & 0 & 0 & 0 & 0 & 0 & 0 & 1 & 0 & 0 \\
$\mathrm{G}$ & 0 & 0 & 0 & 0 & 0 & 0 & 0 & 0 & 0 & 0 & 0 & 1 & 0 & 0 \\
$\mathrm{H}$ & 0 & 0 & 0 & 0 & 0 & 0 & 0 & 0 & 0 & 1 & 1 & 1 & 1 & 0 \\
$\mathrm{I}$ & 0 & 0 & 0 & 0 & 0 & 0 & 0 & 0 & 0 & 1 & 1 & 1 & 1 & 0 \\
$\mathrm{~J}$ & 0 & 0 & 0 & 0 & 0 & 0 & 0 & 0 & 0 & 1 & 1 & 1 & 1 & 0 \\
$\mathrm{~K}$ & 0 & 0 & 0 & 0 & 0 & 0 & 0 & 0 & 0 & 0 & 0 & 0 & 0 & 0 \\
$\mathrm{~L}$ & 0 & 0 & 0 & 0 & 0 & 0 & 0 & 0 & 0 & 0 & 0 & 0 & 1 & 0 \\
$\mathrm{M}$ & 0 & 0 & 0 & 0 & 0 & 0 & 0 & 0 & 0 & 1 & 1 & 1 & 1 & 0 \\
$\mathrm{~N}$ & 0 & 0 & 0 & 0 & 0 & 0 & 0 & 0 & 0 & 1 & 1 & 1 & 1 & 0 \\
$\mathrm{~S}$ & 0 & 0 & 0 & 0 & 0 & 0 & 0 & 0 & 0 & 0 & 0 & 0 & 0 & 0 \\
\hline
\end{tabular}

HU

19992000200120022003200420052006200720082009201020112012

\begin{tabular}{lllllllllllllll}
$\mathrm{B}$ & 0 & 0 & 0 & 0 & 0 & 0 & 0 & 0 & 0 & 0 & 0 & 0 & 0 & 0 \\
$\mathrm{C}$ & 1 & 1 & 1 & 1 & 1 & 1 & 1 & 1 & 1 & 1 & 1 & 1 & 1 & 1 \\
$\mathrm{D}$ & 1 & 1 & 1 & 1 & 1 & 1 & 1 & 1 & 1 & 1 & 1 & 1 & 1 & 1 \\
$\mathrm{E}$ & 0 & 0 & 0 & 0 & 0 & 0 & 1 & 0 & 1 & 1 & 1 & 1 & 1 & 1 \\
$\mathrm{~F}$ & 1 & 1 & 1 & 1 & 1 & 1 & 1 & 1 & 1 & 0 & 0 & 1 & 0 & 0 \\
$\mathrm{G}$ & 1 & 1 & 1 & 1 & 1 & 1 & 1 & 1 & 1 & 0 & 0 & 1 & 0 & 0 \\
$\mathrm{H}$ & 1 & 1 & 0 & 1 & 1 & 1 & 1 & 1 & 1 & 1 & 1 & 1 & 1 & 0 \\
$\mathrm{I}$ & 1 & 1 & 1 & 1 & 1 & 1 & 1 & 1 & 1 & 1 & 1 & 1 & 1 & 0 \\
$\mathrm{~J}$ & 0 & 0 & 0 & 0 & 0 & 0 & 0 & 0 & 0 & 1 & 1 & 1 & 1 & 0 \\
$\mathrm{~K}$ & 0 & 0 & 0 & 0 & 0 & 0 & 0 & 0 & 0 & 0 & 0 & 0 & 0 & 0 \\
$\mathrm{~L}$ & 1 & 1 & 1 & 1 & 1 & 1 & 1 & 1 & 1 & 1 & 1 & 1 & 1 & 0 \\
$\mathrm{M}$ & 0 & 0 & 0 & 0 & 0 & 0 & 0 & 0 & 0 & 1 & 1 & 1 & 1 & 0 \\
$\mathrm{~N}$ & 0 & 0 & 0 & 0 & 0 & 0 & 0 & 0 & 0 & 1 & 1 & 1 & 1 & 0 \\
$\mathrm{~S}$ & 0 & 0 & 0 & 0 & 0 & 0 & 0 & 0 & 0 & 1 & 1 & 0 & 0 & 0 \\
\hline
\end{tabular}

IE

19992000200120022003200420052006200720082009201020112012

\begin{tabular}{lllllllllllllll}
$\mathrm{B}$ & 1 & 0 & 1 & 1 & 0 & 0 & 1 & 1 & 1 & 1 & 1 & 1 & 1 & 1 \\
$\mathrm{C}$ & 1 & 1 & 1 & 1 & 1 & 1 & 1 & 1 & 1 & 1 & 1 & 1 & 1 & 1 \\
$\mathrm{D}$ & 0 & 0 & 0 & 0 & 0 & 0 & 1 & 1 & 0 & 0 & 1 & 1 & 1 & 1 \\
$\mathrm{E}$ & 0 & 0 & 0 & 0 & 0 & 0 & 0 & 0 & 0 & 1 & 1 & 1 & 1 & 1 \\
$\mathrm{~F}$ & 0 & 0 & 0 & 0 & 1 & 1 & 1 & 1 & 1 & 0 & 0 & 1 & 0 & 0 \\
$\mathrm{G}$ & 1 & 1 & 1 & 1 & 1 & 1 & 1 & 1 & 1 & 0 & 0 & 1 & 0 & 0 \\
$\mathrm{H}$ & 1 & 1 & 1 & 1 & 1 & 1 & 1 & 1 & 1 & 0 & 1 & 1 & 1 & 0 \\
$\mathrm{I}$ & 1 & 1 & 1 & 1 & 1 & 1 & 1 & 1 & 1 & 1 & 1 & 1 & 1 & 0 \\
$\mathrm{~J}$ & 0 & 0 & 0 & 0 & 0 & 0 & 0 & 0 & 0 & 1 & 1 & 1 & 1 & 0 \\
$\mathrm{~K}$ & 0 & 0 & 0 & 0 & 0 & 0 & 0 & 0 & 0 & 0 & 0 & 0 & 0 & 0 \\
$\mathrm{~L}$ & 1 & 1 & 1 & 1 & 1 & 1 & 1 & 1 & 1 & 0 & 1 & 1 & 1 & 0 \\
$\mathrm{M}$ & 0 & 0 & 0 & 0 & 0 & 0 & 0 & 0 & 0 & 1 & 1 & 1 & 1 & 0 \\
$\mathrm{~N}$ & 0 & 0 & 0 & 0 & 0 & 0 & 0 & 0 & 0 & 0 & 0 & 0 & 0 & 0 \\
$\mathrm{~S}$ & 0 & 0 & 0 & 0 & 0 & 0 & 0 & 0 & 0 & 0 & 0 & 0 & 0 & 0 \\
\hline \hline
\end{tabular}

Notes: See the notes above. 
Table C.2.3 (Cont'd.): Sector Coverage of Eurostat Countries across Years: 1999-2012

\section{Based on Gross Output}

\begin{tabular}{lrllllllllllllllll}
\hline IT & \multicolumn{11}{c}{10} \\
& 1999 & 2000 & 2001 & 2002 & 2003 & 2004 & 2005 & 2006 & 2007 & 2008 & 2009 & 2010 & 2011 & 2012 \\
\hline $\mathrm{B}$ & 1 & 1 & 1 & 1 & 1 & 1 & 1 & 1 & 1 & 1 & 1 & 1 & 1 & 1 \\
$\mathrm{C}$ & 1 & 1 & 1 & 1 & 1 & 1 & 1 & 1 & 1 & 1 & 1 & 1 & 1 & 1 \\
$\mathrm{D}$ & 1 & 1 & 1 & 1 & 1 & 1 & 1 & 1 & 1 & 1 & 1 & 1 & 1 & 1 \\
$\mathrm{E}$ & 0 & 0 & 0 & 0 & 0 & 0 & 0 & 0 & 0 & 1 & 1 & 1 & 1 & 1 \\
$\mathrm{~F}$ & 1 & 1 & 1 & 1 & 1 & 1 & 1 & 1 & 1 & 0 & 0 & 1 & 0 & 1 \\
$\mathrm{G}$ & 1 & 1 & 1 & 1 & 1 & 1 & 1 & 1 & 1 & 0 & 0 & 1 & 0 & 1 \\
$\mathrm{H}$ & 1 & 1 & 1 & 1 & 1 & 1 & 1 & 1 & 1 & 1 & 1 & 1 & 1 & 1 \\
$\mathrm{I}$ & 1 & 1 & 1 & 1 & 1 & 1 & 1 & 1 & 1 & 1 & 1 & 1 & 1 & 1 \\
$\mathrm{~J}$ & 0 & 0 & 0 & 0 & 0 & 0 & 0 & 0 & 0 & 1 & 1 & 1 & 1 & 1 \\
$\mathrm{~K}$ & 0 & 0 & 0 & 0 & 0 & 0 & 0 & 0 & 0 & 0 & 0 & 0 & 0 & 0 \\
$\mathrm{~L}$ & 1 & 1 & 1 & 1 & 1 & 1 & 1 & 1 & 1 & 0 & 0 & 0 & 1 & 1 \\
$\mathrm{M}$ & 0 & 0 & 0 & 0 & 0 & 0 & 0 & 0 & 0 & 1 & 1 & 1 & 1 & 1 \\
$\mathrm{~N}$ & 0 & 0 & 0 & 0 & 0 & 0 & 0 & 0 & 0 & 1 & 1 & 1 & 1 & 1 \\
$\mathrm{~S}$ & 0 & 0 & 0 & 0 & 0 & 0 & 0 & 0 & 0 & 0 & 0 & 0 & 0 & 0 \\
\hline
\end{tabular}

LT 19992000200120022003200420052006200720082009201020112012

$\begin{array}{lllllllllllllll}\mathrm{B} & 1 & 1 & 1 & 1 & 1 & 0 & 0 & 0 & 0 & 0 & 0 & 0 & 1 & 1 \\ \mathrm{C} & 1 & 1 & 1 & 1 & 1 & 1 & 1 & 1 & 1 & 1 & 1 & 1 & 1 & 1 \\ \mathrm{D} & 1 & 1 & 1 & 1 & 1 & 1 & 1 & 1 & 1 & 1 & 1 & 1 & 1 & 1 \\ \mathrm{E} & 0 & 0 & 0 & 0 & 0 & 0 & 0 & 0 & 0 & 0 & 0 & 1 & 1 & 1 \\ \mathrm{~F} & 1 & 1 & 1 & 1 & 1 & 1 & 1 & 1 & 1 & 0 & 0 & 1 & 0 & 0 \\ \mathrm{G} & 1 & 1 & 1 & 1 & 1 & 1 & 1 & 1 & 1 & 0 & 0 & 1 & 0 & 0 \\ \mathrm{H} & 1 & 1 & 1 & 1 & 0 & 1 & 1 & 1 & 1 & 1 & 1 & 1 & 1 & 0 \\ \mathrm{I} & 1 & 1 & 1 & 1 & 1 & 1 & 1 & 1 & 1 & 1 & 1 & 1 & 1 & 0 \\ \mathrm{~J} & 0 & 0 & 0 & 0 & 0 & 0 & 0 & 0 & 0 & 1 & 1 & 1 & 1 & 0 \\ \mathrm{~K} & 0 & 0 & 0 & 0 & 0 & 0 & 0 & 0 & 0 & 0 & 0 & 0 & 0 & 0 \\ \mathrm{~L} & 1 & 1 & 1 & 1 & 1 & 1 & 1 & 1 & 1 & 0 & 1 & 1 & 1 & 0 \\ \mathrm{M} & 0 & 0 & 0 & 0 & 0 & 0 & 0 & 0 & 0 & 1 & 0 & 1 & 1 & 0 \\ \mathrm{~N} & 0 & 0 & 0 & 0 & 0 & 0 & 0 & 0 & 0 & 1 & 1 & 1 & 1 & 0 \\ \mathrm{~S} & 0 & 0 & 0 & 0 & 0 & 0 & 0 & 0 & 0 & 0 & 0 & 0 & 1 & 0 \\ \mathrm{LU} & & & & & & & & & & & & & & \end{array}$

19992000200120022003200420052006200720082009201020112012

\begin{tabular}{lllllllllllllll}
\hline $\mathrm{B}$ & 0 & 0 & 0 & 0 & 1 & 1 & 1 & 1 & 1 & 1 & 1 & 1 & 1 & 0 \\
$\mathrm{C}$ & 0 & 0 & 0 & 0 & 1 & 1 & 1 & 1 & 1 & 1 & 1 & 1 & 1 & 0 \\
$\mathrm{D}$ & 0 & 0 & 0 & 0 & 1 & 1 & 1 & 1 & 1 & 1 & 1 & 1 & 1 & 0 \\
$\mathrm{E}$ & 0 & 0 & 0 & 0 & 0 & 0 & 0 & 0 & 0 & 1 & 1 & 1 & 1 & 0 \\
$\mathrm{~F}$ & 0 & 0 & 0 & 0 & 1 & 1 & 1 & 1 & 1 & 0 & 0 & 1 & 0 & 0 \\
$\mathrm{G}$ & 0 & 0 & 0 & 0 & 1 & 1 & 1 & 1 & 1 & 0 & 0 & 1 & 1 & 0 \\
$\mathrm{H}$ & 0 & 0 & 0 & 0 & 0 & 1 & 1 & 1 & 1 & 1 & 1 & 1 & 1 & 0 \\
$\mathrm{I}$ & 0 & 0 & 0 & 0 & 1 & 1 & 1 & 1 & 1 & 1 & 1 & 1 & 1 & 0 \\
$\mathrm{~J}$ & 0 & 0 & 0 & 0 & 0 & 0 & 0 & 0 & 0 & 1 & 1 & 1 & 1 & 0 \\
$\mathrm{~K}$ & 0 & 0 & 0 & 0 & 0 & 0 & 0 & 0 & 0 & 0 & 0 & 0 & 0 & 0 \\
$\mathrm{~L}$ & 0 & 0 & 0 & 0 & 1 & 1 & 1 & 1 & 1 & 0 & 0 & 0 & 1 & 0 \\
$\mathrm{M}$ & 0 & 0 & 0 & 0 & 0 & 0 & 0 & 0 & 0 & 0 & 0 & 0 & 0 & 0 \\
$\mathrm{~N}$ & 0 & 0 & 0 & 0 & 0 & 0 & 0 & 0 & 0 & 0 & 0 & 0 & 0 & 0 \\
$\mathrm{~S}$ & 0 & 0 & 0 & 0 & 0 & 0 & 0 & 0 & 0 & 0 & 0 & 0 & 0 & 0 \\
\hline
\end{tabular}

$\mathrm{LV}$

19992000200120022003200420052006200720082009201020112012

\begin{tabular}{lllllllllllllll}
$\mathrm{B}$ & 1 & 0 & 0 & 0 & 0 & 0 & 0 & 0 & 0 & 0 & 1 & 1 & 0 & 0 \\
$\mathrm{C}$ & 1 & 1 & 1 & 1 & 1 & 1 & 1 & 1 & 1 & 1 & 1 & 1 & 1 & 1 \\
$\mathrm{D}$ & 1 & 1 & 1 & 1 & 1 & 1 & 1 & 1 & 0 & 1 & 1 & 1 & 1 & 1 \\
$\mathrm{E}$ & 0 & 0 & 0 & 0 & 0 & 0 & 0 & 1 & 1 & 0 & 0 & 1 & 0 & 1 \\
$\mathrm{~F}$ & 1 & 1 & 1 & 1 & 1 & 1 & 1 & 1 & 1 & 0 & 0 & 1 & 0 & 0 \\
$\mathrm{G}$ & 1 & 1 & 1 & 1 & 1 & 1 & 1 & 1 & 1 & 0 & 0 & 1 & 0 & 0 \\
$\mathrm{H}$ & 1 & 1 & 1 & 1 & 1 & 1 & 1 & 1 & 1 & 1 & 1 & 1 & 1 & 0 \\
$\mathrm{I}$ & 1 & 1 & 1 & 1 & 1 & 1 & 1 & 1 & 1 & 1 & 1 & 1 & 1 & 0 \\
$\mathrm{~J}$ & 0 & 0 & 0 & 0 & 0 & 0 & 0 & 0 & 0 & 1 & 1 & 1 & 1 & 0 \\
$\mathrm{~K}$ & 0 & 0 & 0 & 0 & 0 & 0 & 0 & 0 & 0 & 0 & 0 & 0 & 0 & 0 \\
$\mathrm{~L}$ & 1 & 1 & 1 & 1 & 1 & 1 & 1 & 1 & 1 & 1 & 1 & 1 & 1 & 0 \\
$\mathrm{M}$ & 0 & 0 & 0 & 0 & 0 & 0 & 0 & 0 & 0 & 1 & 1 & 1 & 1 & 0 \\
$\mathrm{~N}$ & 0 & 0 & 0 & 0 & 0 & 0 & 0 & 0 & 0 & 1 & 1 & 1 & 1 & 0 \\
$\mathrm{~S}$ & 0 & 0 & 0 & 0 & 0 & 0 & 0 & 0 & 0 & 0 & 0 & 0 & 0 & 0 \\
\hline \hline
\end{tabular}

Notes: See the notes above. 
Table C.2.3 (Cont'd.): Sector Coverage of Eurostat Countries across Years: 1999-2012

\section{Based on Gross Output}

\section{NL}

19992000200120022003200420052006200720082009201020112012

\begin{tabular}{llllllllllllllll}
$\mathrm{B}$ & 0 & 0 & 1 & 1 & 1 & 0 & 0 & 0 & 0 & 0 & 1 & 0 & 0 & 0 \\
$\mathrm{C}$ & 1 & 1 & 1 & 1 & 1 & 1 & 1 & 1 & 1 & 1 & 1 & 1 & 1 & 1 \\
$\mathrm{D}$ & 0 & 0 & 1 & 1 & 1 & 1 & 0 & 1 & 1 & 1 & 1 & 1 & 1 & 1 \\
$\mathrm{E}$ & 0 & 0 & 0 & 0 & 0 & 0 & 0 & 0 & 0 & 1 & 1 & 1 & 1 & 1 \\
$\mathrm{~F}$ & 0 & 0 & 1 & 1 & 1 & 1 & 1 & 1 & 1 & 0 & 0 & 1 & 0 & 0 \\
$\mathrm{G}$ & 1 & 1 & 1 & 1 & 1 & 1 & 1 & 1 & 1 & 0 & 0 & 1 & 0 & 0 \\
$\mathrm{H}$ & 1 & 1 & 1 & 1 & 1 & 1 & 1 & 1 & 1 & 1 & 1 & 1 & 1 & 0 \\
$\mathrm{I}$ & 1 & 1 & 1 & 1 & 1 & 1 & 1 & 1 & 1 & 1 & 1 & 1 & 1 & 0 \\
$\mathrm{~J}$ & 0 & 0 & 0 & 0 & 0 & 0 & 0 & 0 & 0 & 1 & 1 & 1 & 1 & 0 \\
$\mathrm{~K}$ & 0 & 0 & 0 & 0 & 0 & 0 & 0 & 0 & 0 & 0 & 0 & 0 & 0 & 0 \\
$\mathrm{~L}$ & 0 & 0 & 0 & 0 & 1 & 1 & 1 & 1 & 1 & 1 & 1 & 1 & 1 & 0 \\
$\mathrm{M}$ & 0 & 0 & 0 & 0 & 0 & 0 & 0 & 0 & 0 & 1 & 1 & 1 & 1 & 0 \\
$\mathrm{~N}$ & 0 & 0 & 0 & 0 & 0 & 0 & 0 & 0 & 0 & 1 & 1 & 1 & 1 & 0 \\
$\mathrm{~S}$ & 0 & 0 & 0 & 0 & 0 & 0 & 0 & 0 & 0 & 0 & 0 & 0 & 0 & 0 \\
\hline
\end{tabular}

NO 19992000200120022003200420052006200720082009201020112012

\begin{tabular}{lllllllllllllll}
$\mathrm{B}$ & 0 & 0 & 0 & 0 & 1 & 1 & 1 & 1 & 1 & 1 & 1 & 1 & 1 & 1 \\
$\mathrm{C}$ & 1 & 1 & 0 & 1 & 1 & 1 & 1 & 1 & 1 & 1 & 1 & 1 & 1 & 1 \\
$\mathrm{D}$ & 0 & 0 & 0 & 0 & 0 & 0 & 0 & 1 & 1 & 1 & 1 & 1 & 1 & 1 \\
$\mathrm{E}$ & 0 & 0 & 0 & 0 & 0 & 0 & 0 & 0 & 0 & 1 & 1 & 1 & 1 & 1 \\
$\mathrm{~F}$ & 1 & 1 & 1 & 1 & 0 & 1 & 1 & 1 & 1 & 0 & 0 & 1 & 0 & 0 \\
$\mathrm{G}$ & 1 & 1 & 1 & 1 & 1 & 1 & 1 & 1 & 1 & 0 & 0 & 1 & 0 & 0 \\
$\mathrm{H}$ & 0 & 1 & 0 & 0 & 0 & 1 & 1 & 1 & 1 & 1 & 1 & 1 & 1 & 0 \\
$\mathrm{I}$ & 0 & 1 & 0 & 1 & 1 & 1 & 1 & 1 & 1 & 1 & 1 & 1 & 1 & 0 \\
$\mathrm{~J}$ & 0 & 0 & 0 & 0 & 0 & 0 & 0 & 0 & 0 & 1 & 1 & 1 & 1 & 0 \\
$\mathrm{~K}$ & 0 & 0 & 0 & 0 & 0 & 0 & 0 & 0 & 0 & 0 & 0 & 0 & 0 & 0 \\
$\mathrm{~L}$ & 0 & 1 & 0 & 0 & 1 & 1 & 1 & 1 & 0 & 1 & 0 & 0 & 0 & 0 \\
$\mathrm{M}$ & 0 & 0 & 0 & 0 & 0 & 0 & 0 & 0 & 0 & 1 & 1 & 1 & 1 & 0 \\
$\mathrm{~N}$ & 0 & 0 & 0 & 0 & 0 & 0 & 0 & 0 & 0 & 1 & 1 & 1 & 1 & 0 \\
$\mathrm{~S}$ & 0 & 0 & 0 & 0 & 0 & 0 & 0 & 0 & 0 & 0 & 0 & 0 & 0 & 0 \\
\hline
\end{tabular}

PL

19992000200120022003200420052006200720082009201020112012

\begin{tabular}{lllllllllllllll}
\hline $\mathrm{B}$ & 1 & 1 & 1 & 1 & 1 & 1 & 1 & 1 & 1 & 1 & 1 & 1 & 1 & 1 \\
$\mathrm{C}$ & 1 & 1 & 1 & 1 & 1 & 1 & 1 & 1 & 1 & 1 & 1 & 1 & 1 & 1 \\
$\mathrm{D}$ & 1 & 1 & 1 & 1 & 1 & 1 & 1 & 1 & 1 & 1 & 1 & 1 & 1 & 1 \\
$\mathrm{E}$ & 0 & 0 & 0 & 0 & 0 & 0 & 1 & 1 & 1 & 1 & 1 & 1 & 1 & 1 \\
$\mathrm{~F}$ & 1 & 1 & 1 & 1 & 1 & 1 & 1 & 1 & 1 & 0 & 0 & 1 & 0 & 0 \\
$\mathrm{G}$ & 1 & 1 & 1 & 1 & 1 & 1 & 1 & 1 & 1 & 0 & 0 & 1 & 0 & 0 \\
$\mathrm{H}$ & 1 & 1 & 1 & 1 & 1 & 1 & 1 & 1 & 1 & 1 & 1 & 1 & 1 & 0 \\
$\mathrm{I}$ & 1 & 1 & 1 & 1 & 1 & 1 & 1 & 1 & 1 & 1 & 1 & 1 & 1 & 0 \\
$\mathrm{~J}$ & 0 & 0 & 0 & 0 & 0 & 0 & 0 & 0 & 0 & 1 & 1 & 1 & 1 & 0 \\
$\mathrm{~K}$ & 0 & 0 & 0 & 0 & 0 & 0 & 0 & 0 & 0 & 0 & 0 & 0 & 0 & 0 \\
$\mathrm{~L}$ & 1 & 1 & 1 & 1 & 1 & 1 & 1 & 1 & 1 & 1 & 1 & 1 & 1 & 0 \\
$\mathrm{M}$ & 0 & 0 & 0 & 0 & 0 & 0 & 0 & 0 & 0 & 1 & 1 & 1 & 1 & 0 \\
$\mathrm{~N}$ & 0 & 0 & 0 & 0 & 0 & 0 & 0 & 0 & 0 & 1 & 1 & 1 & 1 & 0 \\
$\mathrm{~S}$ & 0 & 0 & 0 & 0 & 0 & 0 & 0 & 0 & 0 & 1 & 1 & 0 & 0 & 0 \\
\hline
\end{tabular}

PT

19992000200120022003200420052006200720082009201020112012

\begin{tabular}{lllllllllllllll}
$\mathrm{B}$ & 1 & 1 & 1 & 1 & 1 & 1 & 1 & 1 & 1 & 1 & 1 & 1 & 1 & 1 \\
$\mathrm{C}$ & 1 & 1 & 1 & 1 & 1 & 1 & 1 & 1 & 1 & 1 & 1 & 1 & 1 & 1 \\
$\mathrm{D}$ & 1 & 1 & 1 & 1 & 1 & 1 & 1 & 1 & 1 & 1 & 1 & 1 & 1 & 1 \\
$\mathrm{E}$ & 0 & 0 & 0 & 0 & 0 & 0 & 1 & 1 & 1 & 1 & 1 & 1 & 1 & 1 \\
$\mathrm{~F}$ & 0 & 0 & 1 & 1 & 1 & 1 & 1 & 1 & 1 & 0 & 0 & 1 & 0 & 0 \\
$\mathrm{G}$ & 1 & 1 & 1 & 1 & 1 & 1 & 1 & 1 & 1 & 0 & 0 & 1 & 0 & 0 \\
$\mathrm{H}$ & 1 & 1 & 1 & 1 & 1 & 1 & 1 & 1 & 1 & 1 & 1 & 1 & 1 & 0 \\
$\mathrm{I}$ & 1 & 1 & 1 & 1 & 1 & 1 & 1 & 1 & 1 & 1 & 1 & 1 & 1 & 0 \\
$\mathrm{~J}$ & 0 & 0 & 0 & 0 & 0 & 0 & 0 & 0 & 0 & 1 & 1 & 1 & 1 & 0 \\
$\mathrm{~K}$ & 0 & 0 & 0 & 0 & 0 & 0 & 0 & 0 & 0 & 0 & 0 & 0 & 0 & 0 \\
$\mathrm{~L}$ & 1 & 1 & 1 & 1 & 1 & 1 & 1 & 1 & 1 & 1 & 1 & 1 & 1 & 0 \\
$\mathrm{M}$ & 0 & 0 & 0 & 0 & 0 & 0 & 0 & 0 & 0 & 1 & 1 & 1 & 1 & 0 \\
$\mathrm{~N}$ & 0 & 0 & 0 & 0 & 0 & 0 & 0 & 0 & 0 & 1 & 1 & 1 & 1 & 0 \\
$\mathrm{~S}$ & 0 & 0 & 0 & 0 & 0 & 0 & 0 & 0 & 0 & 0 & 0 & 0 & 0 & 0 \\
\hline \hline
\end{tabular}

Notes: See the notes above. 
Table C.2.3 (Cont'd.): Sector Coverage of Eurostat Countries across Years: 1999-2012

\section{Based on Gross Output}

\begin{tabular}{lllllllllllllllll}
\hline $\mathrm{RO}$ & \multicolumn{10}{c}{} \\
& 1999 & 2000 & 2001 & 2002 & 2003 & 2004 & 2005 & 2006 & 2007 & 2008 & 2009 & 2010 & 2011 & 2012 \\
\hline $\mathrm{B}$ & 1 & 1 & 1 & 1 & 1 & 1 & 1 & 1 & 1 & 1 & 1 & 1 & 1 & 1 \\
$\mathrm{C}$ & 1 & 1 & 1 & 1 & 1 & 1 & 1 & 1 & 1 & 1 & 1 & 1 & 1 & 1 \\
$\mathrm{D}$ & 1 & 1 & 1 & 1 & 1 & 1 & 1 & 1 & 1 & 1 & 1 & 1 & 1 & 1 \\
$\mathrm{E}$ & 0 & 0 & 0 & 0 & 0 & 0 & 1 & 1 & 1 & 1 & 1 & 1 & 1 & 1 \\
$\mathrm{~F}$ & 1 & 1 & 1 & 1 & 1 & 1 & 1 & 1 & 1 & 0 & 0 & 1 & 0 & 0 \\
$\mathrm{G}$ & 0 & 1 & 1 & 1 & 1 & 1 & 1 & 1 & 1 & 0 & 0 & 1 & 0 & 0 \\
$\mathrm{H}$ & 0 & 1 & 1 & 1 & 1 & 1 & 1 & 1 & 1 & 1 & 1 & 1 & 1 & 0 \\
$\mathrm{I}$ & 1 & 1 & 1 & 1 & 1 & 1 & 1 & 1 & 1 & 1 & 1 & 1 & 1 & 0 \\
$\mathrm{~J}$ & 0 & 0 & 0 & 0 & 0 & 0 & 0 & 0 & 0 & 1 & 1 & 1 & 1 & 0 \\
$\mathrm{~K}$ & 0 & 0 & 0 & 0 & 0 & 0 & 0 & 0 & 0 & 0 & 0 & 0 & 0 & 0 \\
$\mathrm{~L}$ & 1 & 1 & 1 & 1 & 1 & 1 & 1 & 1 & 1 & 0 & 0 & 1 & 1 & 0 \\
$\mathrm{M}$ & 0 & 0 & 0 & 0 & 0 & 0 & 0 & 0 & 0 & 1 & 1 & 1 & 1 & 0 \\
$\mathrm{~N}$ & 0 & 0 & 0 & 0 & 0 & 0 & 0 & 0 & 0 & 1 & 1 & 1 & 1 & 0 \\
$\mathrm{~S}$ & 0 & 0 & 0 & 0 & 0 & 0 & 0 & 0 & 0 & 0 & 0 & 0 & 0 & 0 \\
\hline
\end{tabular}

$\mathrm{SE}$

19992000200120022003200420052006200720082009201020112012

\begin{tabular}{lllllllllllllll}
$\mathrm{B}$ & 1 & 1 & 1 & 1 & 1 & 1 & 1 & 1 & 1 & 1 & 1 & 1 & 1 & 1 \\
$\mathrm{C}$ & 1 & 1 & 1 & 1 & 1 & 1 & 1 & 1 & 1 & 1 & 1 & 1 & 1 & 1 \\
$\mathrm{D}$ & 1 & 1 & 1 & 1 & 1 & 1 & 1 & 1 & 1 & 1 & 1 & 1 & 1 & 1 \\
$\mathrm{E}$ & 0 & 0 & 0 & 0 & 0 & 0 & 0 & 0 & 0 & 1 & 1 & 1 & 1 & 1 \\
$\mathrm{~F}$ & 1 & 1 & 1 & 1 & 1 & 1 & 1 & 1 & 1 & 0 & 0 & 1 & 0 & 0 \\
$\mathrm{G}$ & 1 & 1 & 1 & 1 & 1 & 1 & 1 & 1 & 1 & 0 & 0 & 1 & 0 & 0 \\
$\mathrm{H}$ & 1 & 1 & 1 & 1 & 1 & 1 & 1 & 1 & 1 & 1 & 1 & 1 & 1 & 0 \\
$\mathrm{I}$ & 1 & 1 & 1 & 1 & 1 & 1 & 1 & 1 & 1 & 1 & 1 & 1 & 1 & 0 \\
$\mathrm{~J}$ & 0 & 0 & 0 & 0 & 0 & 0 & 1 & 1 & 1 & 1 & 1 & 1 & 1 & 0 \\
$\mathrm{~K}$ & 0 & 0 & 0 & 0 & 0 & 0 & 0 & 0 & 0 & 0 & 0 & 0 & 0 & 0 \\
$\mathrm{~L}$ & 1 & 1 & 1 & 1 & 1 & 1 & 1 & 1 & 1 & 1 & 1 & 1 & 1 & 0 \\
$\mathrm{M}$ & 0 & 0 & 0 & 0 & 0 & 0 & 1 & 1 & 1 & 1 & 1 & 1 & 1 & 0 \\
$\mathrm{~N}$ & 0 & 0 & 0 & 0 & 0 & 0 & 1 & 1 & 1 & 1 & 1 & 1 & 1 & 0 \\
$\mathrm{~S}$ & 0 & 0 & 0 & 0 & 0 & 0 & 0 & 0 & 0 & 0 & 0 & 0 & 0 & 0 \\
\hline
\end{tabular}

SI

19992000200120022003200420052006200720082009201020112012

\begin{tabular}{lllllllllllllll}
\hline $\mathrm{B}$ & 1 & 1 & 0 & 0 & 1 & 1 & 1 & 1 & 0 & 1 & 0 & 1 & 0 & 0 \\
$\mathrm{C}$ & 1 & 1 & 1 & 1 & 1 & 1 & 1 & 1 & 1 & 1 & 1 & 1 & 1 & 1 \\
$\mathrm{D}$ & 1 & 1 & 1 & 1 & 1 & 0 & 0 & 0 & 0 & 1 & 1 & 1 & 1 & 1 \\
$\mathrm{E}$ & 0 & 0 & 0 & 0 & 0 & 0 & 1 & 1 & 1 & 1 & 1 & 1 & 1 & 1 \\
$\mathrm{~F}$ & 1 & 1 & 1 & 1 & 1 & 1 & 1 & 1 & 1 & 0 & 0 & 1 & 0 & 0 \\
$\mathrm{G}$ & 1 & 1 & 1 & 1 & 1 & 1 & 1 & 1 & 1 & 0 & 0 & 1 & 0 & 0 \\
$\mathrm{H}$ & 1 & 1 & 1 & 1 & 1 & 1 & 1 & 1 & 1 & 1 & 1 & 1 & 1 & 0 \\
$\mathrm{I}$ & 1 & 1 & 1 & 1 & 1 & 1 & 1 & 1 & 1 & 1 & 1 & 1 & 1 & 0 \\
$\mathrm{~J}$ & 0 & 0 & 0 & 0 & 0 & 0 & 0 & 0 & 0 & 1 & 1 & 1 & 1 & 0 \\
$\mathrm{~K}$ & 0 & 0 & 0 & 0 & 0 & 0 & 0 & 0 & 0 & 0 & 0 & 0 & 0 & 0 \\
$\mathrm{~L}$ & 1 & 1 & 1 & 1 & 1 & 1 & 1 & 1 & 1 & 1 & 1 & 1 & 1 & 0 \\
$\mathrm{M}$ & 0 & 0 & 0 & 0 & 0 & 0 & 0 & 0 & 0 & 1 & 1 & 1 & 1 & 0 \\
$\mathrm{~N}$ & 0 & 0 & 0 & 0 & 0 & 0 & 0 & 0 & 0 & 1 & 1 & 1 & 1 & 0 \\
$\mathrm{~S}$ & 0 & 0 & 0 & 0 & 0 & 0 & 0 & 0 & 0 & 1 & 1 & 0 & 0 & 0 \\
\hline
\end{tabular}

SK

19992000200120022003200420052006200720082009201020112012

\begin{tabular}{|c|c|c|c|c|c|c|c|c|c|c|c|c|c|}
\hline B & 1 & 1 & 1 & 1 & 1 & 1 & 0 & 1 & 0 & 0 & 0 & 0 & 0 \\
\hline $\mathrm{C}$ & 1 & 1 & 1 & 1 & 1 & 1 & 1 & 1 & 1 & 1 & 1 & 1 & 1 \\
\hline D & 1 & 1 & 1 & 1 & 1 & 1 & 0 & 0 & 0 & 0 & 0 & 1 & 0 \\
\hline $\mathrm{E}$ & 0 & 0 & 0 & 0 & 0 & 0 & 0 & 0 & 0 & 0 & 1 & 1 & 1 \\
\hline $\mathrm{F}$ & 1 & 1 & 1 & 1 & 1 & 0 & 0 & 0 & 0 & 0 & 0 & 1 & 0 \\
\hline $\mathrm{G}$ & 1 & 1 & 1 & 1 & 1 & 1 & 1 & 1 & 1 & 0 & 0 & 1 & 0 \\
\hline $\mathrm{H}$ & 1 & 1 & 1 & 1 & 1 & 1 & 1 & 1 & 1 & 1 & 1 & 1 & 1 \\
\hline I & 1 & 1 & 1 & 1 & 1 & 1 & 1 & 1 & 1 & 1 & 1 & 1 & 1 \\
\hline $\mathrm{J}$ & 0 & 0 & 0 & 0 & 0 & 0 & 0 & 0 & 0 & 1 & 1 & 1 & 1 \\
\hline K & 0 & 0 & 0 & 0 & 0 & 0 & 0 & 0 & 0 & 0 & 0 & 0 & 0 \\
\hline $\mathrm{L}$ & 1 & 1 & 1 & 1 & 1 & 1 & 1 & 1 & 1 & 0 & 0 & 1 & 0 \\
\hline $\mathrm{M}$ & 0 & 0 & 0 & 0 & 0 & 0 & 0 & 0 & 0 & 1 & 1 & 1 & 0 \\
\hline $\mathrm{N}$ & 0 & 0 & 0 & 0 & 0 & 0 & 0 & 0 & 0 & 1 & 1 & 1 & 0 \\
\hline S & 0 & 0 & 0 & 0 & 0 & 0 & $63^{0}$ & 0 & 0 & 1 & 0 & 0 & 0 \\
\hline
\end{tabular}

Notes: See the notes above. 

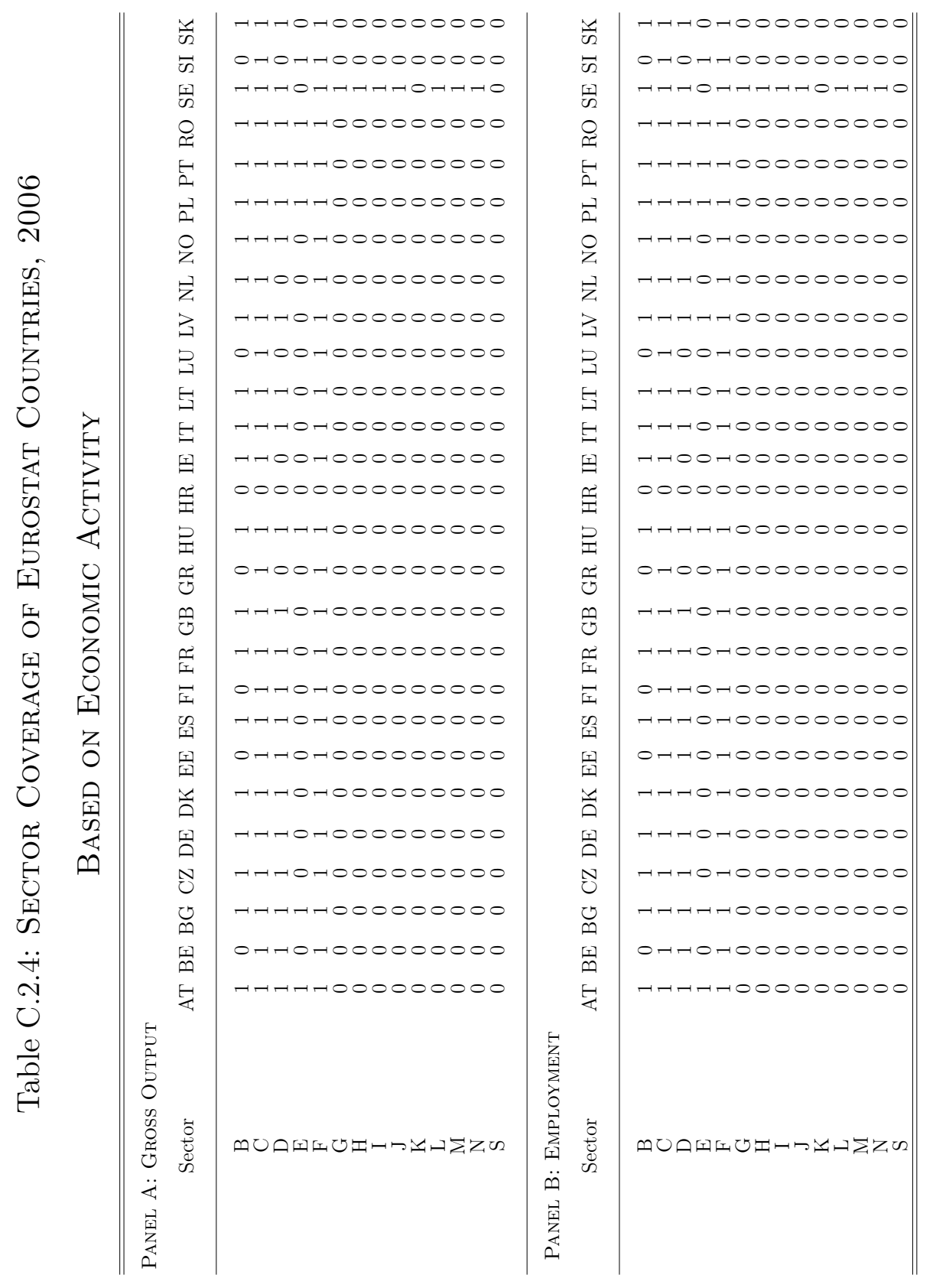

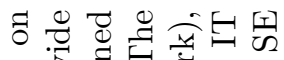

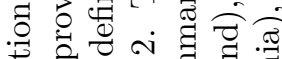
¿्व क्षे कo

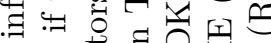

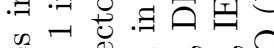

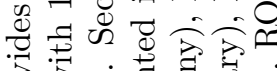

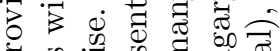

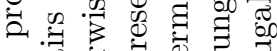
๙ चै

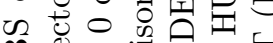
थ

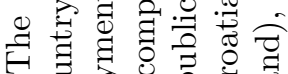

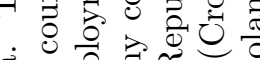

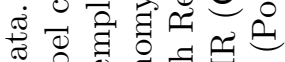

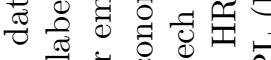

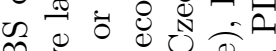
क

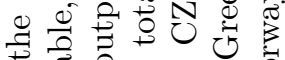
न ○

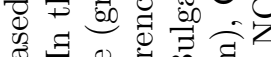
ڤี क $\overrightarrow{\text { क }}$ : ठ 政 $\Xi$ + क. 任 엉 0 फ उ 0 苍 유워 ष क ○ $\because$ की

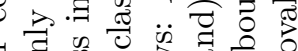
ธิ 总

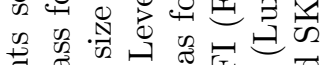

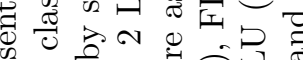

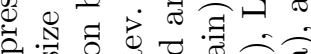
光.

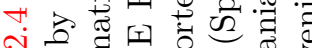

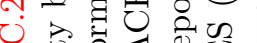

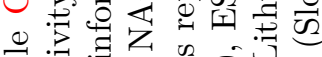

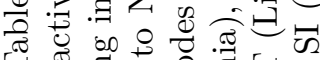
E

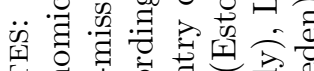
艺 


\section{Additional Material}

In here we present coverage statistics for all countries for which we had information in Orbis and focus on unconsolidated accounts.

\section{D.1 Detailed Statistics for the Aggregate Economy}

Table D.1.4 shows how much of gross output, as reported by Eurostat, is covered by the firms in our dataset. ${ }^{33}$ We measure output by firm operating revenue. Each cell is the ratio of the value of total output produced by "our" firms relative to the value of total output from the official data. BvD provides firm-level information on gross output for all sectors of each European country starting 1999, ${ }^{34}$ however official data from Eurostat SBS provides information on gross output (turnover) for only a subset of sectors. ${ }^{35}$ For each country-year cell, we report the ratio of our aggregated gross output values to official values across those sectors for which the gross-output related variable is available in both datasets. Some ratios will be missing for some country-years due to missing Eurostat data.

As shown in Table D.1.4, with some exceptions, our data account for more than 50 percent of the aggregate output in all countries and close to 80-90 percent in most countries. In some countries, notably Germany, the filing requirements have changed recently and hence in recent vintages coverage has improved.

Table D.1.4 presents the size distribution based on gross output and employment in the aggregate economy. ${ }^{36}$ The patterns do not vary much by year, so we randomly choose to display the results for 2006. The table shows the fraction of economic activity accounted for by firms belonging to each size class with separate countries in the columns. In Panel A, we aggregate our firm-level data to relevant size bins based on gross output and employment. This panel shows that most of the gross output and employment are accounted for by SMEs, using the typical official definition of SMEs as firms with 20-250 employees.

\footnotetext{
${ }^{33}$ Online Appendix C.1 provides details on the official aggregate datasets we use for comparison purposes.

${ }^{34}$ Data go further back in time in Orbis but the coverage is not good as the regulations for filing changed in 1999 requiring all firms to file with the registries if they are located in a EU country.

${ }^{35}$ These sectors are listed in Table C.2.3 of online Appendix C.1.

${ }^{36}$ Table D.1.5 of online Appendix D.1 shows the validation exercise done for the manufacturing sector, for which official data on firm-size distribution is available.
} 
To make sure that our comparisons are "apples-to-apples," we create a "hypothetical aggregate" economy based on aggregating the sectors where official data by size class is provided by Eurostat. We report the results in Table D.1.4, Panel B. As can be seen, our firm-level data match the official size distribution for this limited set of sectors well.

\section{D.2 Detailed Statistics for the Manufacturing Sector}

Tables D.2.1 \& D.2.4 show how much of the official gross output and employment data from Eurostat we cover in our data for the manufacturing sector in the EU countries. We show these tables in two different samples: the Total Sample and the TFP Sample. The Total

Sample consists of firms that report data for the variables employment (EMPL) or wage bill (STAF) and gross-output (OPRE), and TFP sample consists of firms that in addition report data on tangible fixed assets (TFAS) and materials (MATE) so that researchers can calculate total factor productivity for these firms.

The table clearly shows that the coverage improves over time for all countries until 2005 and is stable thereafter. In the case of Germany, on average, we observe worse coverage than in other countries which is explained by the under-representation of small firms in Germany. Only recently, EU harmonization laws made reporting by small firms compulsory also in Germany. There are other countries (Finland, Ireland, the Netherlands, if we were to use employment, and also Latvia, Luxembourg, for the data needed for TFP calculation), with problems similar to Germany, but overall we cover 70-80 percent of the real economy in manufacturing in the bulk of European countries. Denmark and the UK perform worse in the TFP sample, because firms do not report materials use in these countries. Missing percentages appear in some country-years because there is no data available for the corresponding measure in Eurostat for the manufacturing sector.

Table D.2.5 reports the firm size distribution in the manufacturing sector. In the table, each panel presents the share of economic activity (gross-output and employment) accounted for by firms belonging in three size categories in a randomly picked year 2006. In each panel, the first three rows report the measures from Orbis-Amadeus and the next three are the corresponding numbers from Eurostat SBS data. Each column is a different country. Row entries denote the fraction of total economic activity accounted for by firms belonging to each 


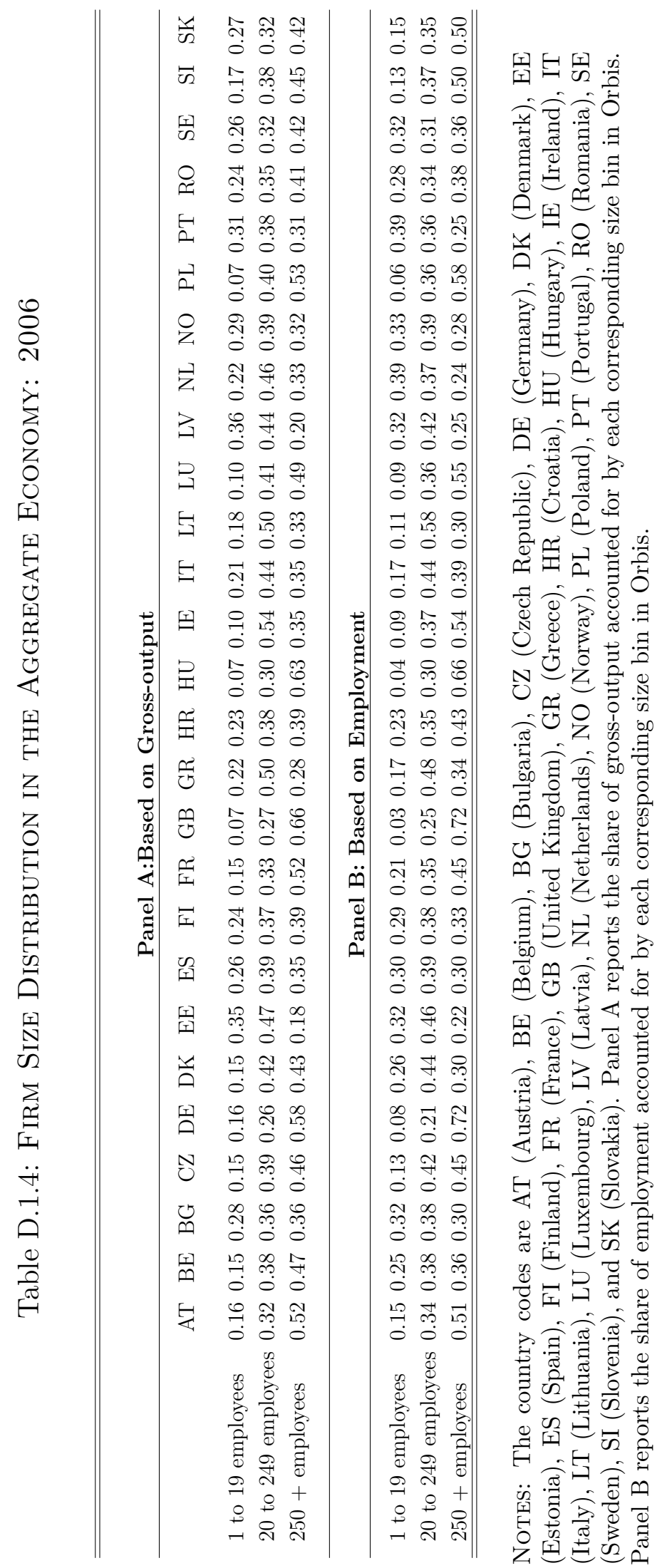


size class. As for the total economy in terms of number of firms, we match well the official statistics in terms of the size distribution of economic activity undertaken in manufacturing sector. 

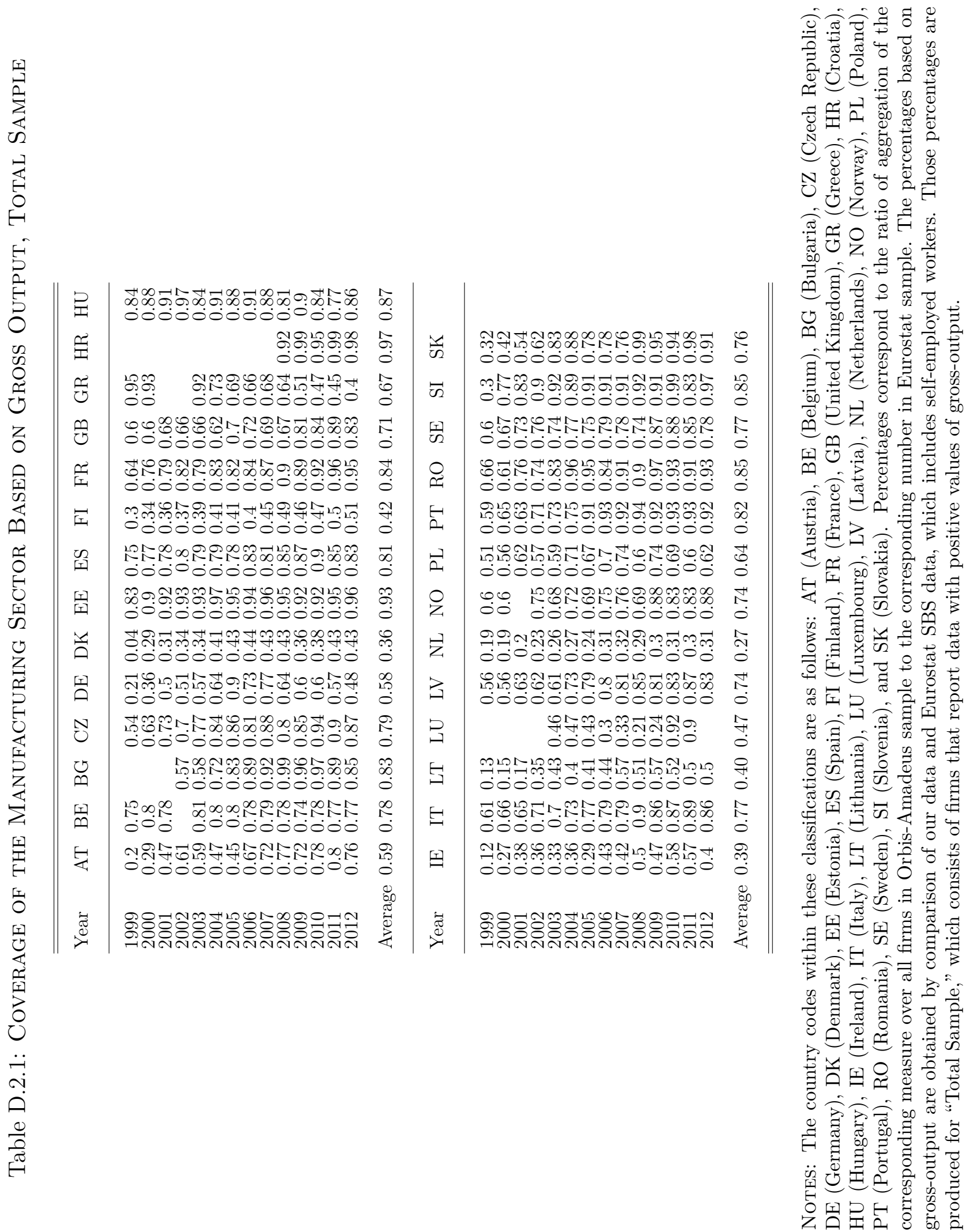


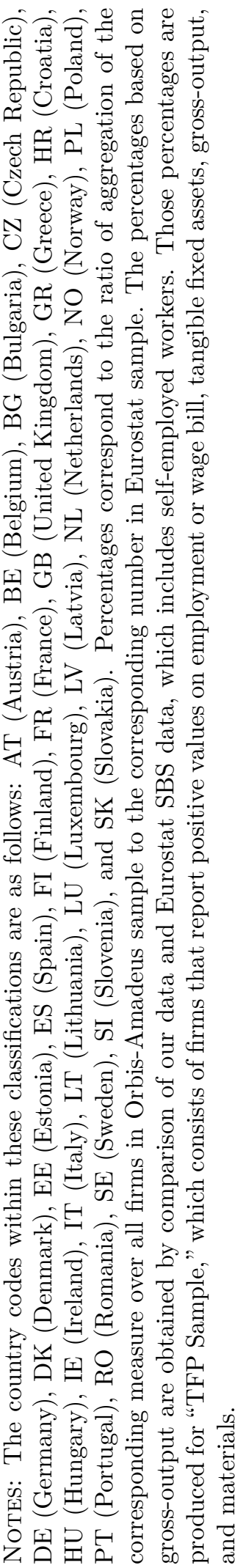



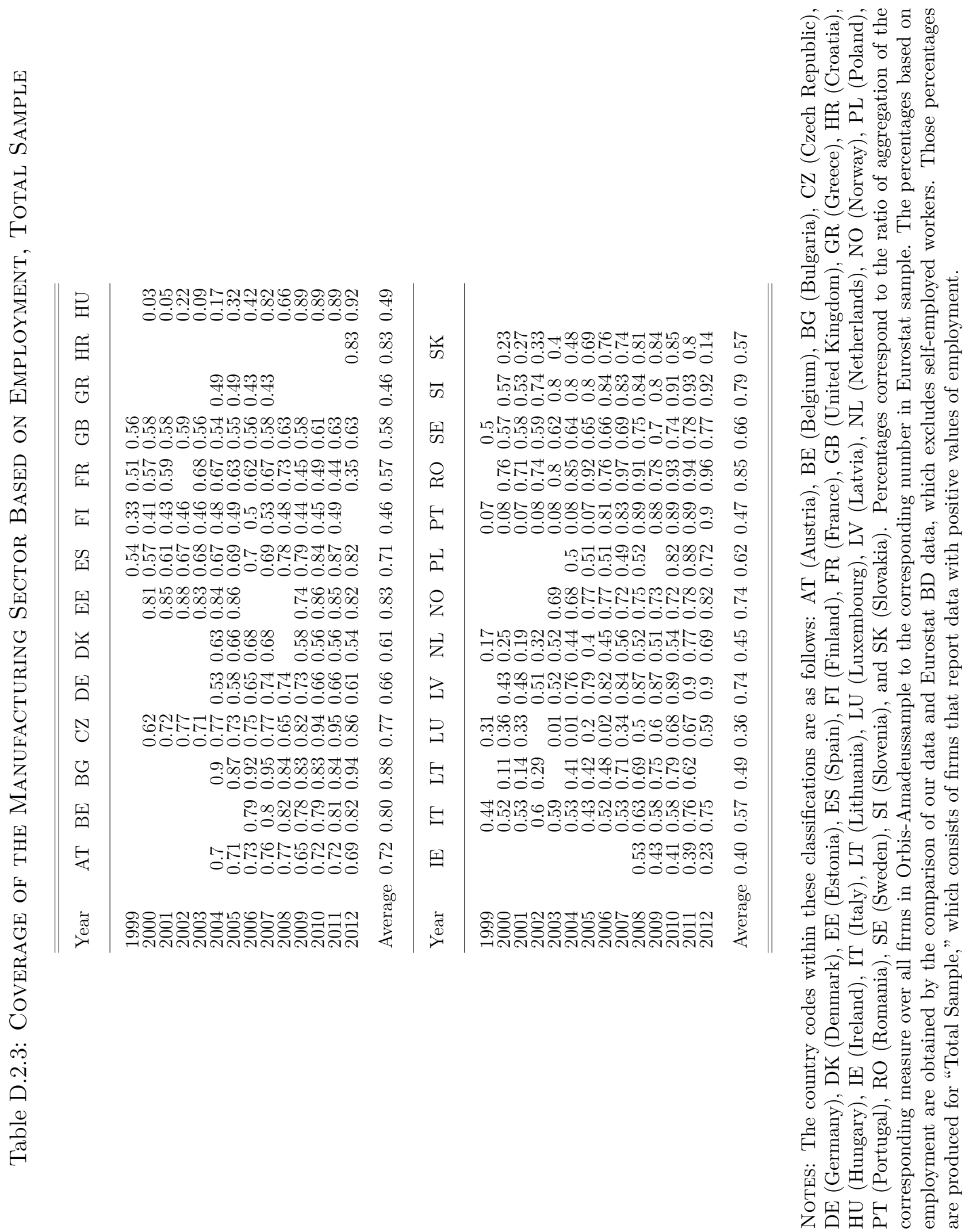
舀

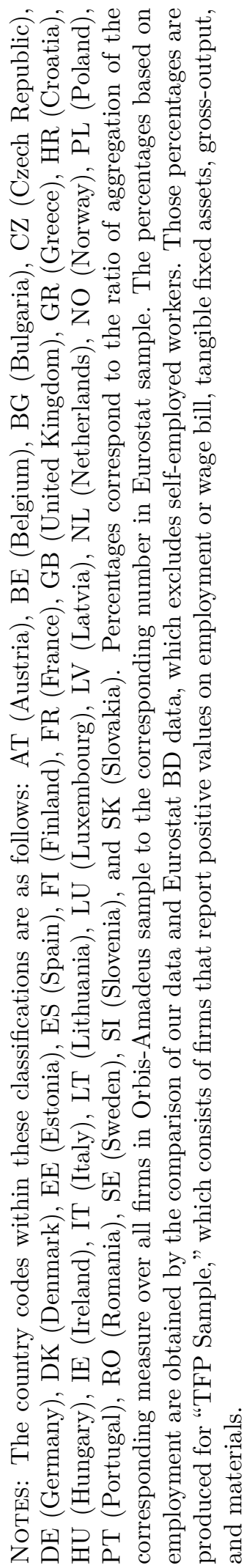




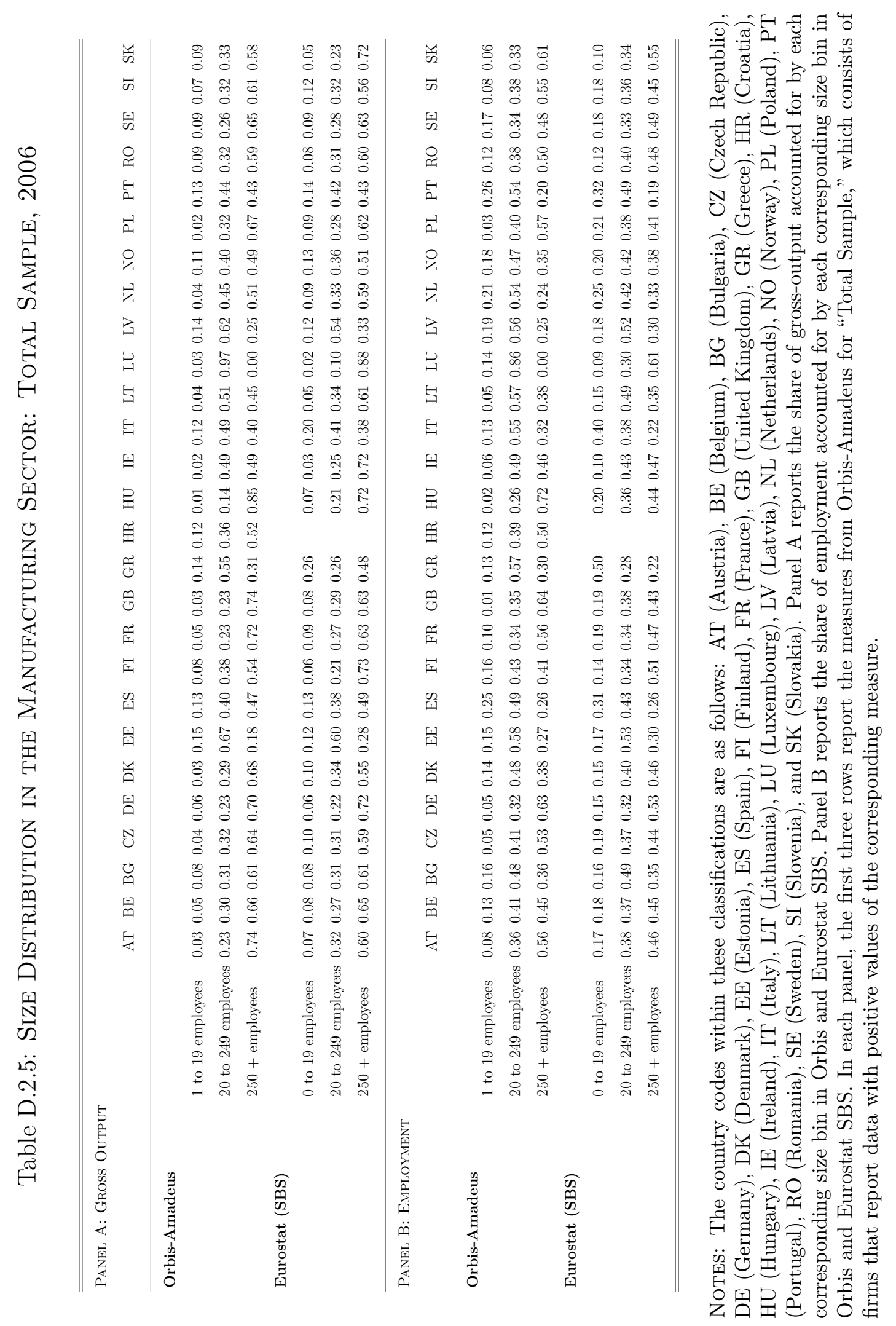




\section{D.3 Alternative Data Sets and Their Coverage}

An alternative data set, CompNet, has recently been developed by the European Central Bank (ECB), covering selected European countries. CompNet is a sector-level database constructed by the ECB from similar sources as Orbis, working with the national central banks. Although it is based on firm-level data taken from business registries, CompNet reports aggregates by sector and country and does not provide the underlying firm-level data set.

Because there are no the firm-level data in CompNet, we cannot sum up the output of firms ourselves. Consequently, the comparison below is based on the number of firms and relative to the "best" (official) Eurostat data.

Tables D.3.1-D.3.2 show these statistics. Table D.3.1 shows the firm coverage of CompNet database and our database constructed from Orbis data relative to Eurostat, with respect to the number of firms in each country-year. We define the total economy as the overlapping sectors of our data with the Eurostat data. Each cell corresponds to the number of firms in the total economy from the relevant data source, relative to the number of firms given by Eurostat. Although this type of comparison is less informative, because many firms in Eurostat have zero employment (self-employed), we show it in order to be able to compare our data to the alternative sector-level database CompNet. Neither our database, nor CompNet, includes self-employed and hence a comparison based solely on the number of firms might be misleading. In spite of this caveat, our data captures the number of firms in the total economy well.

Table D.3.2 may be a more relevant comparison if one worries about "representativeness." The table shows the size and sector distribution of firms in CompNet and BvD, compared to the Eurostat data. ${ }^{37}$ Each cell corresponds to the share of the indicated category's number of firms in the total economy from the relevant data source for the given country-year (\%). For example, in Belgium, 88.9 percent of firms have less than 10 employees in our data and CompNet, whereas the official number from Eurostat is 96 percent. According to this table, our number of firms in terms of employment are very close to what is reported by Eurostat. In terms of sectors; based on our data for Belgium, 13.3 percent of the firms in

\footnotetext{
${ }^{37}$ CompNet and Eurostat numbers come from Tables 6 and 7 of Force (2014).
} 
the total economy operates in the manufacturing sector similarly to the fraction found using the Eurostat data. ${ }^{38}$

Table D.3.1: Coverage Relative to Eurostat for Number of Firms in Total ECONOMY In ORBIS AND COMPNET

\begin{tabular}{lrrr}
\hline \hline & & & \\
\hline Country & YEAR & COMPNET & BvD \\
\hline Belgium & 2008 & 26.5 & 65.2 \\
Estonia & 2007 & 65.9 & 97.1 \\
France & 2009 & 30.6 & 85.2 \\
Germany & 2008 & 3.1 & 63.6 \\
Hungary & 2007 & 3.6 & 37.9 \\
Italy & 2008 & 2.2 & 58.8 \\
Poland & 2007 & 1.2 & 12.3 \\
Slovakia & 2008 & 12.8 & 40.3 \\
Slovenia & 2007 & 28.4 & 19.5 \\
Spain & 2008 & 23.6 & 41.7 \\
& & & \\
\hline
\end{tabular}

NoTES: Each cell corresponds to the number of firms in total economy from the relevant data source relative to the number of firms in Eurostat for the given country-year (\%).

\footnotetext{
${ }^{38}$ We pick these countries for comparison because only these countries' statistics are reported in Tables 6 and 7 of Force (2014). Notice that Tables 6 and 7 of Force (2014) also report coverage numbers on Amadeus/Orbis, but their numbers are clearly different from our numbers reported here, indicating worse coverage. We suspect that this is an artifact of the way the Amadeus/Orbis data was put together by the authors of the Force (2014). As we detail in the current paper, for the best coverage a certain procedure has to be followed.
} 


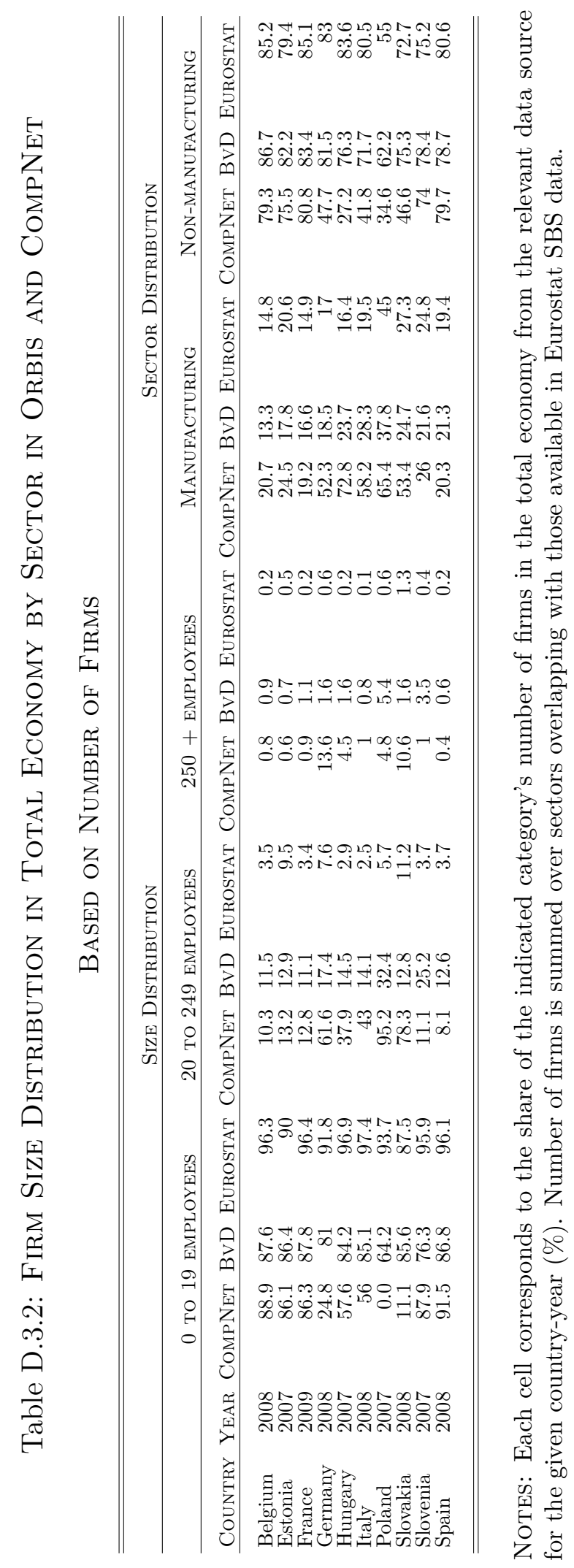




\section{D.4 Treatment of Various Account Types}

In our merged data set, multiple accounts of different types within a given financial year are available for the same company (the same BvD ID Number). We tag those accounts as "duplicate accounts." The number of firm-year observations with duplicate accounts is 607,839 , constituting $0.24 \%$ of total observations in our merged data set. Such duplicate accounts arise for two reasons:

1. A company reports two accounts with the same BvD ID Number and different consolidation codes and the different values of financial and real variables for each consolidation code. The example is the company Ford Otosan Inc. shown in Figure D.4.1. This situation emerges because companies may switch the type of statements they report over time and when we combine different vintages of Orbis (and Amadeus) we might have such different accounts co-exist even in the same year.

2. A company reports two accounts with the same BvD ID Number and different consolidation codes but the same values of financial and real variables for either consolidation code.

Whenever we need a unique company-year observation we make the following choices. For Case 1, we give preference to unconsolidated accounts to avoid double-counting.

To guide us in resolving duplicates in Case 2, Figure D.4.2 presents distribution of du-

plicates by account type, each bar corresponding to the share of a given combination of two different accounts appearing in the same financial year. The highest fraction of duplicate accounts in the same year is the combination of LF\&U (62.52\%) followed by C1\&U1 (32.24\%). Figure D.4.3 represents the distribution of accounts by the length of time series, within the pairs from Figure D.4.2. Within each combination, the upper bar shows the proportion of years when the first account has the longer time series, the middle bar shows the proportion of years when the second account has the longer time series, and the lowest bar the frequency when both accounts in the combination have the same number of years. For example, $32.24 \%$ of duplicate accounts corresponds to firm-year observations with the combination of C1\&U1 (Figure D.4.2). According to Figure D.4.3, within this pair, C1 have the longest time series in $87.2 \%$ of cases, U1 accounts have the longest time series in $9.61 \%$ cases, and in $3.19 \%$ of 
cases they have the same time series. To resolve the duplicates in Case 2, we either retain the accounts reporting the longer time series for a given company, or keep the unconsolidated account if it is reported the same number of years as the other available account type. We also check consolidation codes of duplicate accounts registered in "Historical Product" and verify the accuracy of this procedure.

Figure D.4.1: Consolidation in BvD Accounts

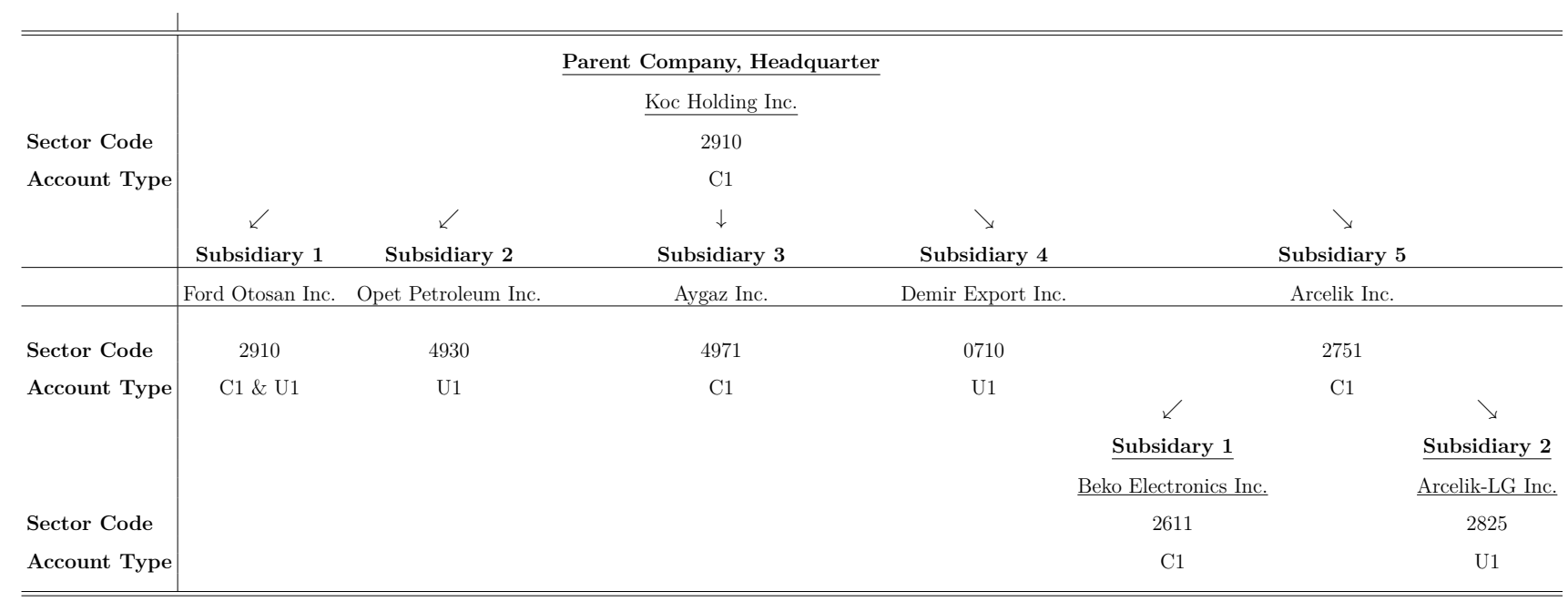

Notes: The diagram illustrates an example of how the real activities of a headquarter and its subsidiaries are registered in $\mathrm{BvD}$ data. $\mathrm{BvD}$ registers the given firm in the sector to which largest portion of its revenue belongs to. The sector codes are classified according to NACE Revision 2, 4-digit Core Codes: 2910: Manufacture of Motor Vehicles; 4930: Retail sale of automotive fuel in specialised stores; 4971: Wholesale of solid, liquid and gaseous fuels and related products (4971); 0710: Mining of iron ores; 2751: Manufacture of electronic domestic appliances; 2611: Manufacture of electronic components; 2825: Manufacture of nondomestic cooling and ventilation equipment. The account types are as follows: C1-account of a companyheadquarter of a group, aggregating all companies belonging to the group (affiliates, subsidiaries, etc.), where the company headquarter has no unconsolidated account; U1-account of a company with no consolidated account. In this example, Ford Otosan Inc. reports both U1 and C1 accounts in our merged data set because these accounts come from different vintages, therefore we drop $\mathrm{C} 1$ account to avoid from double-counting. 


\section{Figure D.4.2: The Distribution of Duplichte Accounts By Account Type}

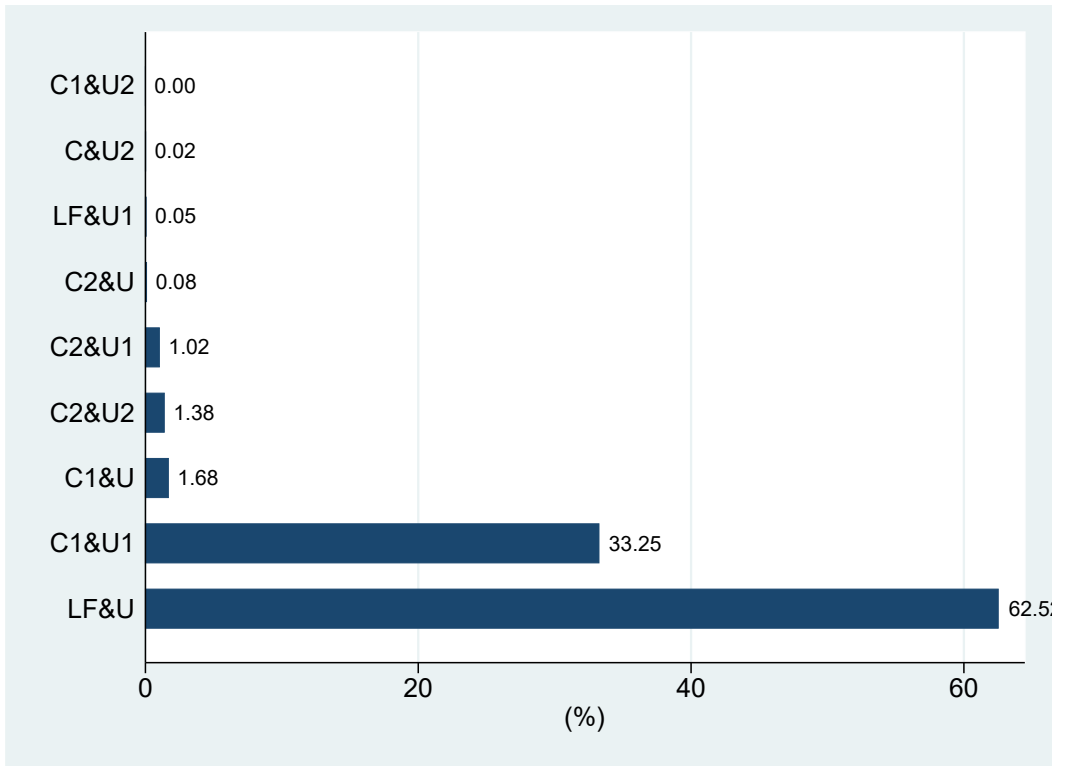

Notes: The figure represents distribution of duplicates by account type. In the figure, each bar corresponds to the share of a given combination of two different accounts appearing in the same financial year. BvD reports firm-level accounts in five types: C1: account of a company-headquarter of a group, aggregating all companies belonging to the group (affiliates, subsidiaries, etc.), where the company headquarter has no unconsolidated account, C2: account of a company-headquarter of a group, aggregating all companies belonging to the group (affiliates, subsidiaries, etc.) where the company headquarter also presents an unconsolidated account, U1: account of a company with no consolidated account, and U2: account of a company with a consolidated account. LF: accounts with financial information. For the firms with missing consolidation code, we derive 1-letter consolidation codes from the BvD account number and fill consolidation codes with either $\mathrm{U}$ or $\mathrm{C}$. 


\section{Figure D.4.3: The Distribution of Duplicate Accounts By Account Type}

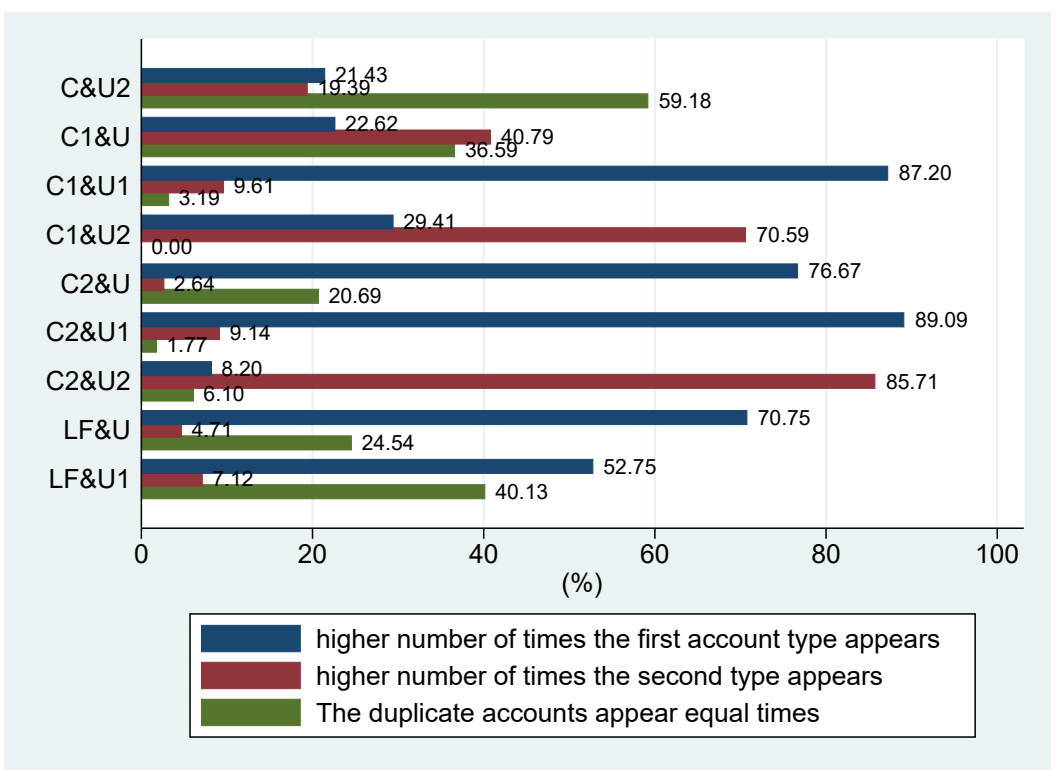

Notes: The figure represents the distribution of duplicates by account type. In the figure, each bar within a given combination of account types corresponds to the share of the first duplicate account that appears higher times than the latter, the share of the latter duplicate account that appears higher times than the first, and the share of duplicate accounts that appear equal times, respectively. BvD reports firm-level accounts in five types: C1: account of a company-headquarter of a group, aggregating all companies belonging to the group (affiliates, subsidiaries, etc.), where the company headquarter has no unconsolidated account, C2: account of a company-headquarter of a group, aggregating all companies belonging to the group (affiliates, subsidiaries, etc.) where the company headquarter also presents an unconsolidated account, U1: account of a company with no consolidated account, and U2: account of a company with a consolidated account. LF: accounts with financial information. For the firms with missing consolidation code, we derive 1-letter consolidation codes from BvD Account Number, and fill consolidation code with $\mathrm{U}$ or $\mathrm{C}$. 


\section{E BvD Disks Interface}

\section{E.1 Formatted Export Interface of Older BvD Disks}

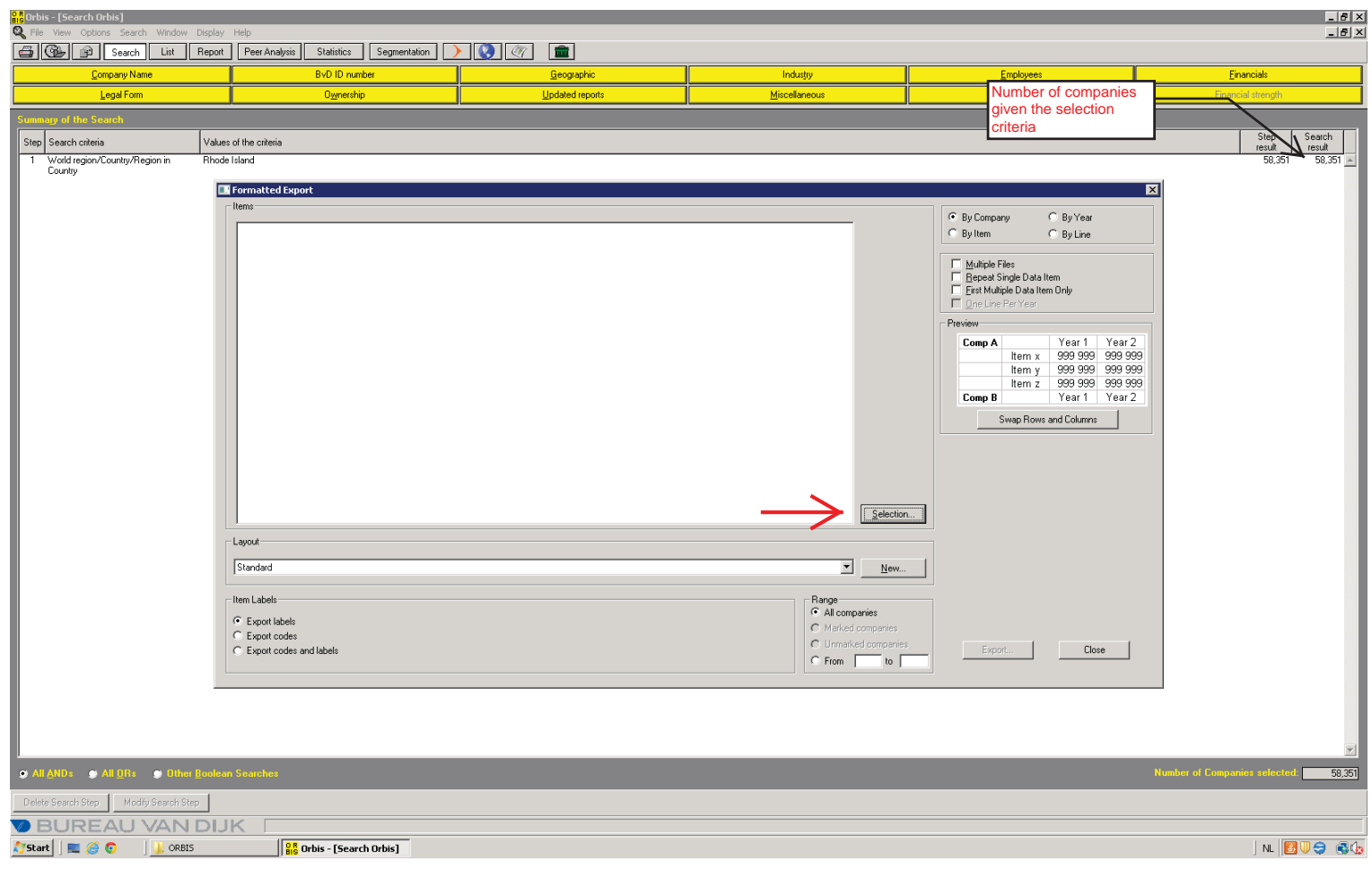



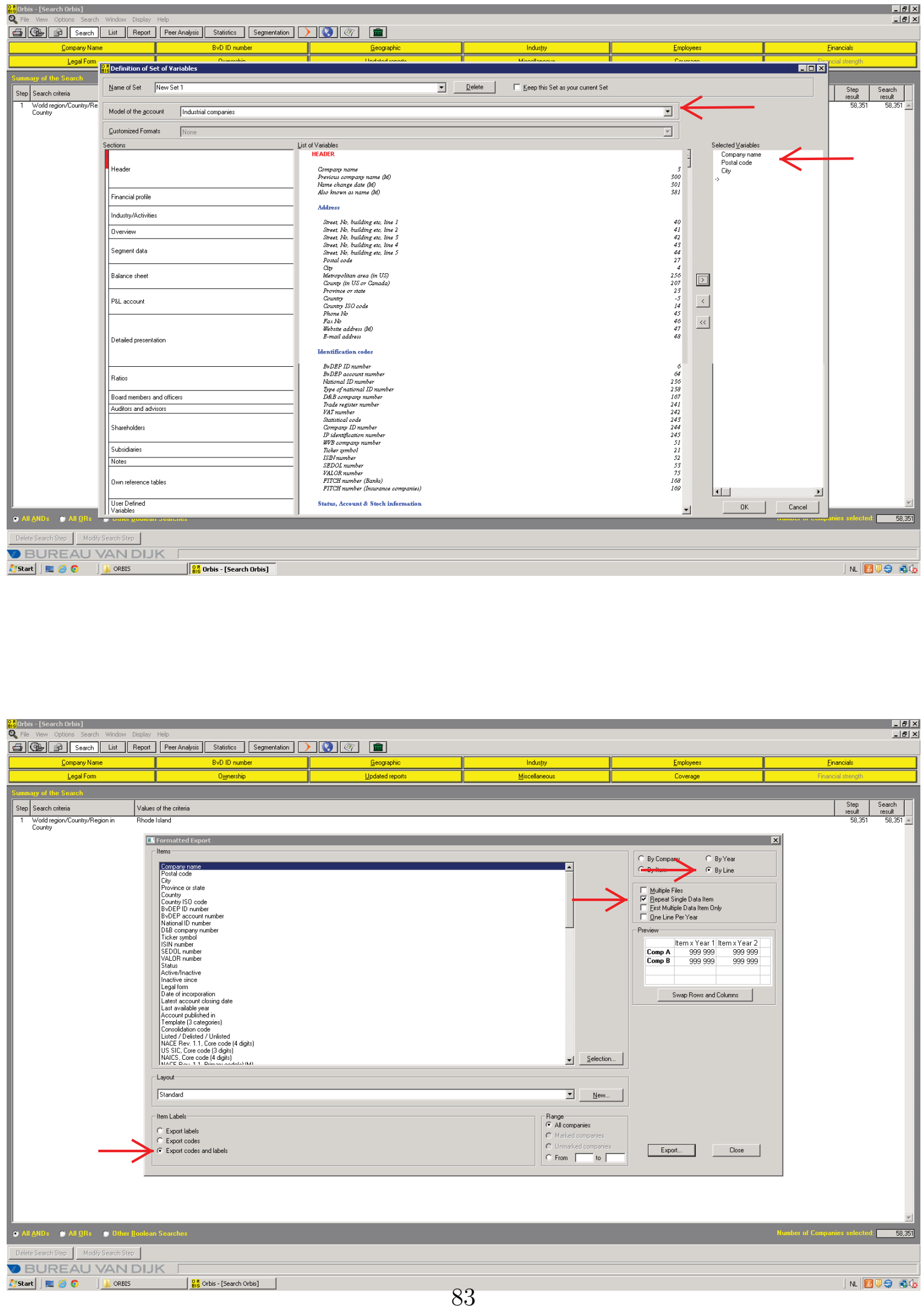

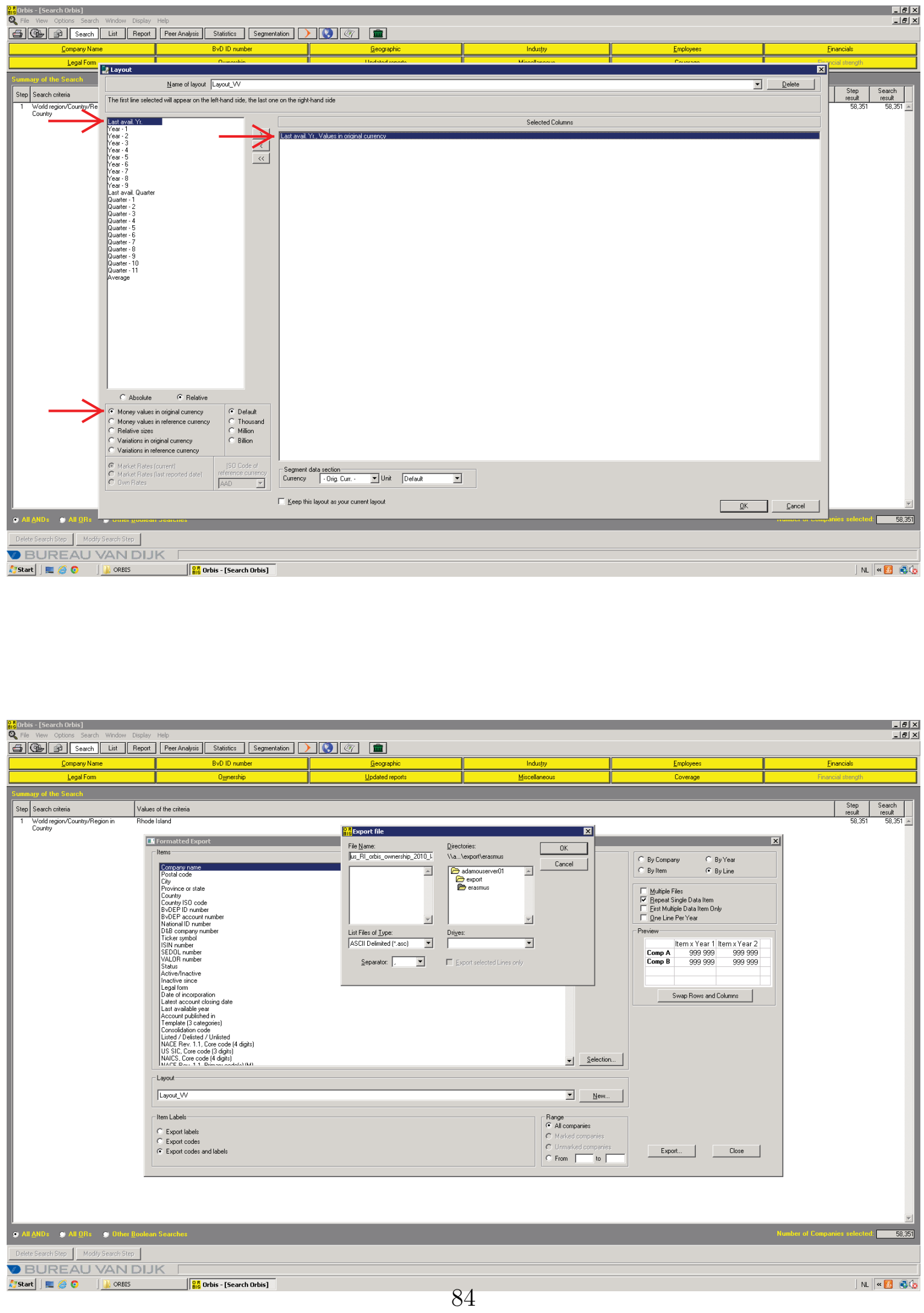



\section{E.2 Custom Export Interface of Newer BvD Disks}
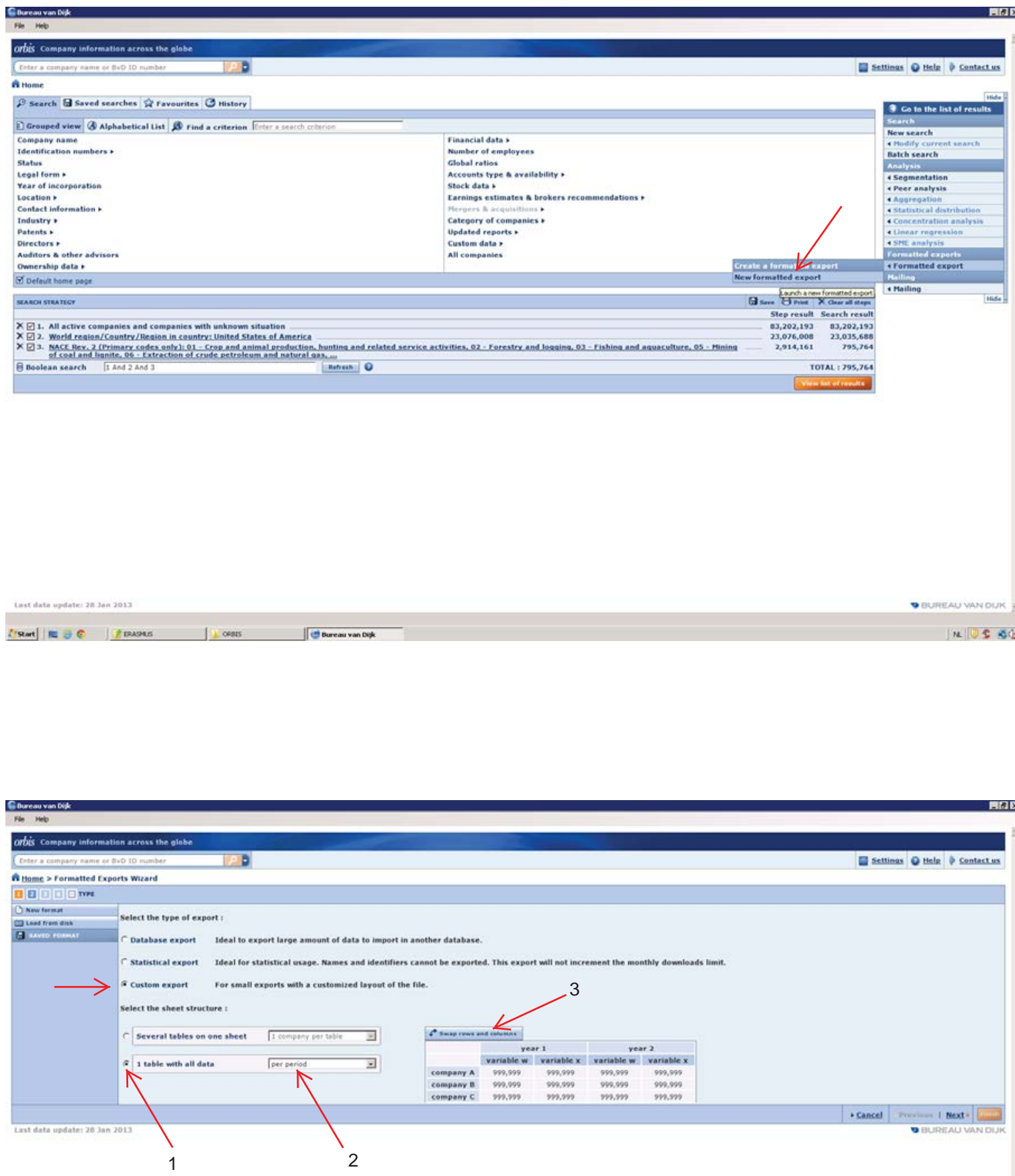


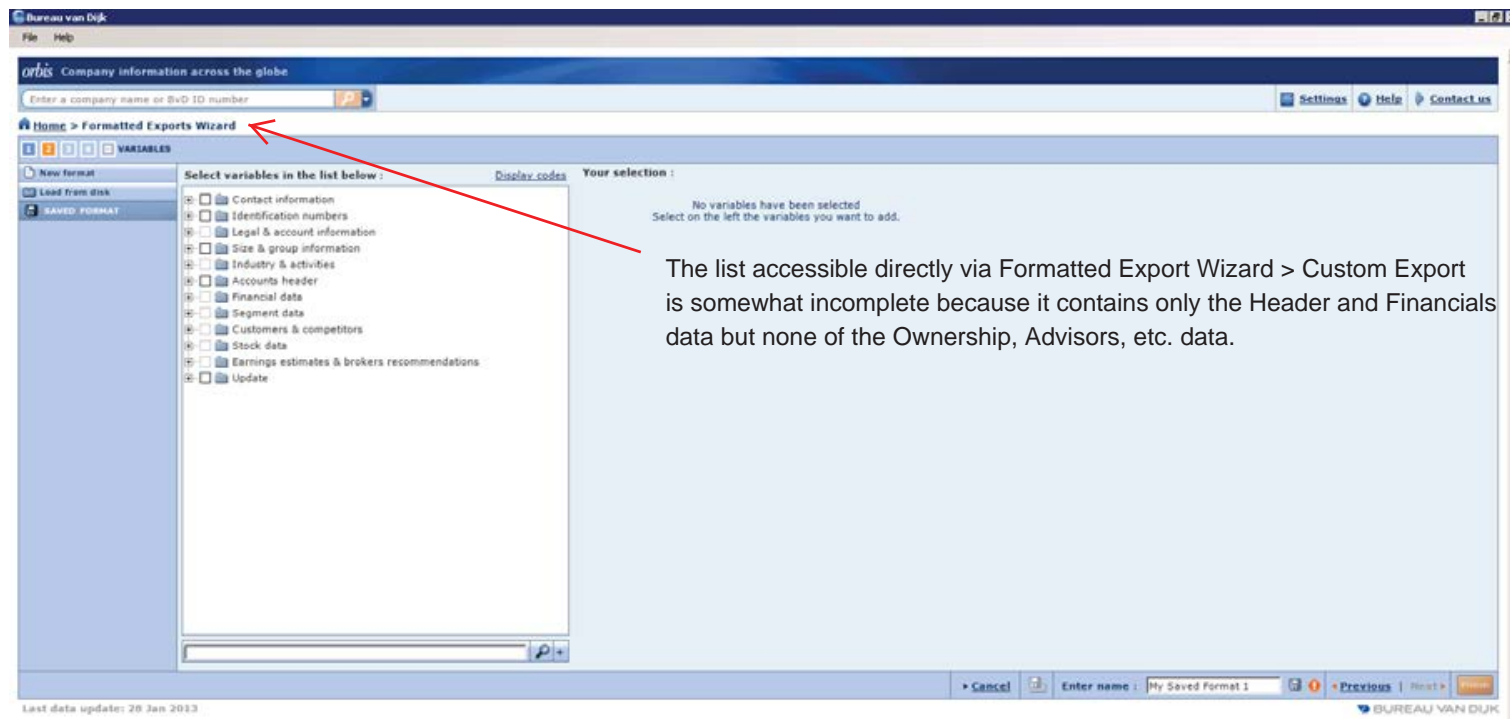

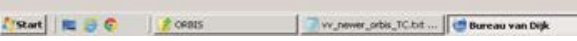

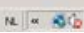

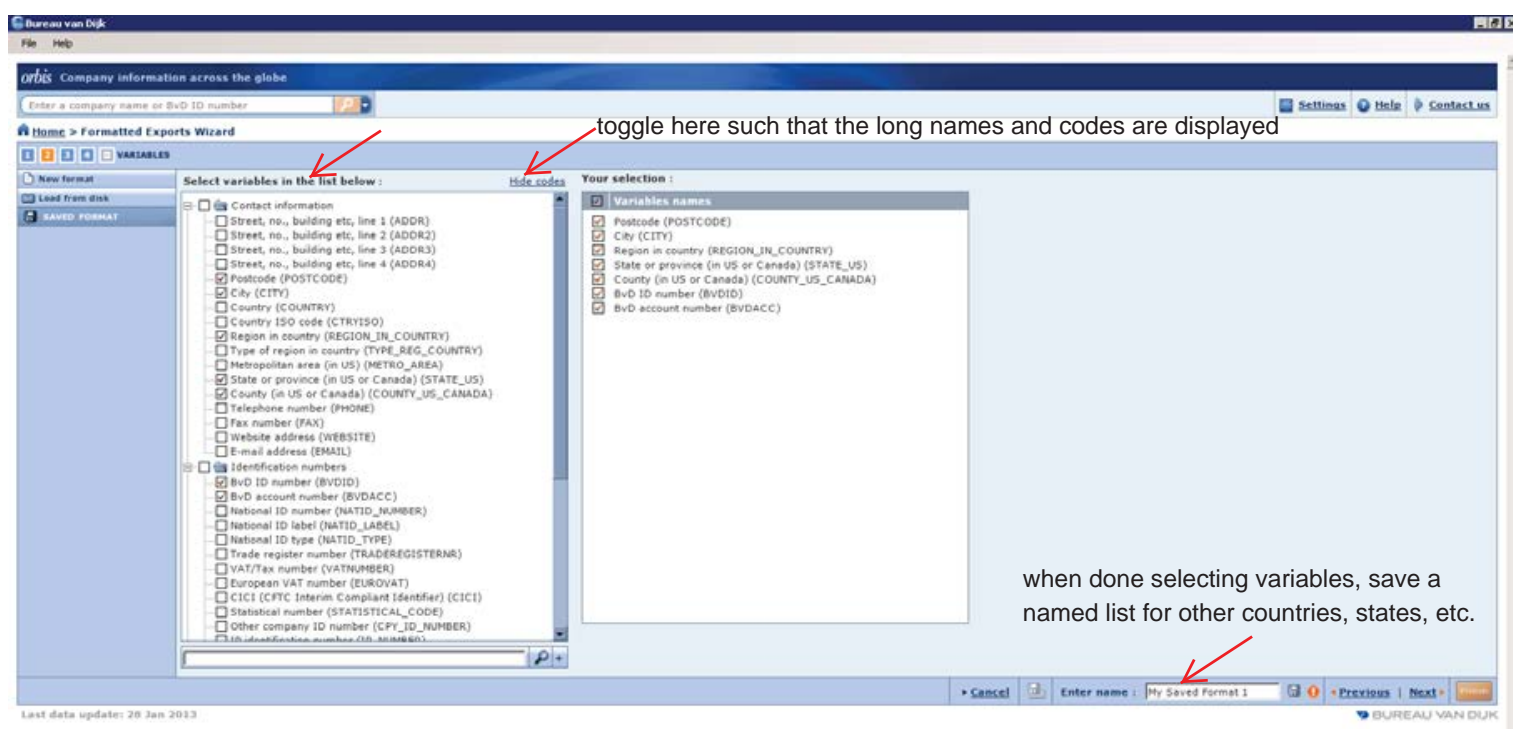




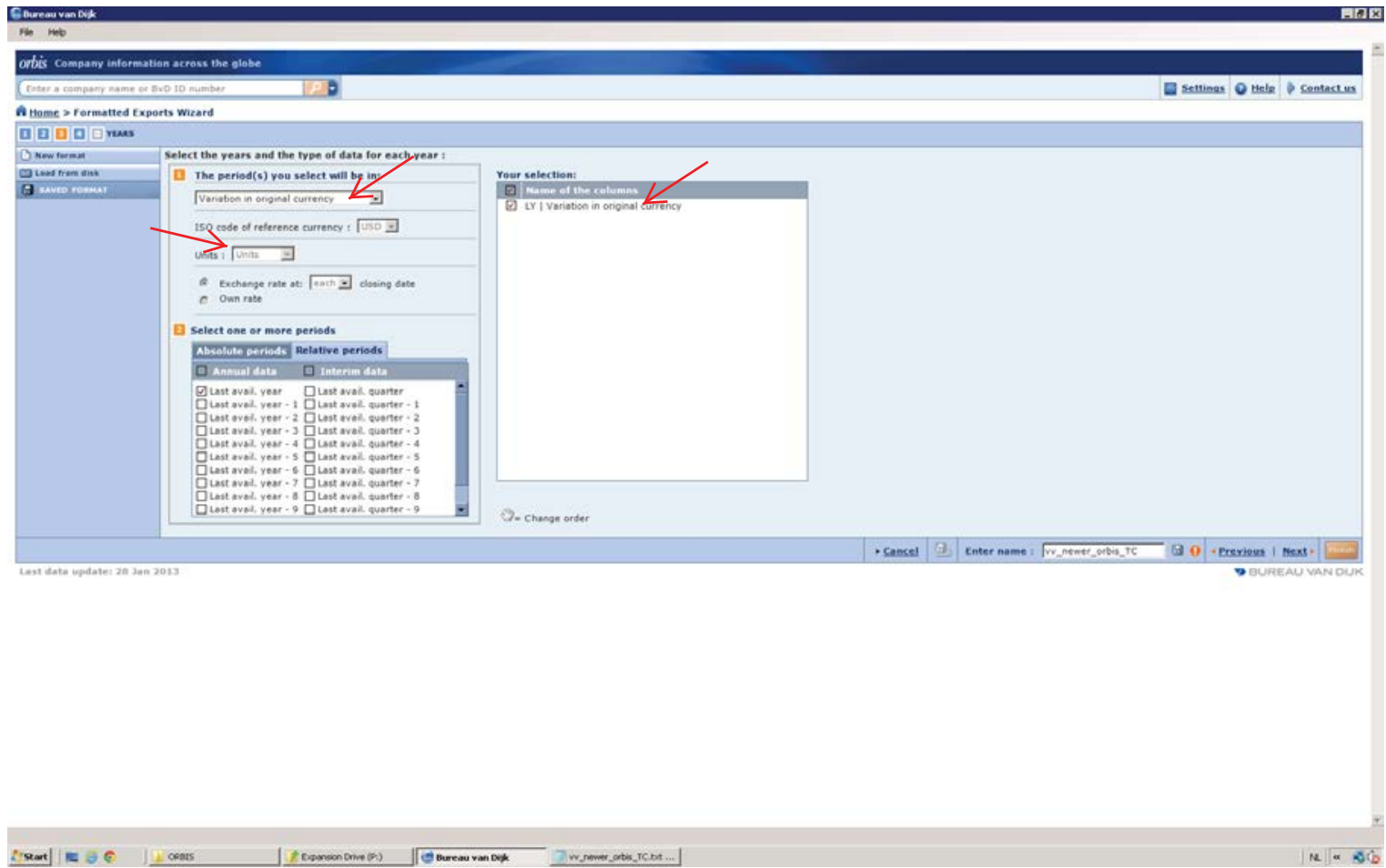

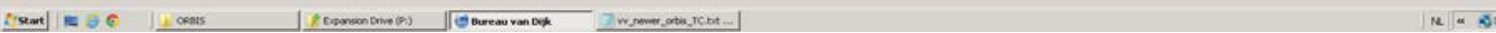

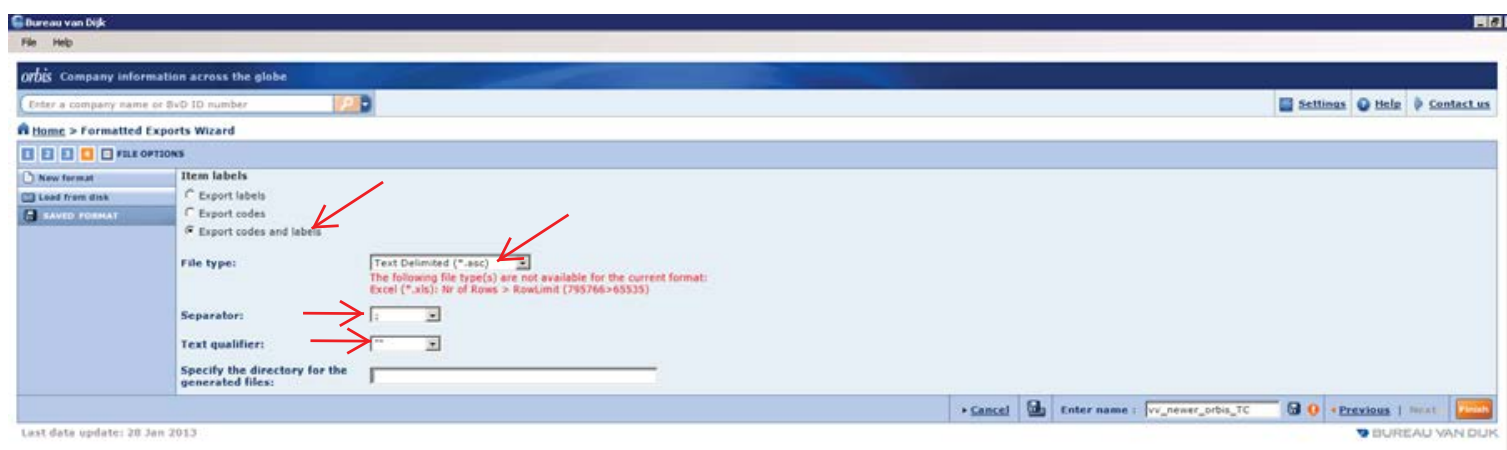





\section{E.3 Database Export Interface of Newer BvD Disks}

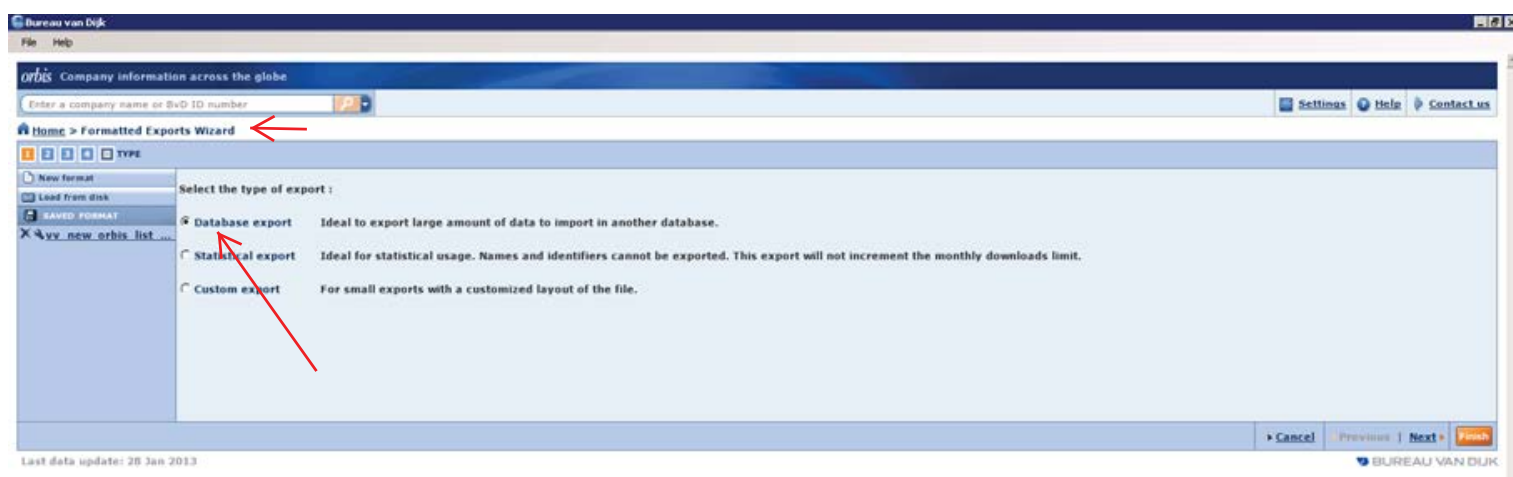

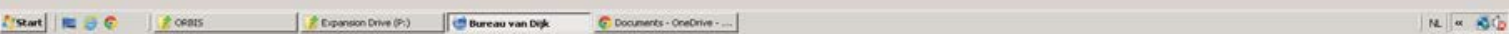

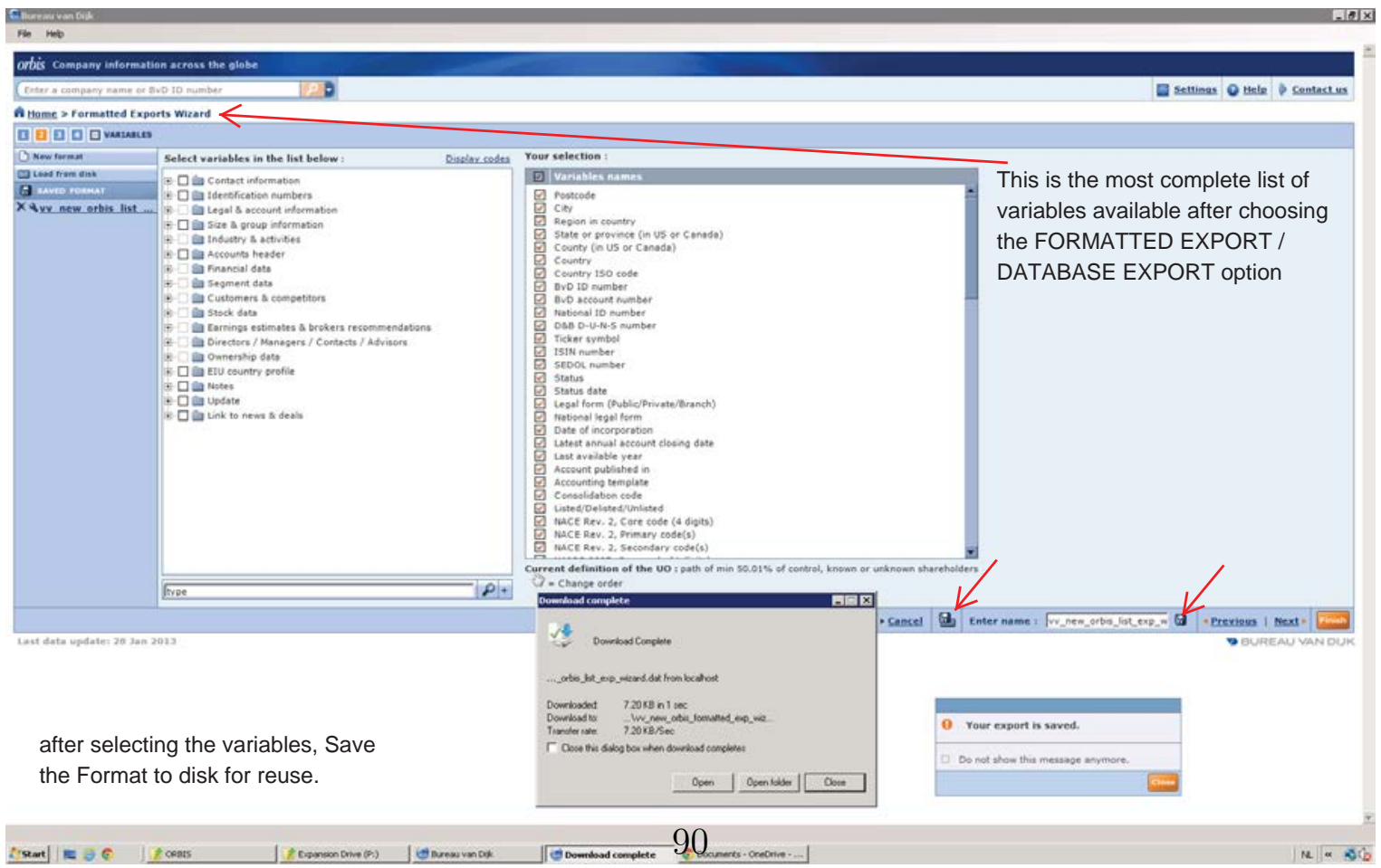




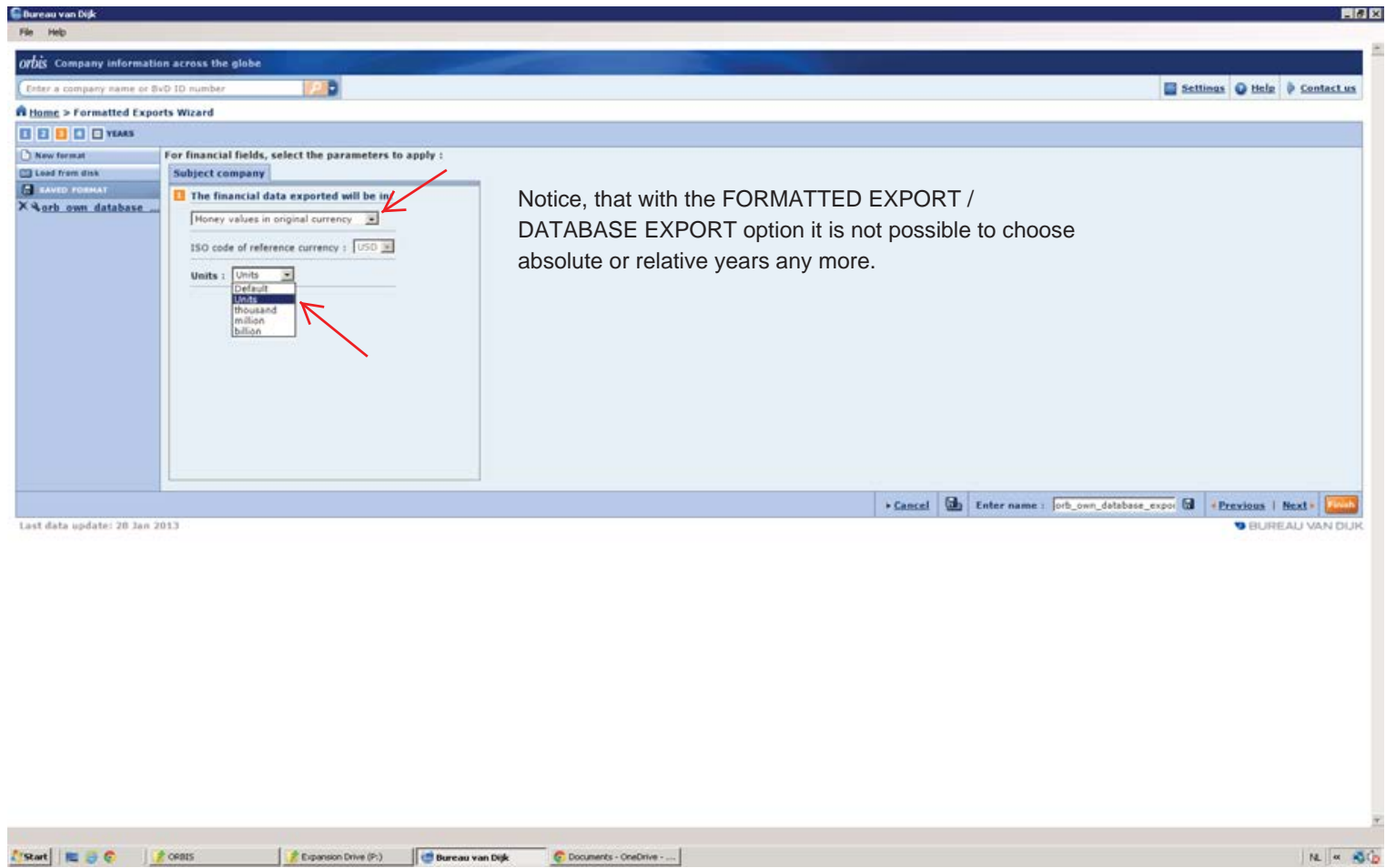

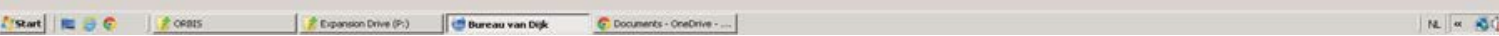

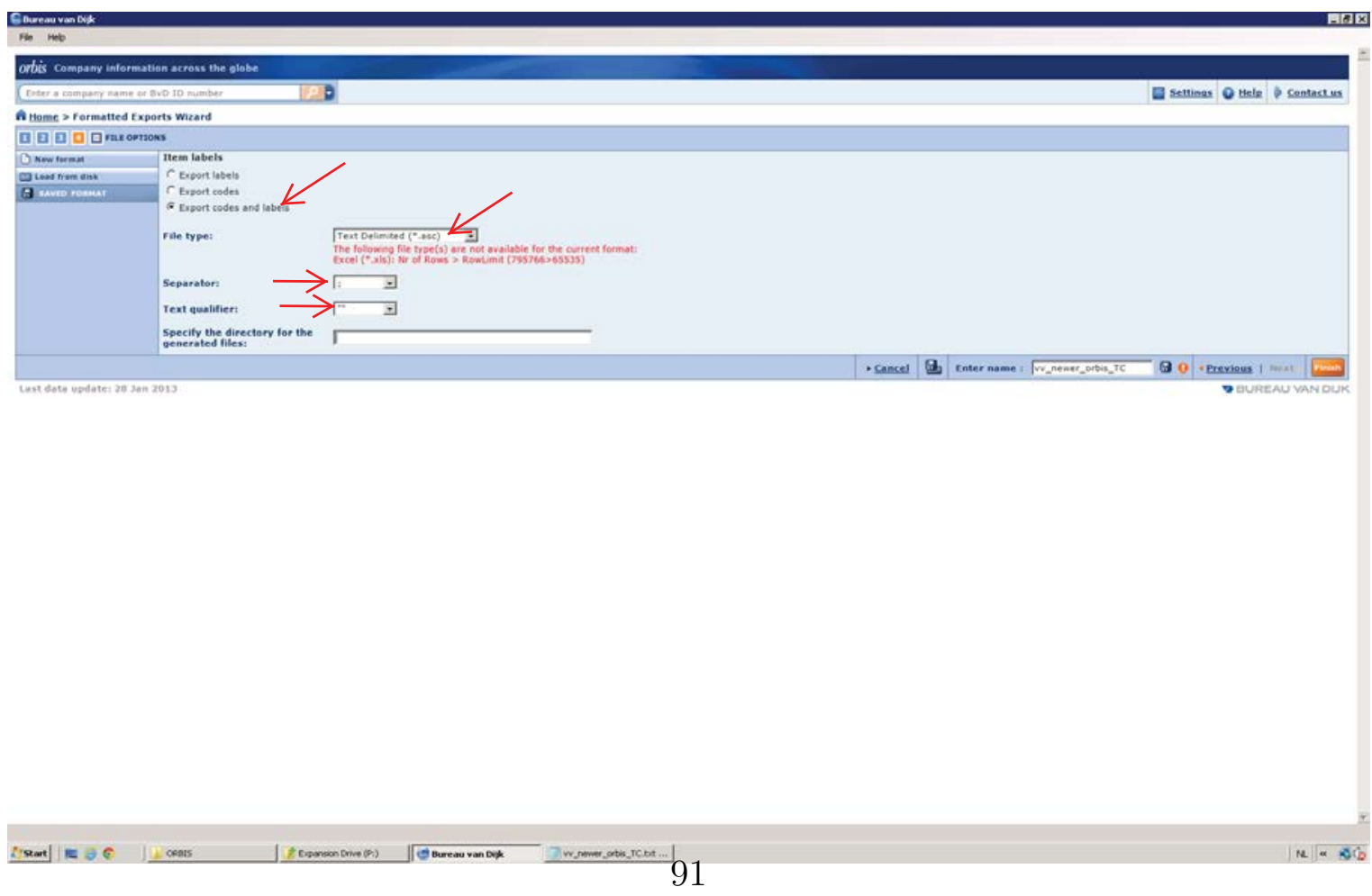





\section{E.4 List Export Interface of Newer BvD Disks}
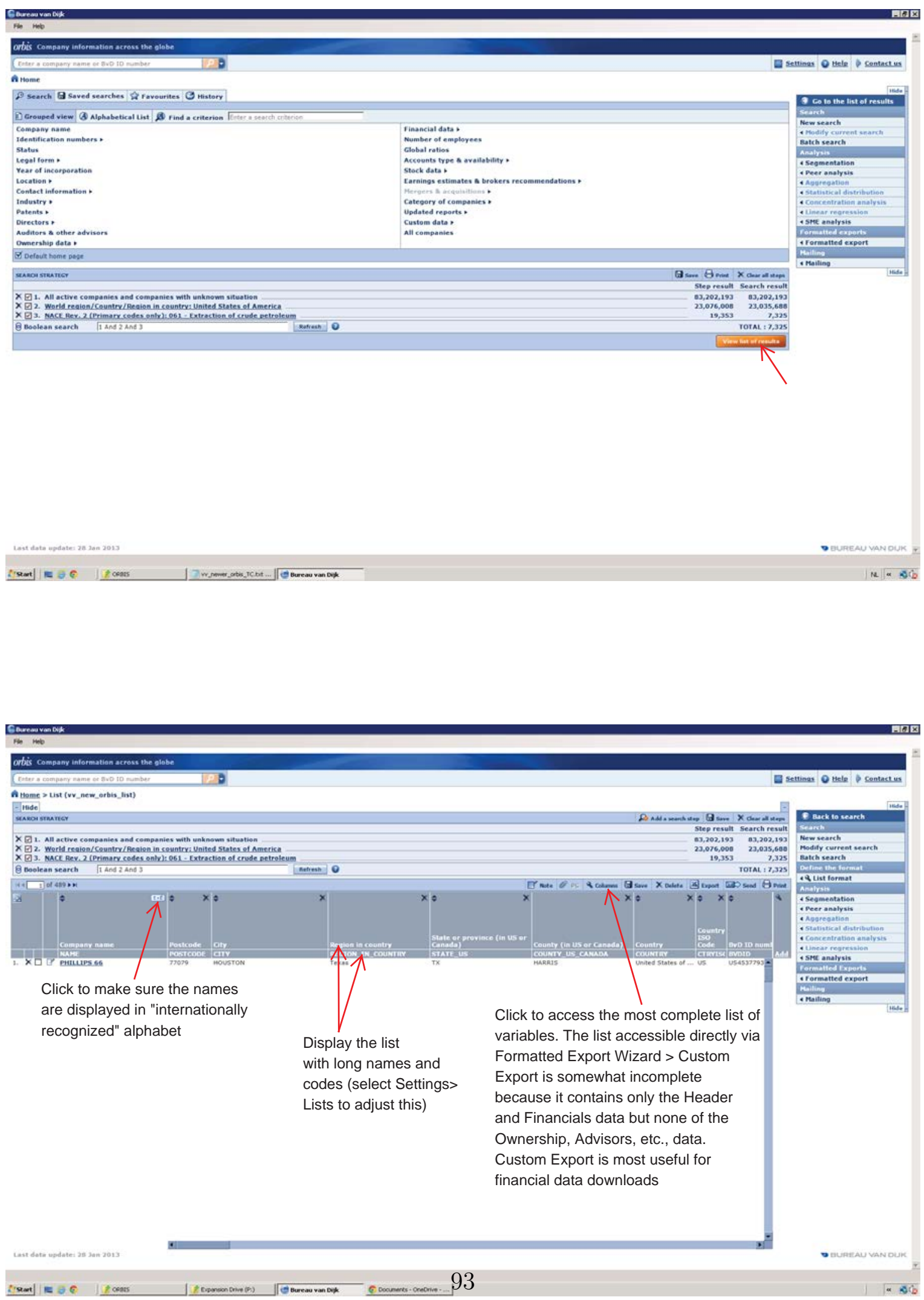

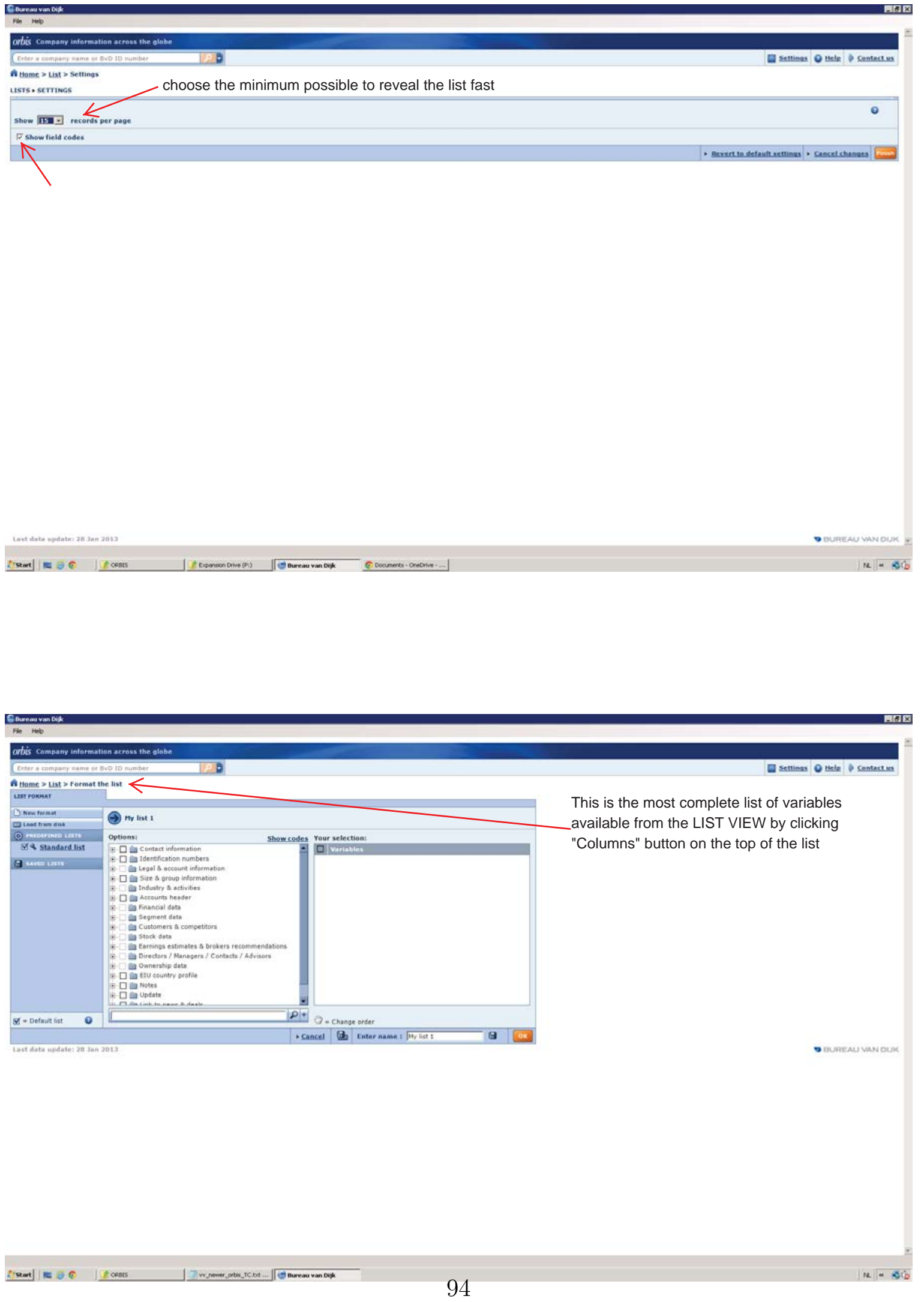


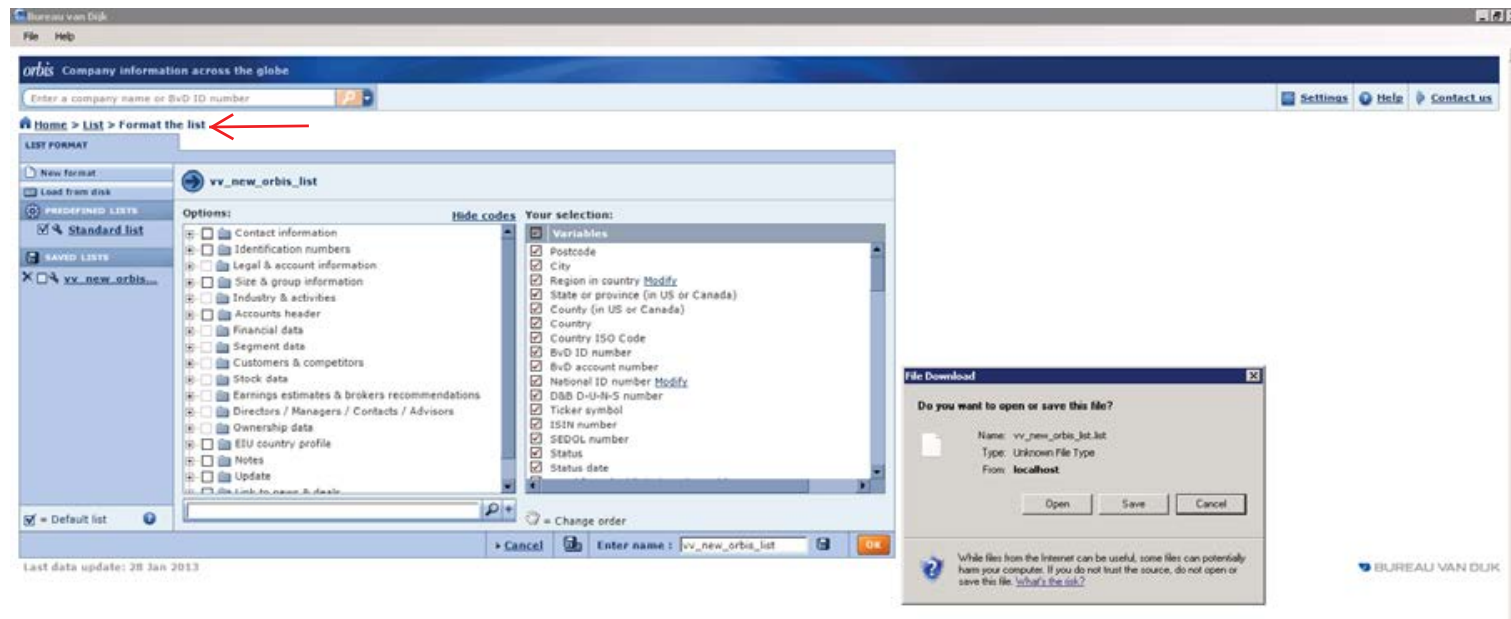

after selecting the variables, Save your List to disk for reuse.

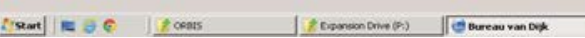

n. 506

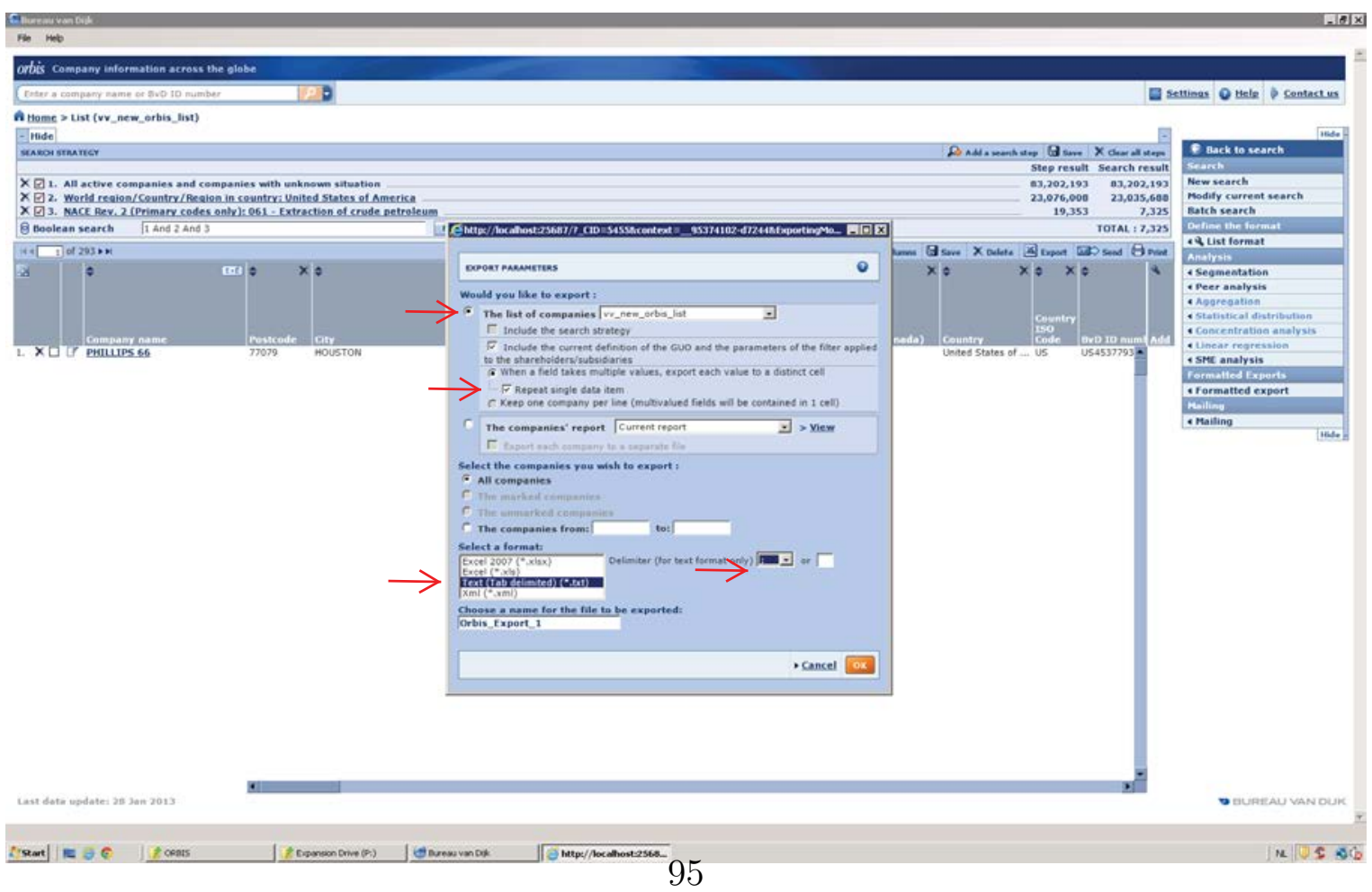




\section{References}

Aykut, Dilek, Apurva Sanghi, and Gina Kosmidou, "What to do when foreign direct investment is not direct or foreign: FDI round tripping," World Bank Policy Research Working Paper, 2017, (8046).

Force, CompNet Task, "Micro-based evidence of EU competitiveness: The CompNet database," NBB Working Paper, 2014. 